\title{
Poverty initiatives in the ILO: A review of past and present approaches
}

Working Paper No. 8

\section{Pat Holden}

and

\section{Dagmar Walter}

\section{Policy Integration Department \\ National Policy Group \\ International Labour Office \\ Geneva}

February 2004 
Copyright $\odot$ International Labour Organization 2004

Publications of the International Labour Office enjoy copyright under Protocol 2 of the Universal Copyright Convention. Nevertheless, short excerpts from them may be reproduced without authorization, on condition that the source is indicated. For rights of reproduction or translation, application should be made to the Publications Bureau (Rights and Permissions), International Labour Office, CH-1211 Geneva 22, Switzerland. The International Labour Office welcomes such applications.

Libraries, institutions and other users registered in the United Kingdom with the Copyright Licensing Agency, 90 Tottenham Court Road, London W1T 4LP [Fax: (+44) (0)20 7631 5500; email: cla@cla.co.uk], in the United States with the Copyright Clearance Center, 222 Rosewood Drive, Danvers, MA 01923 [Fax: (+1) (978) 750 4470; email: info@copyright.com] or in other countries with associated Reproduction Rights Organizations, may make photocopies in accordance with the licences issued to them for this purpose.

ISBN 92-2-115159-X (printed version)

ISBN 92-2-115160-3 (web version)

First published 2004

Cover:

The designations employed in ILO publications, which are in conformity with United Nations practice, and the presentation of material therein do not imply the expression of any opinion whatsoever on the part of the International Labour Office concerning the legal status of any country, area or territory or of its authorities, or concerning the delimitation of its frontiers.

The responsibility for opinions expressed in signed articles, studies and other contributions rests solely with their authors, and publication does not constitute an endorsement by the International Labour Office of the opinions expressed in them.

Reference to names of firms and commercial products and processes does not imply their endorsement by the International Labour Office, and any failure to mention a particular firm, commercial product or process is not a sign of disapproval.

ILO publications can be obtained through major booksellers or ILO local offices in many countries, or direct from ILO Publications, International Labour Office, CH-1211 Geneva 22, Switzerland. Catalogues or lists of new publications are available free of charge from the above address, or by email: pubvente@ilo.org

Visit our website: www.ilo.org/publns

Printed by the International Labour Office, Geneva, Switzerland 


\section{Poverty initiatives in the ILO: A review of past and present approaches}

\section{Contents}

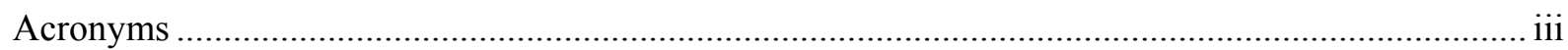

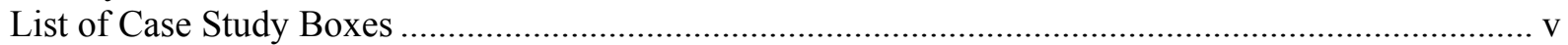

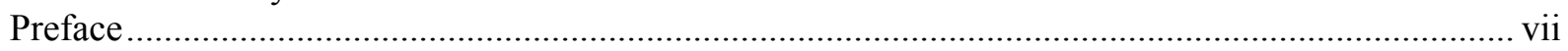

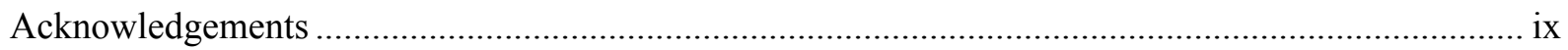

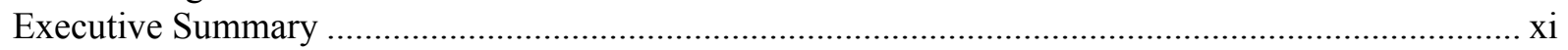

PART 1: Responding to the new poverty reduction agenda ...................................................... 1

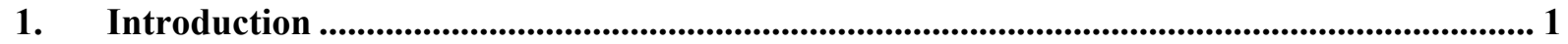

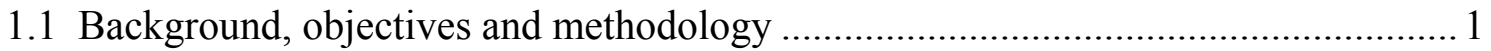

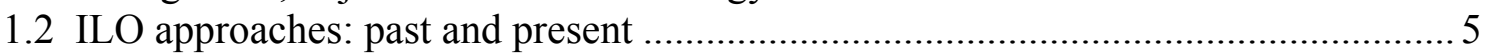

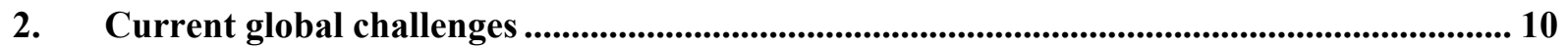

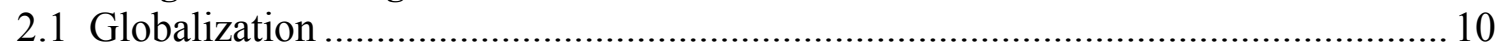

2.2 Employment at the centre of economic and social debates.................................... 10

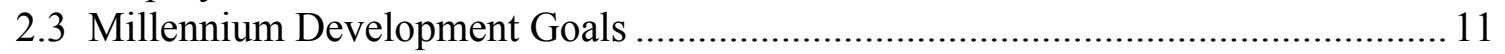

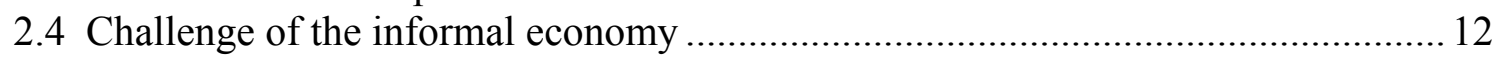

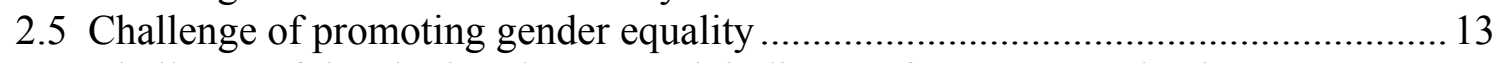

2.6 Challenge of developing decent work indicators for poverty reduction ................... 15

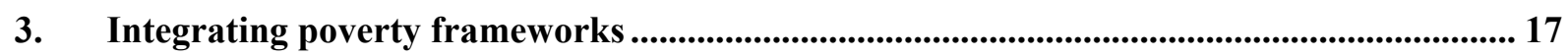

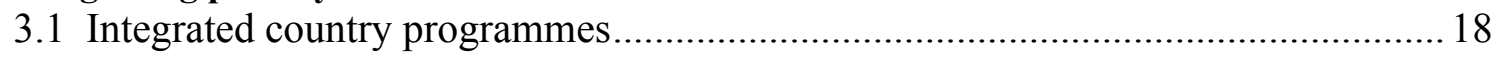

3.2 Poverty Reduction Strategy Papers ….............................................................. 20

3.3 The MDGs: promoting an integrated approach to Pro-poor Growth and Decent Work for Poverty Reduction ................................................................ 23

4. The ILO and international development partners ..................................................................... 25

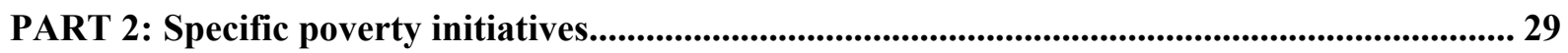

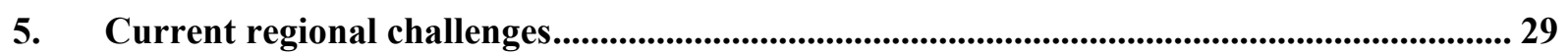

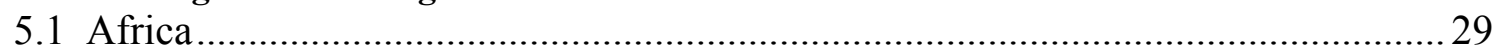

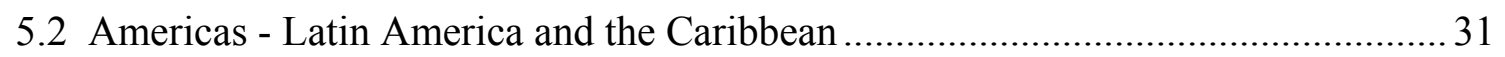

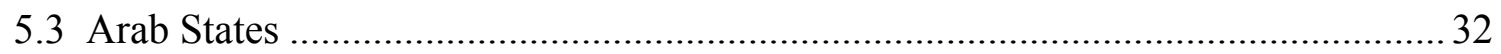

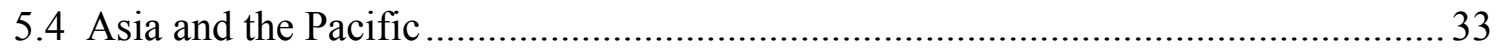

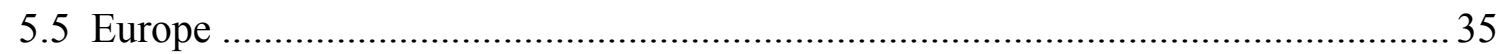

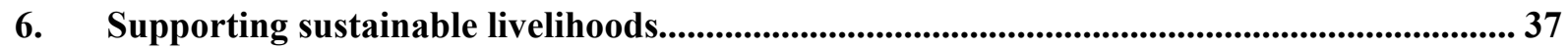

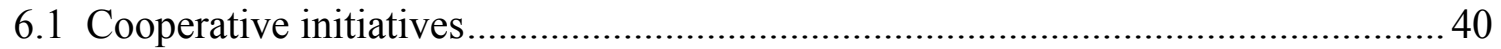

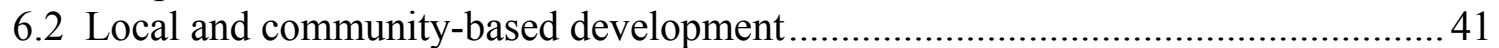

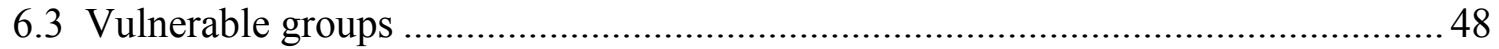




\section{Poverty initiatives in the ILO: \\ A review of past and present approaches}

Contents (continued)

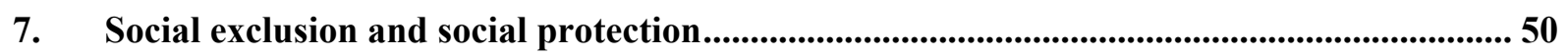

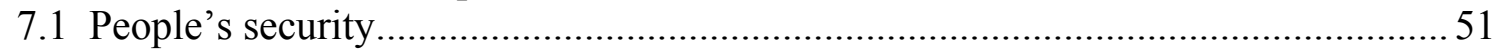

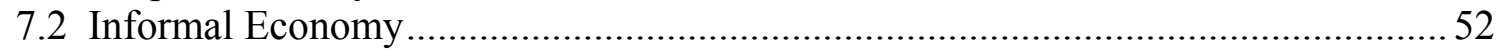

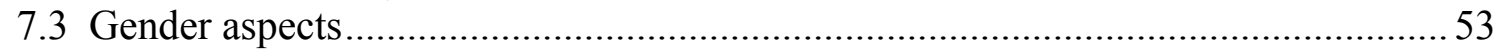

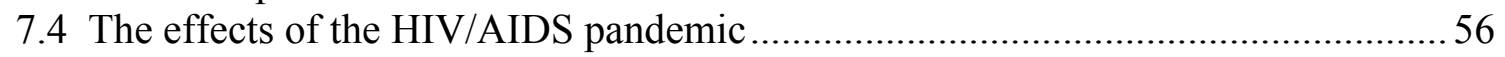

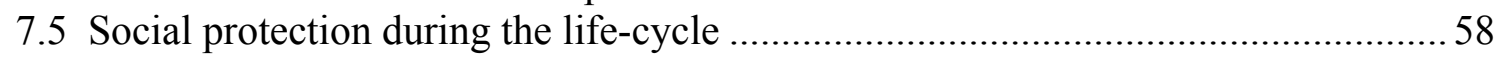

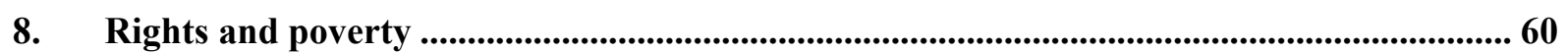

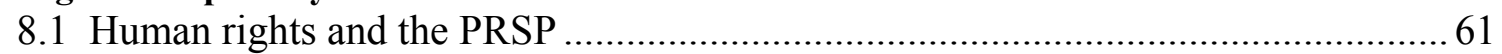

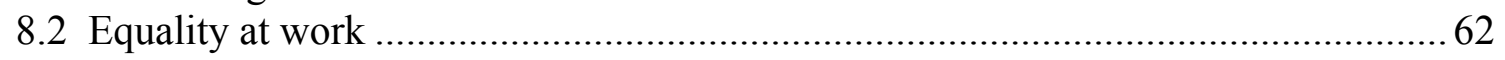

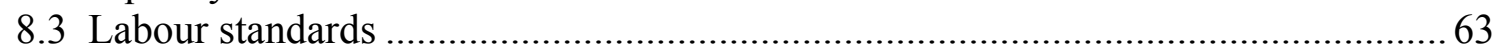

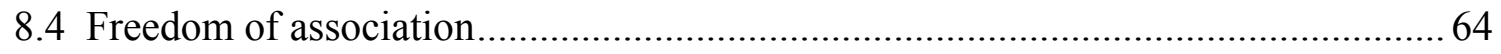

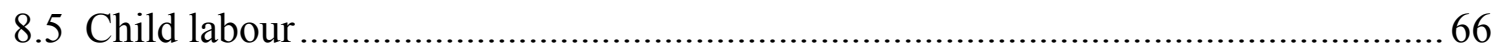

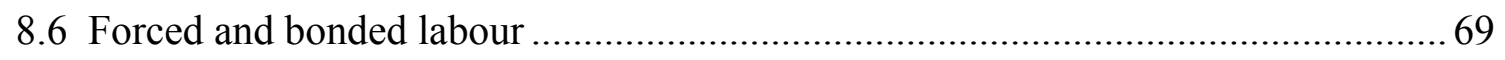

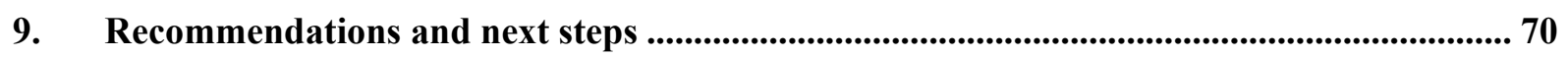

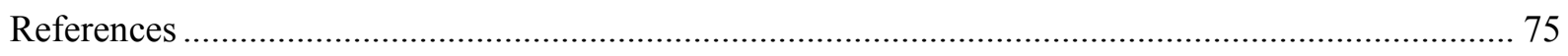

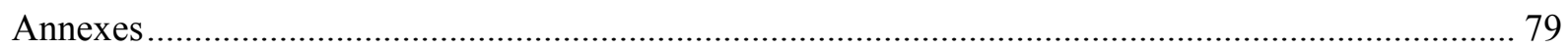




\section{Acronyms}

\begin{tabular}{|c|c|}
\hline ACTRAV & Bureau for Workers' Activities \\
\hline AU & African Union \\
\hline CBT & Community Based Training \\
\hline CESM & Comprehensive Employment Strategy Mission \\
\hline CODEV & Development Cooperation Department \\
\hline COOP & Cooperatives Branch \\
\hline DfID & Department for International Development (of the United Kingdom) \\
\hline DWPP & Decent Work Pilot Programme \\
\hline EIIP & Employment Intensive Infrastructure Programme \\
\hline EMP/INVEST & Employment-Intensive Investment Branch \\
\hline EMP/RECON & Recovery and Reconstruction Department \\
\hline EMP/SFP & Social Finance Programme \\
\hline EMP/STRAT & Employment Strategy Department \\
\hline EU & European Union \\
\hline FDI & Foreign Direct Investment \\
\hline GENPROM & Gender Promotion Programme \\
\hline GPE & Gender, Poverty and Employment \\
\hline GPRS & Ghana Poverty Reduction Strategy \\
\hline HIV/AIDS & $\begin{array}{l}\text { Human Immunodeficiency Virus/Acquired Immune } \\
\text { Deficiency Syndrome }\end{array}$ \\
\hline HQ & Headquarters \\
\hline IFAD & International Fund for Agricultural Development \\
\hline IFI & International Financial Institutions \\
\hline IFP/CRISIS & InFocus Programme on Crisis Response and Reconstruction \\
\hline IFP/DIALOGUE & $\begin{array}{l}\text { InFocus Programme on Social Dialogue, Labour Law and Labour } \\
\text { Administration }\end{array}$ \\
\hline IFP/SEED & $\begin{array}{l}\text { InFocus Programme on Boosting Employment through Small Enterprise } \\
\text { Development }\end{array}$ \\
\hline IFP/SKILLS & InFocus Programme on Skills, Knowledge and Employability \\
\hline IILS & International Institute for Labour Studies \\
\hline ILC & International Labour Conference \\
\hline ILO & International Labour Office/Organisation \\
\hline ILS & International Labour Standards \\
\hline IMF & International Monetary Fund \\
\hline IPEC & InFocus Programme on Child Labour \\
\hline JFA & Jobs for Africa Programme \\
\hline LED & Local Economic Development \\
\hline MDG & Millennium Development Goals \\
\hline NEPAD & New Partnership for Africa's Development \\
\hline NGO & Non-governmental organization \\
\hline OHCHR & Office of the High Commissioner for Human Rights \\
\hline PLWHA & People living with HIV/AIDS \\
\hline PROGRAM & Bureau of Programming and Management \\
\hline PRSP & $\begin{array}{l}\text { Poverty Reduction Strategy Papers (here also referring to the } \\
\text { Poverty Reduction Strategy Process) }\end{array}$ \\
\hline SL & Sustainable Livelihoods \\
\hline $\mathrm{SOC} / \mathrm{FAS}$ & Social Security Financial, Actuarial and Statistical Services \\
\hline $\mathrm{SOC} / \mathrm{POL}$ & Social Security Policy and Development Branch \\
\hline SOE & State owned Enterprise \\
\hline STEP & Strategies and Tools against Social Exclusion and Poverty Programme \\
\hline SIYB & Start and Improve Your Business \\
\hline TC/RAM & Technical Cooperation/Resource Allocation Mechanism \\
\hline TBP & Time Bound Programme \\
\hline UN & United Nations \\
\hline
\end{tabular}


Acronyms (continued)

UNCDF
UNCTAD
UNDAF
UN-DESA
UNDG
UNDP
UNESCO
UNFPA
UN-HABITAT
UNICEF
WB
WEP
WFP
WHO

United Nations Capital Development Fund

United Nations Conference on Trade and Development

United Nations Development Assistance Framework

United Nations Department for Economic and Social Affairs

United Nations Development Group

United Nations Development Programme

United Nations Educational, Scientific and Cultural Organisation

United Nations Population Fund

United Nations Human Settlements Programme

United Nations Children's Fund

World Bank

World Employment Programme

World Food Programme

World Health Organization 


\section{List of Case Study Boxes}

Number

Title

Page

Objectives of the poverty mapping project

Gender inequality, the life cycle and poverty

The Philippines' Poverty-free Zones 19

Bangladesh, topics for policy dialogue 20

Nepal, ILO policy recommendations on the PRSP 22

Chile, contributing to the MDGs with others 23

Youth Employment Network, results of the first key meeting 24

ILO Tenth African Regional Meeting, December 2003

Chile, strategic planning on gender equality and poverty 32

Honduras, the National Centre for Continuing Education 32

Bahrain, an integrated decent work country programme 33

Cambodia, vocational training and microfinance $\quad 34$

Nepal, child labour and trafficking $\quad 34$

Mongolia, Social dialogue $\quad 35$

$\begin{array}{lll}15 & \text { Estonia, one woman's story } & 36 \\ 16 & \text { Sustainable Livelihoods, summarising the approach } & 37\end{array}$

17 Research, linking employment policies and poverty 39

18 The Sahel, practical efforts to reduce poverty 41

19 Grande Comoro, an entrepreneur's success story 42

20 Croatia, credit for small entrepreneurs 43

21 Ecuador, strengthening ecological and cultural tourism 44

22 India, a practical example of promoting decent work 44

23 Cambodia, labour-based technology and infrastructure is expanding 45

24 Better services and more jobs - Collaborating with UN-HABITAT 46

25 West Africa, mapping the microfinance landscape 47

26 Microfinance in conflict-affected communities 47

27 Community-based Training 47

$28 \quad$ Microfinance-led strategies for preventing debt bondage 49

29 Poverty and social exclusion, an overview 50

30 The Socio-Economic Security Programme 52

31 Mutual health organizations, the concept of social protection among 53

32 Latin America, strengthening the voice of home workers 54

33 A Zambian widow's story: life without social security 55

34 West Africa, mutual health schemes are growing 56

35 Global Social Trust Fund 56

36 HIV/AIDS strengthening informal worker's abilities to protect themselves 57

37 Zambia, sensitizing workers and employers 57

38 Brazil, action to reduce gender and race discrimination 63

$39 \quad$ Asia and the Pacific, improving labour standards 64

40 Costa Rica, the challenge of the Banana Traders' Union 65

41 Brazil, a response to child labour in sisal production 67

42 Turkey, reducing poverty to reduce child labour 68

$\begin{array}{lll}43 & \text { China's rural-based training } & 69\end{array}$ 


\title{
Preface
}

The international development agenda has increased its focus on poverty reduction, and the ILO's role within this is growing in significance. From the global targets articulated in the Millennium Development Goals to new planning frameworks such as the PRSPs, the ILO's Decent Work Agenda is being called upon to play a key role in the global effort to reduce poverty.

The Director-General's Report, Working out of poverty, discussed at the International Labour Conference in 2003, highlighted the ILO's Decent Work Agenda as a crucial foundation for the broader development agenda. It provided a synthesis of the extensive work that ILO technical units, together with constituents, have been involved in around the world. Underpinning this important policy report was an extensive process of information gathering and internal brainstorming, reflected in part in the research contained in this working paper.

This working paper provides an initial overview and analysis of efforts in poverty reduction to date. It has been written in response to requests for more information about existing ILO poverty-focused work, raised at the Decent Work and Poverty Reduction Workshop in Turin, July 2002, and in recognition of the need for our poverty work to gain further coherence and visibility. This work has further contributed to the development of a more dynamic ILO facility in the form of an ILO Resource Database on Poverty, Local Development and Decent Work. It is available on the ILO Internet site http://www.ilo.org/dyn/dwresources. Its purpose is to generate further discussion and feedback on ILO's poverty reduction framework.

This publication is a contribution of the National Policy Group (NPG), Policy Integration Department, to ILO initiatives on decent work, poverty reduction and PRSPs. It has been written by Pat Holden (Social Development Adviser, NPG 2001-2003) and Dagmar Walter (NPG). It has been finalised with Alana Albee (Social Development Adviser, NPG) and is a key output of the "Poverty Mapping" exercise carried out within the framework of the Partnership Agreement between the United Kingdom Department for International Development (DFID) and ILO (2001-2006).

\author{
Azita Berar Awad \\ Manager \\ National Policy Group \\ Policy Integration Department
}

February 2004 


\section{Acknowledgements}

This paper, written over the period of a year, has benefited from fruitful discussions and insights from many people within the ILO. We would particularly like to thank the Sectors (Rights, Employment, Social Protection, and Social Dialogue) and respective Units which contributed substantial materials. Information from ILO field offices has strengthened the paper significantly, although we recognise that this is not a comprehensive reflection of all initiatives undertaken in the field and further consultations are needed. 


\section{Executive Summary}

This paper provides an initial overview of the ILO's approaches to reducing poverty. It is a step in drawing together examples of its diverse range of initiatives. The paper has been written in response to requests for information that link the ILO's Decent Work Agenda with poverty reduction, expressed at the ILO workshop on "Decent Work and Poverty Reduction" in Turin, July 2002.

Overall, the paper gives emphasis to describing the ILO's practical poverty reduction efforts. In Part 1, it considers the Office's contribution to achieving the Millennium Development Goals (MDGs). The MDGs, now at the centre of work undertaken by international development partners and the whole United Nations system, provide the context in which the ILO must raise international and national awareness on the vital role of decent work in reducing poverty and social exclusion. The challenge is to do this while ensuring coherent policy approaches. In the words of the Director General, "I intend to advance our own thinking on the Strategic Policy Framework of the ILO, our communications work and our programme delivery and policy integration mechanisms to mainstream the idea of working out of poverty into the daily work of the ILO."1

Poverty reduction is embedded in the ILO's Constitution. However, the emphasis on povertyrelated work has differed throughout the ILO's history. The ILO has produced important conceptual work on poverty and has also had an impact on poverty through many of its field operations. The paper makes the case that because its work brings together economic, social and rights-based approaches, it faces an analytical challenge of meshing together varied conceptual and philosophical approaches. The ILO's current approach is inherently normative, encompassing participation, inclusion and obligations. The ILO is promoting policies that include these key elements, in recognition that pro-poor growth is only achievable with the creation of productive work and employment. This is reinforced in the Director General's report to the Tenth African Regional Meeting that highlights that the “...barriers to a faster pace of job creation and poverty reduction lie in the unfair nature of the emerging system of rules governing international economic relations. Others are to be found inside Africa itself. Action to overcome these obstacles to development is urgently needed".

In Part 2, the paper provides an analysis of concerns in various regions. This is followed by the extensive results of the mapping of the ILO's poverty initiatives, organised around three complementary development approaches, namely sustainable livelihoods, social exclusion, and rights. Examples include a wide range of information from ILO units at Headquarters and in the field.

\footnotetext{
${ }^{1}$ Reply by the Director-General to the discussion of his Report ("Working out of Poverty"), Provisional Record No. 25, International Labour Conference, $91^{\text {st }}$ session, ILO Geneva, 2003 (p. 7).

2 Decent work for Africa's development. Report of the Director-General. Tenth African Regional Meeting, Addis Ababa, December 2003. ILO
} 
The authors make recommendations and suggestions for future work in that highlight the need to prioritise efforts to further embed the Decent Work Agenda into the priorities of key development partners, including the ILO constituents. The emphasis is laid on shifting beyond small-scale project initiatives, towards coordinated and coherent efforts in policy and programming that are driven by agreed national and international frameworks. The case is made for broadening the skills and competencies of the ILO staff towards a more integrated and coherent way of working. Indeed, the authors contend that the ILO needs to strengthen its perception of itself as an integral part of the UN system and exert further influence with regard to the Decent Work Agenda at the international and national policy levels. 
"We have a mandate based on fundamental values but we spend most of our time and effort making practical tools that piece by piece transform vision into reality. The broadening and deepening of shared commitments creates a space for pragmatic agreements that solve problems. Successes in making international action relevant to people's lives and work encourage us to continue to strive for the achievement of the vision expressed in our mandate."

Reply by the Director-General to the discussion of his report, Working out of Poverty, ILC, June 2003.

\section{PART 1: Responding to the new poverty reduction agenda}

\section{Introduction}

\subsection{Background, objectives and methodology}

Addressing poverty is inherent in the ILO's Constitution. However, the emphasis on poverty-related work has differed throughout its history. The ILO has produced important conceptual work on poverty and has also had an impact on poverty through many of its field level operations. Various Governing Body papers have pointed to both the strengths and limitations of ILO's poverty related work. For example, the Governing Body paper on "Poverty Reduction and Decent Work in a Globalizing World", March 2001, recommended (among other things):

- “A more comprehensive effort to 'map' ILO work on poverty reduction ... to give a better picture of the way in which action on employment, social protection, standards and social dialogue relate to each other."

- "A parallel mapping exercise to enable ILO and others to see how its work connects with that of other agencies with a view to maximising its specific contribution within an integrated policy framework."

The Governing Body paper further states, "ILO activities on poverty reduction ... have evolved in a somewhat compartmentalised way." There is a need to begin to address this issue, in part by providing information to constituents and others in a more coherent way. This paper is a contribution to this effort.

The broader international context for considering poverty reduction is now influenced by the international consensus built around the Millennium Development Goals (Annex 1) and the ILO's commitment as part of the UN system to contribute to the achievement of these goals. In addition there are integrative frameworks such as the United Nations Development Assistance Framework (UNDAF) and the New Partnership for Africa's

\footnotetext{
${ }^{3}$ Poverty reduction and Decent Work in a globalizing world, March 2001 (GB.280/WP/SDG/1).
} 
Development (NEPAD), which have poverty reduction as over-arching goals. Instruments such as the Poverty Reduction Strategy Papers (PRSP) ${ }^{4}$ are now assuming greater importance in the wider development agenda and in the allocation of resources. In the light of this, many of the ILO's development partners are looking for more evidence of the poverty-focus in the ILO's work, as well as evidence of impact on poor people's lives. For example the TC/RAM (Technical Cooperation/Resource Allocation Mechanism) within the ILO has heavily focused on poverty reduction as a criterion for project proposals.

Various developments within the ILO have demonstrated an increasing concern with the relationship between decent work and poverty reduction. A staff workshop, "Decent Work and Poverty Reduction" (Turin, July 2002), identified some key issues to be developed. ${ }^{5}$

- The need for more information and knowledge about existing initiatives;

- The need for more discussion and elaboration of the links between decent work and poverty eradication;

- The need to understand how this could be applied in practice, including the development of guidelines and other instruments.

This paper which begins to map the ILO's poverty initiatives seeks to take forward these recommendations by both collecting information and providing an opportunity for wider discussion within the ILO. Work on poverty mapping has been in progress since October 2001 although the first phase of the current project did not commence until October 2002. The first phase has been concerned with collecting information on past and existing ILO activities in order to 1) document experiences, and 2) to initiate discussion on the ILO's approach to poverty reduction and decent work and how this can be made more visible and coherent.

The project in its second phase will build on ongoing work in response to needs at the country level, such as articulated in PRSPs.

\section{Box 1: Objectives of the poverty mapping project}

- Development objective

- To improve the quality of life of poor people in member States by promoting policies and programmes that contribute to poverty reduction.

- Immediate objectives

- The ILO and its constituents will have a greater understanding of the ILO's approach to poverty reduction, what this means in practice, and how it can be measured and monitored.

- $\quad$ Production of publication/manual produced for information sharing and awareness raising, presenting best practice and practical guidelines. It will demonstrate the ILO's contribution to poverty eradication through decent work. The publication/manual will be accessible to the ILO, its constituents and other partners.

- Tools and guidelines produced, in response to demand, from the ILO procedures and practices.

\footnotetext{
${ }^{4}$ The acronym PRSP, rather than PRS, is used throughout this document to denote the instrument and process that guides debt relief from International Financial Institutions. This is done in order to avoid confusion with the more generically 'poverty reduction strategy' phrase used by many organisations and programmes.

${ }^{5}$ See also Annex 2 and http://training.itcilo.it/decentwork/ for a full report.
} 
Since the work began, as might be expected given the context described above, there have been various ongoing developments within the ILO. In effect, mapping of what goes on in an organisation cannot be static. For this reason, a dynamic ILO Resource Database on Poverty, Local Development and Decent Work has been developed and is available on the ILO's Internet site. ${ }^{6}$

The ILO's Programme and Budget guidelines for 2004 and 2005 strongly emphasise poverty reduction as a shared policy objective for achieving the ILO's strategic objectives. Africa, the Americas, the Arab States, and the Asia and the Pacific region have identified poverty reduction as one of the key priorities in their Region, the Europe region is targeting social inclusion.

The research undertaken for this paper contributed to the most recent Director-General's report, "Working out of poverty" (produced for the International Labour Conference, June 2003). This report focuses on the working poor and those excluded from work. It reaffirms the ILO's commitment to a concerted effort in attacking poverty, and it provides an indepth and detailed account of the dimensions of ILO efforts for poverty reduction to date, including recent work on PRSPs. The constituents strongly supported and endorsed the report. This working paper should be seen as complementary to the report.

Following on from the ILC discussion on the informal economy in June 2002, work is commencing in this area and in particular its links with poverty reduction and decent work. A workshop held in Turin in February 2003 proved a means for developing a strategic framework for action ${ }^{7}$. This work overlaps with PRSP efforts as it contributes to an understanding of the conceptual links between poverty and decent work that the ILO is seeking to promote through the PRSP. It also links strongly with the work on Decent Work Country Programming where initiatives are being undertaken in countries where poverty reduction strategies are the overarching development framework for donor assistance and government planning.

As a follow up to these events, various departments have begun to look at how they can more effectively address poverty reduction. There are certainly many examples. The following gives a flavour of activities:

- A policy team on Small Scale Enterprise Development is launching a paper, "Policies for Small Enterprises," on how national and local Small Enterprise Development policies can be made more relevant to poverty reduction. A global report, "Generating decent work through small enterprise development, $t$ " is being finalised with a strong emphasis on addressing the twin challenge of poverty and informality.

- A publication has been produced, "Rediscovering the cooperative advantage: Poverty reduction through self-help" (2003) which takes a critical look at the work of the cooperative movement, analysing whether it has had an impact on reducing poverty and making recommendations for action.

- Case studies of the ILO work involving micro-finance are being undertaken in order to look at how the poor can be reached more effectively.

- Papers have been produced on disability and HIV/AIDS in relation to PRSPs.

\footnotetext{
${ }^{6}$ http://www.ilo.org/dyn/dwresources/

${ }^{7}$ The report of this workshop is available at http://training.itcilo.it/decentwork/IEWS2003
} 
Findings to date suggest that much work has been carried out on poverty but there is still a lack of a systematic assessment of their objectives and a coherent approach to monitoring and evaluation of poverty focused work. Practical guidelines, tools and sourcebooks are still needed. The ILO needs to develop a more consistent and coherent approach to these. Training will be required in the long run to ensure their utilisation.

The objective of this paper is to provide a snapshot of some of the ILO's work in the area of poverty reduction as part of a process of assessing how it can contribute more effectively to the achievement of the Millennium Development Goals (MDGs), particularly that of halving the proportion of people in absolute poverty by 2015 .

The current focus of the ILO's work is on decent work, expressed in its mission statement as "creating opportunities for women and men to obtain decent and productive work in conditions of freedom, equity, security and human dignity". Decent work is a way of describing the core sectors of the ILO's work (rights and standards, promoting employment, social protection, and social dialogue). But it is also a way of characterising a normative approach to development, which involves commitment to the idea that poverty reduction can only be addressed through an approach that combines equity, efficiency and inclusion. The ILO's current approach to poverty reduction is inherently a rights-based approach, which encompasses participation, inclusion and fulfilment of obligations. All these issues underpin economic growth and should also be the outcomes of such growth. In recognising that pro-poor growth is not achievable without a focus on the creation of productive work and employment, the ILO is promoting the idea that such policies also have to include participation and fulfilment of obligations and rights.

However, the focus of the ILO's work in the past has not always been characterised in this way and there have been many different approaches, with at times varying degrees of emphasis on poverty. The development of a coherent approach to poverty reduction has not been particularly helped by its bureaucratic compartmentalisation of activities. The challenge remains to mesh together different conceptual and sometimes philosophical approaches to poverty reduction.

Because the ILO's work brings together both economic and rights-based approaches, it faces an analytical challenge. Research on the links between poverty reduction, rights and economic growth is thin. And in claiming that an integrated approach to decent work can make a major contribution to poverty reduction, the necessary analytical framework is still lacking. In the area of employment there has been substantial work done on the links with poverty reduction. In the other areas of its work less conceptual work has been produced in this regard. The purpose of this paper is not to delve deeply into these conceptual/analytical areas but to capture the situation as it is at the moment and point to some areas for further work.

Many ILO staff believe implicitly that what they do (or have done for many years) has been concerned with poverty reduction. However, it has been difficult to find evaluations or assessments of the impact of this work and how it has been measured. Today many now wish to articulate more clearly how their work contributes to poverty reduction. This paper reflects this ongoing work. It should also provide ideas to influence work in progress, to point to areas where more work is needed, and to try to give some coherence to the work that has been done.

The methodology of collecting information has included requesting the ILO HQ units and field offices to provide inputs about work they believe has contributed to poverty reduction; to look at ways in which their work takes an integrated decent work approach to poverty reduction, and where they have collaborated with other international 
organisations. The work has been organised around three complementary approaches to development and poverty reduction, namely employment and sustainable livelihoods, social exclusion and social justice, and rights. We have used this as an organising principle since these three approaches correspond to the four key areas of the ILO's work. Such an organising principle also invites consideration of how the various areas fit into different approaches and complement each other. We have categorised projects in accordance with our own judgement but we are aware that those who provided information may not always share our views. We have for example not included a separate chapter on "voice" because it crosscuts all of the ILO's work.

As the project evolves it is open to discussion as to how best to categorise poverty activities. An alternative way of organising, for example, could have been on the lines of an enabling country environment for governance, capacity building, direct poverty reduction, etc.

From the outset the intention has been that this project should be participatory with full consultations both within HQ and in the field. The idea being that approaches to poverty reduction should emerge from ongoing practices and that ILO staff should have the opportunity to shape their own vision for the future. The first phase seeks to help build a common internal ILO understanding of decent work and poverty reduction. The objective is also to generate collective discussion of what tools and instruments are likely to be needed in future to ensure that poverty is a clearly identified objective of projects, and to ensure proper monitoring and evaluation of impact. This work should complement ongoing work in CODEV and PROGRAM on programme and project accountability.

\subsection{ILO approaches: past and present}

The ILO has a long history of pursuing action against poverty dating back to the 1944 Declaration of Philadelphia ${ }^{8}$, which states that "poverty anywhere constitutes a danger to prosperity everywhere". However, poverty reduction has not always been specified as a major objective in ILO work, which is often seen as more standard-setting than developmental.

The various UN conferences of the $1990 \mathrm{~s}^{9}$ provided a new international consensus on the nature of socio-economic development and during this period poverty eradication gradually emerged as the primary focus for most development efforts. International commitment around this consensus was finally achieved in 2000 in the form of the Millennium Development Goals (Annex 1) which among other things pledged to "halve the number of people living in poverty by 2015 ". This has presented new challenges to the ILO in considering how its primary goal of "promoting opportunities for women and men to obtain decent and productive work in conditions of freedom, equity, security and human dignity" can also be shown to be making a distinctive contribution to the international efforts to reduce poverty.

\footnotetext{
${ }^{8}$ This Declaration forms part of the ILO Constitution.

${ }^{9}$ The Social Summit in 1995 was one key component of a major effort by the United Nations in the course of the 1990s to systematically address the most urgent issues of development through global conferences. These include children, sustainable development, human rights, population, gender equality, food, habitat, and least developed countries. As a whole, their conclusions constitute the broadest agreement ever reached by governments on the needs of women, men, their families and their communities.
} 
At the ILC in 1999, the ILO set out its vision for decent work, a concept and strategy which provides a framework for bringing together its key areas of work - promoting rights and standards, productive employment, social protection, and social dialogue. Decent work is concerned with the quality not just the quantity of jobs created and strives for a situation in which all work (paid and unpaid) is secure, adheres to the rights of individuals, and enables them to organise freely to obtain their goals. "The need today is to devise social and economic systems which ensure basic security and productive work and employment while remaining capable of adaptation to rapidly changing circumstances in a highly competitive global market". ${ }^{10}$ Decent work is especially concerned with the poor and most vulnerable who need to have acceptable or adequate working conditions.

With the emergence of the Decent Work Agenda and the new challenges presented by the MDGs, it is important to consider how decent work as an integrated concept can contribute to the goals of poverty reduction in both rich and poor countries.

There are many ways of analysing the causes and consequences of poverty, and for defining it, and thus for providing policy prescriptions. Whilst many of these have focused on income and consumption measurements of poverty, there is now widespread consensus that poverty is multidimensional and is not a static concept. The concept of multidimensionality owes much to the work of those involved with the Human Development Report of the UNDP and in particular to authors such as Amartya Sen. But it equally owes much to the views of poor people themselves - whose voices have been heard through the many methodologies developed in the 1980s and onwards for capturing their views, such as the work of Robert Chambers and others. ${ }^{11}$ The influential World Bank World Development Report of 2000/2001 focused, for example, on the importance of recognising lack of fundamental freedoms, vulnerability to shocks of all sorts, and powerlessness in the face of state institutions when considering the underlying causes of poverty.

The ILO has incorporated a number of approaches to poverty reduction in its ongoing work: holistic approaches which put people in the centre such as sustainable livelihoods approaches; rights-based approaches which promote universal rights as a basis for poverty reduction; and social exclusion and the promotion of social justice.

All of these approaches have been represented in the ILO's work at various times but the issue remains as to whether there is a coherent ILO approach to poverty reduction. This Working Paper argues that there could be - and that the ILO has a distinct comparative advantage in tackling poverty through its Decent Work Agenda.

${ }^{10}$ ILO: Decent Work, Report of the Director-General, International Labour Conference, 87th Session, Geneva, 1999.

${ }^{11}$ See for example, R. Chambers: Whose Reality Counts: Putting the first last, 1997. 
This is by no means the first attempt to review the ILO's past approaches and to try to synthesise work into a more coherent and integrated framework. As a contribution to the World Summit for Social Development in 1995, the ILO produced a series of publications New Approaches to Poverty Analysis and Policy $I$ - III. ${ }^{12}$ These emerged from a symposium convened on the $50^{\text {th }}$ anniversary of the Declaration of Philadelphia, held by the International Institute for Labour Studies (IILS) in 1994. Many of the issues raised in this paper were also extensively discussed in these publications. It seems that 10 years on, in the context of decent work, the ILO still faces the same challenges with respect to poverty reduction. The Preface to Volume 1 notes that "the attempt to integrate normative social policies with macro-economic strategies and with institutional change is the hallmark of ILO action against poverty [...] The emphasis on the organisation of social actors and their participation in development reflects the tripartite dynamic of the ILO." The authors of this paper would argue that this framework has become even more relevant in the context of current challenges. The following provides a very brief summary of approaches as set out in Volume 1 of the above-mentioned publication.

The dominant view of poverty in the ILO has been that of satisfying minimum needs through productive work and employment. Debates and discussions continue around the issue of linking this approach to rights and standards promoted within the ILO. However, it is a central tenet of the ILO's normative approach to development that labour standards and workers' rights have both economic and social value in addressing poverty reduction. Various policy strands for addressing poverty have been detected in its work: policies related to asset distribution, policies aimed at restructuring production systems to create productive work and employment; policies to improve access to jobs and reduce vulnerability of particular population groups; policies to transfer income, goods, services, directly to the poor; and policies concerned with the organisation of the poor.

A second major idea that has consistently influenced the ILO's work is that of social justice. This has often focused on groups such as children and migrants working in inhumane conditions, and on the question of social security and income protection for those unable to work because of sickness, age and other causes. ILO has addressed this through legislation and social security schemes. At the core of an ILO vision is the notion of society. The ILO's concern with social justice stresses rights and standards as a basis for participation by labour in society. Standards are a means of expressing these rights. With respect to poverty, the prevailing philosophy can be expressed as a right to inclusion - participation, protection, access to decent jobs and decent incomes. Fulfilment of the right depends on economic and social conditions.

Much of the work of the ILO is built round the notions of rights and standards. The challenge is to establish a moral baseline in which universal labour standards are seen as part of a package, which also includes the right to social inclusion and freedom from poverty. A successful mapping out of rights and social objectives and their relationship with economic strategies can provide the basis for action against poverty to be presented to the international community as a global responsibility.

${ }^{12}$ G. Rodgers, ed.: New Approaches to Poverty Analysis and Policy - I, The poverty agenda and the ILO - Issues for research and action, ILO, IILS, Geneva, 1995; J. B. Figueiredo and Z. Shaheed, eds.: New Approaches to Poverty Analysis and Policy - II, Reducing poverty through labour market policies, ILO, IILS, Geneva, 1995; G. Rodgers and R. van der Hoeven, eds.: New Approaches to Poverty Analysis and Policy - III. The poverty agenda: Trends and policy options, ILO, IILS, Geneva, 1995. 
The ILO's work has, as might be expected, mirrored trends in development thinking. In the post-independence period as a contribution to modernisation, it developed programmes to assist governments develop poverty-related policies on productive employment. In 1969 the ILO set up the World Employment Programme (WEP), which became its single most important contribution to poverty reduction. From the beginning the emphasis was on integrating economic and social polices as a pre-requisite for poverty eradication. As well as emphasising productive work and employment, the ILO has consistently placed emphasis on equity and normative action, establishing standards to regulate the terms and conditions of employment in the context of its tripartite structure.

The WEP produced in the 1970s and 1980s a series of Comprehensive Employment Strategy Missions (CESMs), which addressed the issue of the link between employment strategies and poverty, focusing on the employment and development nexus. The WEP also contributed significantly to expanding participatory development methods. Drawing from practical examples in the Indian Sub-continent, the WEP supported, documented and disseminated new information about poor people's movements and methodologies in which poor people became their own agents of change (Sri Lanka, Bangladesh). These were subsequently drawn on heavily in the 1990s in programme approaches of other UN agencies (notably UNICEF and UN-Habitat) as well as by NGOs.

This work fed into the basic needs strategy developed by the ILO, which emphasize moving beyond productive work and employment objectives towards a broad-based antipoverty strategy which encompasses the provision of education, health and water supplies.

The concepts and methodologies that emerged from WEP were widely recognised and provided innovative insights into new ways of working towards poverty reduction for many other agencies. It influenced the World Bank's focus on redistribution with growth, and the UNDP Human Development Reports. However, as a model for development, the basic needs approach was not successful, mainly because it was not considered politically acceptable to some countries. Participation and empowerment were at the time insufficiently developed. Moreover, it came at a time of declining resources for public services and at the emergence of structural adjustment policies as a development paradigm.

When structural adjustment was at its zenith, the ILO contributed work to the discussion but was not a key influence in the debates with the Bretton Woods Institutions. However, a further strand of work began to be promoted by ILO together with UNDP - the sustainable livelihoods approach. Again, this approach was taken up by other organizations but remained weakly articulated within the ILO.

There have been many debates about the nature and causes of poverty, but the ILO has retained a commitment to addressing contextual and structural causes in terms of differing rules, institutions and opportunities. It has also been involved in the debates about the international dimensions of poverty such as the discussions on trade barriers in the 1970s.

The ILO has developed the concept of the "working poor": those people in the labour market who work but remain poor. The definition of the working poor involves two statistical units: the individual and the household. The individual is the basis for establishing the "working" and "not working" classification, and the household is the basis for establishing the "poor" and "not poor" classification. To some extent the ILO classification system addresses the weaknesses inherent in the World Bank household surveys. It has to be borne in mind that almost all poor people work, that some of this work is in the unpaid, care economy (where women are often found), and is largely unaccounted for in national accounting systems. The ILO's response promotes two broad approaches to raise the incomes of the working poor; to, as part of an overall growth 
strategy, encourage policies aimed at raising the growth of higher productivity activities in which the working poor can be absorbed, and, to formulate policies and programmes to tackle the issue of raising productivity of activities of the working poor. 
"We have a rich historic mandate that calls us to the challenge of fighting poverty. Our experience on the ground is bringing that mandate to life throughout the world. And we face common challenges as we join with others to provide men and women with the tools and support to work out of poverty."

Report of the Director-General, Working out of Poverty, ILC 2003

\section{Current global challenges}

Today, the ILO is operating in a context where it increasingly needs to respond to major challenges globally and internationally.

\section{$2.1 \quad$ Globalization}

Major challenges and opportunities are presented by globalization and these have varied depending on national and local contexts and situations. Globalization has altered the conditions of work and access to work for many people, often increasing their insecurity. The global environment for work poses challenges in relation to workers rights, which are no longer contained within nation state borders. Migration has increased with many social and economic implications. For example, the conditions of work experienced by migrant workers in Bahrain can have major implications for families in say poor remote areas of Pakistan. International labour mobility has increased while exploitation and deregulation have flourished. The role of civil society in the face of globalization poses new challenges to employers and workers associations. Social security is being eroded rather than increased.

The ILO is contributing to the global debate through its work with the World Commission on the Social Dimension of Globalization, established in February 2002. This independent body aims to move the debate from confrontation to dialogue, and thereby set the stage for action. The Commission delivered its report on 24 February 2004 (after the completion of this Working Paper) ${ }^{13}$.

\subsection{Employment at the centre of economic and social debates}

The ILO's main challenge in tackling poverty reduction continues to be in the promotion of policies that create employment. More than ever, there is a need to emphasise the importance of sound employment policies that lead to decent work. Opportunities for promoting such policies are created through instruments such as PRSPs and the UNDAF, but these instruments do often not yet adequately reflect such policies or commitment to implementing them. Recent ILO contributions to the global debates have also included the World Employment Report 1998-1999 that covered employability in the global economy. The World Employment Report 2001 and the World Labour Report 2000 both focused on the impact of trends in the information economy and social protection, and their effect on different groups, particularly the least well-off. The Global Employment Forum in 2001 dealt with employment, growth and poverty eradication. It stated that the principal challenge is to make productive work and employment central to all economic and social policies. To do so requires many things, but the cornerstone resides in

\footnotetext{
${ }^{13} \mathrm{http}: / /$ mirror/public/english/wcsdg/docs/report.pdf.
} 
increasing the productivity of labour, especially that of the working poor. Productivity growth is the source of sustainable, non-inflationary improvement in living standards and employment opportunities, and it sets the scene for faster growth and development leading to increased scope for macroeconomic policies to be directed toward better employment outcomes and decent work. To offer opportunities for creating decent work, the ILO is for example promoting small and medium-sized enterprises, strengthening microfinance programmes, improving rural infrastructure, and implementing agricultural extension and labour-intensive public works programmes.

\subsection{Millennium Development Goals}

In 2000, heads of state from around the world committed themselves to the Millennium Development Targets (see Annex 1), in particular to the goal of "Halving between 1990 and 2015, the proportion of people whose income is less than one dollar a day". Much of the ILO's work on the Decent Work Agenda contributes directly or indirectly to attaining this target. A greater number of productive jobs would create more opportunities for poor people to move into activities that lift them out of poverty.

The ILO has an important role to play in achieving the MDGs and also in strengthening the monitoring of these goals by measuring progress at the regional and global levels. It has been made directly responsible for two indicators:

\begin{tabular}{ccl}
\hline Goal & Target & Indicator \\
\hline 3 & 4 & 11: Share of women in wage employment in the non-agricultural sector \\
\hline 8 & 16 & $45:$ Unemployment rate of 15-24 year olds \\
\hline
\end{tabular}

The ILO has provided statistics as from 1990 for use in computing these indicators for regional and global levels. Indicator 11 is calculated as the number of women in nonagricultural paid employment divided by the total number of persons in paid employment in the non-agricultural sector. Indicator 45 is calculated as the number of youth (aged 1524) who are unemployed as a proportion off all youth in the labour force. Both datasets are derived from official national statistics. Work is being carried out to review the quality and range of available data regarding women's employment and youth unemployment and to assess them in conjunction with other meaningful variables. ${ }^{14}$ In addition, the ILO is suggesting further indicators in relation to MDG targets.

The ILO also contributes to many of the other MDGs through its work, for example, with teachers' unions, on gender equality, and on HIV/AIDS. Ridding the world of forced labour, tackling child labour and preventing discrimination are also core themes that the ILO is committed to in reducing poverty. Societies that respect basic rights like freedom of association and collective bargaining favour greater voice for the poor and more democratic and participatory processes of development. Extension of social protection will give the poor a buffer against risks that can now wipe out income and perpetuate disadvantage.

\footnotetext{
14 Report I, General report, Seventeenth International Conference of Labour Statistics. ILO Geneva, November 2003 (ICLS/17/2003/1).
} 
Today, 1 billion people are between 15 and 24 years of age, of which $85 \%$ live in developing countries. Many of these young people are struggling to earn a living, most of them active in the informal economy. The ILO is a core partner, together with the UN and WB, in the Youth Employment Network, and hosts the permanent secretariat (see Section 3.3). Employability, equal opportunities, entrepreneurship and employment creation have been identified as cornerstones for success. Further, youth is seen as an asset and treated as today's partners, promoting involvement of youth throughout the process.

Although contributing to achieving the MDGs is of central importance, the ILO's role in strengthening the capacity to monitor and report on the MDGs is also highly relevant. The ILO harvests national level information for international level analysis and comparison, and its current work captured in the Yearbook of Labour Statistics and Key Indicators of the Labour Market is evidence of this. This important function is currently the core means through which macro changes in poverty are monitored. Without this it is not possible to judge whether the many diverse development efforts indeed lead to significant changes in employment, work patterns and poverty. Doing this demands close links and technical assistance to national level statistics bureaus as well as international linkages with other agencies engaged in the macro-level assessment of change in poverty, most notably UNDP and the World Bank.

\subsection{Challenge of the informal economy}

The correlation between being poor and working in the informal economy is not simple. Working in the informal economy is no guarantee of escaping poverty. However, to a poor person, any job seems better than no job. Poverty is one of the underlying causes of informality and the majority of poor people in the world are active in the informal economy, both in rural and urban areas. In 2002 the ILO International Labour Conference reaffirmed the importance of the ILO's work in tackling the problems of the informal economy. The Report of the Committee on the Informal Economy noted that its approach should:

"...reflect the diversity of situations and their underlying causes found in the informal economy. The approach should be comprehensive, involving the promotion of rights, decent employment, social protection and social dialogue. The approach should focus on assisting member States in addressing governance, employment-generation and povertyreduction issues. The ILO should take into account the conceptual difficulties arising from the considerable diversity in the informal economy." 15

The current challenge for the ILO is to develop coherent approaches to addressing the problems faced by people working in the informal economy as a means of reducing their poverty and minimising decent work deficits. ${ }^{16}$ Continued progress towards recognised, protected decent work will only be possible by identifying and addressing the underlying causes of informality and the barriers to entry into the economic and social mainstream.

\footnotetext{
${ }^{15}$ Report of the Committee on the Informal Economy. ILC Provisional Record 25. ILO. 2002.

${ }^{16}$ See the conclusions from the ILO Turin workshop on the Informal Economy in February 2003 http://training.itcilo.it/decentwork/IEWS2003/default.htm. For further materials relating to the informal economy see also ILO's informal economy website

http://www.ilo.org/public/english/employment/infeco/ and a forthcoming database on decent work and the informal economy (to be available at http://www.ilo.org/public/english/bureau/integration).
} 
The ILO increasingly sees that informality as principally a governance issue. The informal economy is often not recognised, regulated or protected by national laws. The ILO's country level and international work with its tripartite partners will become key in addressing this challenge.

In order to improve the information and data available on the informal economy, the ILO is an active member of the Expert Group on Informal Sector Statistics (Delhi Group) established in 1997 by the United Nations Statistical Commission. The ILO contributed to the publication Measuring the non-observed economy - A handbook, which was published in 2002. It also participated in the development of a conceptual framework for defining the informal economy, presented in the ILO report Decent work and the informal economy for the ILC in 2002. A database established in 1998 with statistics on employment in the informal economy allowed for the publication of an ILO Compendium of official statistics on employment in the informal sector. ${ }^{17}$ At its Seventeenth Session (24 Nov.- 3 Dec. 2003) the International Conference on Labour Statisticians adopted guidelines on measurement of informal employment. ${ }^{18}$

\subsection{Challenge of promoting gender equality}

Gender equality and the empowerment of women are essential preconditions for the elimination of global poverty, and therefore constitute one of the MDGs. Gender equality is also a central element in the wider struggle for universal human rights. Inequalities in economic development and livelihood security, in human development, human rights and personal security all contribute to the process whereby women continue to make up the majority of the world's poor.

In the ILO, gender equality is actively promoted by the Gender Bureau (GENDER), which emphasizes gender mainstreaming, and the Gender Promotion Programme in the Employment Sector, which backstops field-based projects. Both have produced tools and networking for use across the ILO. The ILO's 2004-05 Programme and Budget includes a shared Policy Objective of Gender Equality.

${ }^{17}$ STAT Working Paper No. 2002-1 (ILO Geneva 2002).

${ }^{18}$ These are reproduced as an Appendix to the Report of the ICLS (ILO Governing Body document GB.289/STM/6 (March 2004). 


\section{Box 2: Gender inequality, the life cycle and poverty}

Throughout all stages of life, from birth to old age, gender inequality persists and is perpetuated, and contributes both to the feminisation of poverty and to a vicious cycle of poverty from one generation to the next. About two-thirds of the people living on $\$ 1$ a day or less are women and girls. Girls account for 56 per cent of children without schooling. Young women face greater difficulties finding employment than young men, with unemployment rates sometimes 50 per cent higher. The school-to-work transition is harder for young women than for young men, but more and more women have been entering the labour force - as much out of need as of choice. The bulk of women workers are going into the informal economy, outside the scope of labour legislation and social protection. For those in wage employment, a large gap persists between male and female earnings, despite the increasing adoption of equal pay legislation. There has been a tremendous rise in dual-income families and single parent households, but societal perceptions of work and family have not changed. Women continue to have primary responsibility for housework, childcare and unpaid work, so that their increasing participation in paid employment in many cases simply means women work extra long hours. To balance work and family responsibilities, women tend to move in and out of the labour force several times over their life course. But then they further lose out to men, not only in terms of accumulated social security but also in terms of opportunities for lifelong learning and continuous training without which they have lower employability. Ageist and sexist discrimination in the world of work appears to be occurring at earlier and earlier chronological ages; in a growing number of countries, women over 35 years of age are finding it increasingly difficult to get jobs or be rehired - and thereby fall into poverty.

At older ages, it is the women who are most likely to end up in abject poverty. Nearly everywhere in the world, women live longer than men and account for the majority of single person households. In many countries, public expenditures on social security and health care have been cut, often based on the mistaken belief that families and communities will take care of their aged. The sad fact is that there has been a reversal of inter-generational care. Older women who have already spent their lifetime looking after other people increasingly cannot expect to be cared for in their twilight years. In many least developed countries, the impact of the HIV/AIDS pandemic has left older women with responsibility for caring for their infected children and, later on, their children's children. AIDS now provides a further distortion of gender inequalities both at the beginning and end of a woman's life cycle and accounts also for the increasing feminisation of poverty.

From a life cycle perspective, today's girl child is tomorrow's older woman worker and it is her opportunities and experiences now which will shape her ability to access and maintain decent work throughout her adult life, and enjoy security and protection in her old age. If girls, compared to boys, face negative cultural attitudes and practices and discrimination from birth, they will grow up to be women with greater constraints and few choices and opportunities. In turn, they are less able to positively influence the lives of their daughters and sons, so that one generation to the next is likely to remain poor. Hence, the links between a vicious cycle of poverty and gender discrimination that starts at the earliest stages of life within families against the girl child.

The ILO is preparing a publication to commemorate Beijing +10 in 2005 , ten years after the Fourth World Conference on Women, that will highlight the ILO's particular niche vis-à-vis other international organizations in promoting gender equality throughout all stages of life. The basic message of the publication will be that breaking the cycle of gender discrimination goes to the heart of realizing decent work for women and men and is also central to ending feminisation and the vicious cycle of poverty. (ILO: Gender Promotion Programme). 
Although women's share of the labour force in developing countries is rising, the majority of women continue to work in household subsistence, in the informal economy and in the care economy. Generally speaking women's work outside the formal economy is unrecognised and undervalued, in spite of efforts in various countries to introduce concepts such as gender-based budgeting. Perceptions of women and work such as, women's productive and domestic responsibilities being perceived to be their primary function, and women being perceived as secondary income earners, serve to reinforce the cycle that keeps women impoverished.

As far as decent work is concerned, women face particular additional discrimination. With the double burden of work and family, they may be likely than men to be involved or active in formal organisations such as trade unions and employers' associations. They are less likely to have access to rights. Social protection systems consistently discriminate against women because women spend most of their lives in unpaid, caring work balancing multiple roles of household tasks, work tasks and community managing roles.

In response to this the ILO takes a "mainstreaming" approach to gender issues, internally beginning to ensure that gender is integrated into all programmes undertaken. Promoting the same strategy in member States, the ILO has developed a major training package on "Gender, Poverty and Employment" (GPE). It was one of the first ILO products that specifically linked poverty with decent work. The package provides training materials that focus on the importance of multi-pronged, inter-related strategies for combating the feminisation of poverty. These include the promotion of productive employment, empowerment through organisation and social protection.

\subsection{Challenge of developing decent work indicators for poverty reduction}

In promoting the idea of decent work, the ILO is also taking on the challenge of developing decent work indicators so that decent work can be measured. A set of 29 statistical indicators has been suggested, organised under 10 headings, supplemented by an $11^{\text {th }}$ concerning the economic and social context. Each heading is meant to represent a characteristic of work that individuals from around the world would consider as a key element of decent work. An ILO Working Paper on decent work indicators makes strong links between decent work and poverty:

"Current knowledge about poverty strongly suggests that economic growth is a necessary but not sufficient condition for sustained reduction in poverty. Rising labour productivity is indispensable if economic growth is to lead to less poverty. For any given rate of economic growth, different combinations of economic, employment and social policies will lead to faster or slower poverty alleviation. It is these combinations which are of particular interest to countries committed to poverty alleviation. Aggregate data on the share of the population living in extreme poverty do not reveal whether poverty results from insufficient employment, low rates of pay, inability to work due to an uncompensated injury at work, discrimination, lack of access to social protection, unavailability of a basic pension, or one of the many other aspects of labour markets observed the world over. Better measurement of decent work and especially the extensiveness of social protection and low pay will provide useful insights into the many possible policy options to address poverty. Understanding decent work and its relationship to poverty is, therefore, a critical aspect of the struggle to reduce extreme poverty by half by 2015." 19

\footnotetext{
${ }^{19}$ Policy Integration Department, Statistical Development and Analysis Group, Measuring Decent Work with Statistical Indicators, Working Paper No. 2, 2002.
} 
In building statistical indicators to measure decent work, two central considerations should be highlighted. Firstly, decent work is of special importance for the poorest and most vulnerable. Therefore, decent work indicators should often be concerned with distributions and measuring the situation of the least well-off rather than averages covering the whole working population. Secondly, decent work is concerned with the actual situation that people face. Thus indicators should generally measure actual outcomes and conditions. When considering the legal situation in a country or international standards, the indicators should measure effectiveness and coverage, not just the existence of legislation. ${ }^{20}$

${ }^{20}$ The decent work indicators formed part of the General report to the Seventeenth International Conference of Labour Statisticians. 
"The challenge of integration is an internal one... The office is continuing to build upon an integrated approach in which standards, protection, employment creation and social dialogue all contribute in a strategic and unified way. It is a key objective of the next programme and budget."

Report of the Director-General, Working out of Poverty, ILC 2003

\section{Integrating poverty frameworks}

The ILO Decent Work Agenda covers all core areas of work, but it is also important to see decent work as a framework that captures both social and economic goals of development. In reviewing the situation, Gerry Rodgers notes that the interaction between freedoms and development is an important aspect of the rationale for decent work as a development goal. ${ }^{21}$ Decent work brings together different types of freedoms: workers' rights, income security and employment opportunities. These are goals in their own right, but taken together they are more than the sum of the parts whereby both social and economic factors are involved. The Decent Work Agenda attempts to bring them together within a coherent framework. Decent work has a floor but no ceiling. The ILO's core labour standards are recognised as the floor of the global economy, and poverty (as noted elsewhere) is not just a question of income but also rights and capabilities. The improvement of basic rights has clear links with improvement in living conditions.

The ILO concern with social justice leads naturally to a stress on rights and standards; rights as the basis for participation by labour in society; standards as a means to express those rights. With respect to poverty, the prevailing philosophy can be expressed as a right to inclusion, in the sense of participation, protection, access to decent jobs, and decent incomes. But the fulfilment of a number of rights also depends on economic conditions, and to meet these conditions it is necessary to build up the capacities of labour and the corresponding systems of production. Thus the achievement of rights involves the development of both economic and social capability. ${ }^{22}$

The challenge for the ILO is to both further the links between an integrated approach to decent work and poverty reduction, and to work with the ILO's social partners as advocates for this approach within the broader policy environment. In the context of globalisation and the issues related to trade and protectionism it is extremely important to make the case for an integrated view of social and economic objectives as a means of enhancing opportunities for all.

\footnotetext{
${ }^{21}$ G. Rodgers: "Decent work as a development objective", in The Indian Journal of Development Economics, Vol. 44, No. 1, 2001.

${ }^{22}$ G. Rodgers, ed.: New Approaches to Poverty Analysis and Policy - I, The poverty agenda and the ILO - Issues for research and action, ILO, IILS, Geneva, 1995.
} 
Most importantly, the ILO's response has to make sense and be translated into what it can offer through technical cooperation and other means at the country level. As a contribution to this, the ILO has set up a Decent Work Pilot Programme ${ }^{23}$ involving Bahrain, Bangladesh, Denmark, Ghana, Kazakhstan, Morocco, Panama and the Philippines. The objective is to work with the constituents to analyse decent work problems in relation to a country's broader political and socio-economic context and to develop integrated policies and approaches to solving identifiable problems. In some countries this process is closely linked with the major instruments for national planning such as the PRSP.

In Ghana, the informal economy was identified as a major issue in poverty reduction. This features in the Ghana Poverty Reduction Strategy, GPRS (Ghana's PRSP), which is the key national policy framework and resource allocation mechanism. A majority of poor people work in agriculture and/or in the informal economy, where decent work deficits abound, including the denial of fundamental rights. The implementation of the GPRS is to be carried out at the district level by the 110 districts in the country.

In response to this challenge, the pilot programme has taken a two-pronged approach. One, working with social partners to influence the GPRS so that it reflects decent work issues - especially those found in the informal economy. And two, developing a local development approach at the district level as a means for demonstrating how the Decent Work Agenda can be applied within the informal economy and can contribute to poverty reduction in the long term. The programme thus brings together ILO competences, forging a comprehensive ILO response to the problem at hand.

In the Philippines, the pilot programme is also focusing on poverty issues by linking activities to national plans. The Medium Term Philippine Development Plan 2001-2004 stipulates that the country will take action "to formulate strategies under a unified policy framework to promote full, decent and productive employment as a means of alleviating poverty". A key feature of the Philippine's National Plan of Action for Decent Work is development of integrated responses that support the government's efforts in this regard. For this purpose, the action plan provides a component of the framework under which the ILO will provide its support to poverty reduction through local economic and social development.

\footnotetext{
${ }^{23}$ A complete overview of the Programme is provided in a Governing Body paper of November 2003, A review of the ILO decent work pilot programme (GB.288/ESP/5). An update is contained in a paper submitted to the March 2004 Governing Body session: An update of the implementation of the Global Employment Agenda and related aspects of policy integration (GB.289/ESP/3).
} 


\section{Box 3: The Philippines' Poverty-free Zones}

Technical support to the Department of Labour and Employment in the implementation of their Poverty Free Zones programme - In support of the government's overall anti-poverty policies, the Department of Labor and Employment has launched its Poverty-Free Zones (PFZ). This programme is designed to transform targeted poor communities into selfsufficient communities through a systematic and rational convergence of the assistance efforts of government agencies and private organisations. This work will involve packaging existing ILO resource materials and training for PFZ managers and other stakeholders, such as:

- Application of labour standards in the PFZ programme

- Ensuring a gender sensitive approach is mainstreamed into the PFZ programme

- Micro-enterprise and skills development (e.g. Simplified SYB, CBTED, Managing People and Productivity, Cooperative development, Micro-credit materials)

- Integration of viable health micro-insurance initiatives

- Rural infrastructure planning and implementation

- Promoting worker organizations and co-operatives

- Resource mobilization and networking

Support for local government and other stakeholders in local economic and social development built around the decent work framework.

- Review of existing tools and practices in local economic and social development planning

- Identification of planners' needs for economic and social development tools

- Review and identification of ILO's (and others) existing tools that could fulfil the above-mentioned needs

○ Development of documents for Local Economic and Social Development based on the reviews

(Philippines Decent Work Pilot Programme)

In Bangladesh, the policy challenges facing the country lie in how the demands of globalisation and economic growth could be harmonized with the demands of poverty reduction. The pilot programme, "Harnessing the benefits of globalisation for decent work: policy challenges, " is meant to achieve the following 2 objectives:

1. To engage social partners and stakeholders in meaningful and concrete policy dialogue around the specific policy issues associated with globalisation, decent work and poverty reduction (demonstrated by their participation in actual mechanisms, institutional processes and instances), based on a much better understanding of the multiple dimensions of these policy issues.

2. To enable social partners and stakeholders to adopt and implement an integrated set of economic and social policies and measures aimed at improving decent work and reducing poverty.

To start with, informed policy dialogues are planned. They will draw from existing research, experiences and good practices, and be complemented with empirical policy research and capacity building. 


\section{Box 4: Bangladesh, topics for policy dialogue}

In a series of consultative meetings held in 2003, representatives of workers' and employers' organisations, and government ministries selected four priority areas:

1. Improving employment, competitiveness and decent work in global markets;

2. Spreading the benefits of globalisation to the poor;

3. Overseas employment;

4. Measuring decent work in the Bangladesh context.

These topics pull together issues from across the Descent Work Agenda, for example: competing pressures on standards and basic rights at work, trade and investment; job quality and enterprise productivity; vulnerability and insecurity in labour markets, social protection and labour market policies; and gender equality.

(Bangladesh Decent Work Pilot Programme)

\section{Poverty Reduction Strategy Papers}

Poverty Reduction Strategy Papers (PRSPs) were initiated by the Bretton Woods Institutions in 1999 as a way of ensuring that their concessional financing through the IMF's Poverty Reduction and Growth Facility, and the World Bank's International Development Association (IDA), as well as debt relief under the HIPC initiative, more effectively address poverty reduction. The PRSP involves principles of national ownership, a full participatory process, a holistic approach and a long-term vision.

PRSPs can provide a useful mechanism for integrating the ILO's approach to decent work and poverty reduction into national poverty reduction efforts. It has become increasingly clear that employment, social protection and social dialogue are all integral parts of the PRSP process. In particular, building the capacity of the ILO's social partners at the country level to advocate for the Decent Work Agenda has become a central part of its work.

In March 2000 the Director General of the ILO and the President of the World Bank agreed that the two organizations should work more closely together to assist countries in the preparation, implementation and evaluation of PRSPs.

A pilot programme with the objective of strengthening the ILO's contribution to the PRSP and providing mutual lesson learning has been established in five countries Tanzania, Mali, Cambodia, Nepal and Honduras. ${ }^{24}$ However, the ILO is now responding to demand for involvement in the PRSPs in many countries. ${ }^{25}$ For example, through the Jobs in Africa Programme and other means, a number of countries have, through consultative processes, managed to put employment and social protection issues on the PRSP agenda.

\footnotetext{
${ }^{24}$ The Governing Body paper Poverty Reduction Strategy Papers (PRSPS): An assessment of the ILO's experience, November 2002 (GB.285/ESP/2), gives a full review of the pilot programme.

${ }^{25}$ To take stock, an ILO staff seminar on "Decent Work, Poverty Reduction and PRSPs: A Thematic Review and Cross-country Experiences", was organised in Turin, September 2003. The report can be consulted on http://raining.itcilo.it/decentwork/StaffConf2003-sep/default.htm .
} 
The ILO regards the PRSP as a dynamic process providing opportunities for improved policy dialogue on poverty reduction and decent work. In Tanzania, for instance, it has offered to facilitate the creation or adaptation of social dialogue mechanisms for the purpose of informing and consulting employers and workers on the PRSP. A tripartite meeting produced recommendations outlining action "Towards a Decent Work Strategy for Poverty Reduction in Tanzania". ${ }^{26}$ In Mali, the PRSP process has become an example to emulate in the West African region in terms of its content, stress on employment and the degree of participation and political pluralism involved in its preparation. ILO technical cooperation has been useful on both counts. The PRSP acknowledges employment as a crosscutting theme, not limiting its discussion to the chapter on employment and training. The value of labour intensive processes is stressed throughout, as is the need to support small enterprises, informal economy employment and forms of cooperation among the self-employed.

The ILO's work on PRSPs in the Asia and Pacific Region has been based on three critical activities: process, analysis, and policy advocacy. All of the PRSP activities have been guided by the inclusion in the process of constituents, representatives of civil society like academics and NGOs, and representatives of particularly vulnerable groups such as poor women, poor communities, and poor regions. There has been regular consultation and collaboration where possible, with the World Bank, UNDP, and the Asian Development Bank (ADB). Their views have been respected, but not always adhered to, and thereby a very stimulating policy dialogue has opened up.

Three elements of a decent work strategy for poverty reduction have been promoted through the PRSP process in the Asia and Pacific Region: 1) Generating work, 2) Improving the conditions of work, and 3) Protection of workers and strengthening their capacity to work.

1. Generating employment entails a macro strategy for growth, employment and income distribution. Traditional sector growth is constrained but labour intensive exports are highly competitive. Generation of demand for employment then requires that niche sectors and markets be found, as for instance in Cambodia. Generating employment also entails active labour market policies for employment services and training, to better match supply and demand in the labour market.

2. Improving the conditions of employment entails beginning by removing the grossest deficits in rights, which are frequently observed to be trafficking of women and children, and child labour in hazardous and difficult conditions, a challenge particularly confronted by Cambodia. Deficits in rights in the Asian region are increasingly perceived as analogous to child labour, this is judged to be in part due to the aggressive drive to attract Foreign Direct Investment and to focus on exportorientated production. Improvement in rights, in industrial relations, and in dialogue and voice, all work to improve the investment climate, to generate growth and employment, and to reduce poverty.

3. Protection of workers involves better occupational safety and health and better social protection. A volatile investment climate and increasing demand for labour flexibility have shown the Region that a job is not a substitute for social protection. The restructuring of state-owned enterprises further threatens the notion of stability of employment. The large informal economy lacks stability and security. The battle for preserving and extending social protection in the region must then proceed in

\footnotetext{
${ }^{26}$ G. Casale and S. Pursey: Towards a Decent Work Strategy for Poverty Reduction in Tanzania,
} Working Paper No.8, IFP/DIALOGUE, ILO, Geneva, February 2002. 
two directions. In sectors where stability and security of employment are difficult, such as the large informal economy in Pakistan, or increasing non-standard forms of employment in South Korea, more innovative forms of income insurance are needed. The large agricultural sectors ridden with poverty, because of great volatility of income from year to year, leading to a vicious cycle of low investment low and uncertain income - and low investment again, such as Nepal, clearly need some form of income and crop insurance.

\section{Box 5: Nepal, ILO policy recommendations on the PRSP}

1. Make employment-impact analysis an explicit criterion of macroeconomic policy decisionmaking, and make employment-intensive growth objectives an explicit criterion of public expenditure programmes.

2. Link essential investments in infrastructure to private-sector development with a focus on products and services in which Nepal has a distinctive comparative advantage or the opportunity to development one.

3. Train for emigration of Nepalese workers, systematize and streamline public support for outward-bound and returning migrants, render transparent and expand the productive uses of remittances.

4. Begin the reform of Nepal's system of vocational training, linking it more closely to employment policy objectives and labour demand, and extending it to workers in the informal economy.

5. Strengthen the implementation of measures already agreed, including the enforcement of relevant legislation, including land distribution to former kamaiya families, laws on minimum wages and child labour, and the extension of targeted labour inspection services to informal/unorganised sectors.

6. The pervasive nature of gender discrimination warrants that specific policy measures for women be "mainstreamed" throughout the strategies and activities of policy recommendations. Therefore, it is advisable that specific proposals for impact analysis and affirmative action accompany all poverty alleviation strategies contained in the PRSP policy matrix.

7. Bring draft of updated Social Security Bill before Parliament, following full consultations with the social partners and a full-scale technical assessment and design exercise, and strengthen support to the most vulnerable members of society through an increase in allocation to the existing national social assistance scheme.

8. Develop a national strategy for extending social protection to the poor and excluded. Priority could be given to identify ways to provide access to better healthcare, including HIV/AIDS, life insurance, maternity protection, livestock insurance, etc.

9. Promote the organization of workers and employers in those economic sectors, industries, and forms of work that are currently unorganised.

10. Review and prepare recommendations for an integrated set of reforms to labour legislation, the institutions for social dialogue, labour administration, and possibly other related policy fields, such as wage policy, social security, training, and patterns of employment. Facilitate the development of consensus on a mutually beneficial package of reforms and monitor the implementation of this reform strategy.

Decent Work for Poverty Reduction: An ILO contribution to the PRSP in Nepal, ILO Employment Strategy Department, 2002.

A number of departments in the ILO now see the PRSP process as relevant to their work. For example, the Social Finance Programme organised a high level meeting on debt for job swaps; drawing on country debt reviews it examined the scope for linking PRSPs to micro finance capacity building and wealth creation. Further, at a meeting of the Committee on the Advancement and Promotion of Cooperatives (COPAC) in Stockholm, it was agreed that the ILO should find ways of helping to build the capacity of cooperatives to contribute to the PRSP process. Regional and national capacity building workshops were conducted in Africa and Asia in the second half of 2003. In addition, a number of discussion papers have been produced, for example, "The HIV/AIDS Epidemic and Poverty Reduction Strategy papers: A case for greater integration of HIV/AIDS issues 
in PRSPs and Policy Options for the ILO", and "Disability and Poverty Reduction Strategies". The Gender Bureau, together with other ILO units, is looking at gender issues and the PRSP.

The PRSP process is providing the ILO with ongoing experience in advocacy for poverty reduction. Influencing policy has not always been easy. There are a number of reasons for this:

- $\quad$ The ILO is on a learning curve when it comes to influencing broad based policies such as the PRSPs, which range from agreements with the IMF on macro fundamentals, to fiscal and monetary policies, to sectoral strategies, to debt and project loans, and to cross-cutting issues of governance, monitoring and implementation. The ILO's advocacy experience in the past has been more modest, and on single issues.

- The ILO is learning to work with the Ministries of Planning and Finance, who often lead the process and are the final national arbiters of the PRSP. Its traditional focal point in government, the Ministries of Labour, have at best weak links with Planning and Finance, and it is the ILO that has to help build these new institutional bridges. However, some examples of more longstanding collaboration exist. The SFP is engaged in consultations with Ministries of Finance and Central Banks in Africa about the design of financial sector policies that take the interests of the majority better into consideration.

\subsection{The MDGs: promoting an integrated approach to Pro-poor Growth and Decent Work for Poverty Reduction}

The MDGs provide an important vehicle for strengthening the integrated approach to decent work at the national and regional levels. The ILO's general approach to the MDGs, and their monitoring, has been discussed in section 2.3 above. Yet, in addition, practical coordinated efforts are also being made.

\section{Box 6: Chile, contributing to the MDGs with others}

From the beginning, the ILO has been an active partner in the inter-agency meetings regarding the design of the Millennium Development Goals monitoring in Chile. The ILO Sub-regional Office in Santiago has been participating in several meetings on the MDGs organized by the UN Resident Coordinator. It has also been providing technical assistance to the whole process by commenting draft outlines of the Chilean MDG document, prepared by a research team of the University of Chile ("Instituto de Asuntos Políticos"), and by providing the research team with relevant ILO material. Specific technical comments have been given with regard to ILO topics like employment, social protection, discrimination, etc., but also to other topics and aspects related to the design and implementation of the MDGs in Chile.

The Asia and the Pacific Region illustrates ILO participation in the MDG process. The first regional meeting on the issue was held in Vientiane in October 2002. The meeting held by UNDP and the UNDG, helped clarify, not just for the ILO but for much of the UN agency community, and other development partners, the perspective of the MDGs. It also allowed the ILO to put forward its own perspective of decent work strategies for poverty reduction through the PRSPs, and to plot areas of collaboration with the UNDG and UNDP. The ILO has planned a number of actions to participate in the MDG process in the Region. It contextualised the MDGs into its work on the PRSPs, beginning with Indonesia and Vietnam. UNDP's Bureau for the Asia-Pacific has invited the ILO to participate in its 
pro-poor growth programme, especially in the area of employment intensive growth. The ILO is planning collaboration with the UNDG's Sub Regional Facilities on poverty reduction in a number of countries.

\section{The Youth Employment Network}

With the world's major economies slowing down and threatening the growth prospects of developing countries, the unemployment of youth is now a major focus for concerted UN action. Target 16 under the MDGs (Goal 8: Develop a Global Partnership for Development) is directly addressing this problem: "In cooperation with developing countries, develop and implement strategies for decent and productive work for youth". The ILO Director-General, Juan Somavia, has joint the UN Secretary-General, Kofi Annan, and the World Bank President, James Wolfensohn, in forming a High-Level Panel on Youth Employment. The ILO was requested to take the lead in organizing the future work of the Youth Employment Network and to assume the responsibility for hosting a permanent secretariat. The network draws on creative leaders in private industry, economic policy and civil society (including youth leaders) to explore imaginative approaches to the youth employment challenge.

\section{Box 7: Youth Employment Network, results of the first key meeting}

The panel's recommendations encourage world leaders to take personal responsibility for translating the commitments taken at the Millennium Summit into action through a specific political process. First Heads of State and Government are invited to develop national action plans with targets for the creation of jobs and for the reduction of unemployment and to present these plans to the United Nations. Furthermore, ten governments are invited to volunteer to be champions of this process, to take the lead in preparing their action plans and in showing the way to others. Main messages of the recommendations are:

- In developing their plans, governments are encouraged to closely involve young people and to integrate their actions for youth employment into a comprehensive employment policy. Employment policy is seen not as a sectoral policy among others; it is rather the successful mobilization of all public policies.

- Youth should be seen as an asset, not as a problem. In the next 10 years 1.2 billion young women and men will enter into the working age population, the best educated and trained generation of young people ever, a great potential for economic and social development.

- Youth are a creative force today - and not only tomorrow. "Young people are now asking that their voices be heard, that issues affecting them be addressed and that their roles be recognized. Rather than being viewed as a target group for which employment must be found, they want to be accepted as partners for development, helping to chart a common course and shaping the future for everyone."

Actions to be taken can be summarized in four "Es":

1. Equal opportunities: give young women the same opportunities as young men;

2. Employability: invest in education and vocational training for young people, and improve the impact of those investments;

3. Entrepreneurship: make it easier to start and run enterprises to provide more and better jobs for young women and men;

4. Employment creation: place employment creation at the centre of macroeconomic policy.

More information can be found through: http://www.ilo.org/yen 
"I have often talked about the need for team play in the multilateral system...Most would agree that the multilateral system is underperforming in this respect. We can and must renew our efforts to work together in a true global partnership..."

Report of the Director-General, Working out of Poverty, ILC 2003

\section{The ILO and international development partners}

Over the past few years, there has been an emerging recognition that major development challenges such as poverty eradication can only be tackled if all development partners work together, building on their strengths and individual mandates avoiding duplication of efforts. This has culminated, for the UN Agencies, in the work of the UN Development Group (UNDG) and in efforts at country level to provide a coordinated framework for UN country programmes - the UN Development Assistance Framework (UNDAF). Evaluations of this process are ongoing but the general consensus is that coordination is improving and that the UNDAF is increasingly likely to become a funding mechanism for joint UN country programming in the future. The ILO has to face this challenge, especially in countries where its presence is not strong and in areas where there are large numbers of uncoordinated development projects.

However, as noted in Part 2 of this paper, the ILO has many ongoing programmes that involve collaboration with other partners in the UN system, in bilateral agencies, and the World Bank. Many bilateral donors now regard the ILO as a partner for taking forward areas of mutual concern rather than as a recipient of funds.

Since 2001, the ILO has been a member of the UN Development Group. It takes an active role in the task forces of the Millennium Development Committee, which is developing collaborative ways for taking forward the achievement of the MDGs. It co-ordinates international statistics on progress on several of the MDGs (see Part 2), and at the country level is often actively engaged with the UNDAF and its theme groups relating to decent work. For example, in Russia the ILO played a leading role in the UN Theme Group on Poverty, providing substantive support to the development of their poverty eradication strategy. ${ }^{27}$ Further, the ILO is chairing the UNDG Working Group on PRSPs, set up in 2003 in New York. It is contributing to the UNDG work on providing guidance and support to UN country teams on its role in supporting the PRSP process, and mainstreaming the MDGs through PRSPs. An assessment of UNDG participation in PRSPs and the drafting of guidelines for country teams on participation in PRSPs have been undertaken.

The ILO and the UNDP have been working in partnership for many years in the implementation of Technical Cooperation projects. However, a new initiative has recently been developed which jointly involves the intellectual resources of ILO and UNDP focusing on Employment and Poverty Reduction. The MDGs and PRSPs will constitute the overarching strategic approach and provide the key entry points for the ILO-UNDP collaboration at the country-level. Background papers have been produced and a process has been started which will involve ILO Sub-Regional Offices and UNDP Sub-regional Research Facilities, both providers of technical expertise.

\footnotetext{
${ }^{27}$ United Nations Theme Group on Poverty, Working Towards a Poverty Eradication Strategy in Russia: Analysis and Recommendations, ILO, Moscow, 2002.
} 
The programme components include:

- Policy-oriented research at the global level to establish an analytical framework linking employment and poverty reduction.

- Country-collaboration at the field level between the ILO and the UNDP.

- Joint participation in inter-governmental and global fora, e.g. the Human Development Forum, the ECOSOC High Level Segment in 2003 and the Global Employment Forum.

There is also a long history of collaboration between the ILO and the World Bank on issues of employment and social protection. More recently, the World Bank and the ILO have agreed on the importance of the ILO's role in the PRSP both as a means for addressing issues related to work and employment and also as means for involving social partners in the participatory process which underpins the PRSP process. A unique contribution took place under an ILO Workers' Activities Bureau project in December 2002 when a regional trade union policy dialogue with the World Bank was organised. It brought together trade union leaders from 9 African countries. Together with senior officials from the World Bank and the IMF, PRSP governmental coordinators from Tanzania and Zambia, as well as representatives from the civil society, crucial policy topics such as macroeconomic policy and poverty reduction, privatisation, trade policy, labour market policies and participation in PRSPs were discussed. The evaluation showed it to be a positive and appreciated experience, which will create several spin-offs.

Through the Social Finance Programme, the ILO has been a member since 1996 of the Consultative Group to Assist the Poorest (CGAP) that regroups 29 bi- and multi-lateral donors. Its secretariat is hosted at the World Bank. The CGAP is the authoritative source for the definition of good practices in microfinance and the forum for donor coordination. Further, the ILO is actively supporting the Microcredit Summit Campaign, and its Director-General is a member of the executive committee. Through advocacy and exchange of information one seeks to reach the objective of providing stable financial services to 100 million of the poorest families by 2005 .

The ILO has developed, in collaboration with the World Bank, the concept of Community Contracting ${ }^{28}$. This falls under the Community Driven Development Approach of the Bank whereby poor communities are more involved in the prioritisation, planning and implementation of infrastructure works and enter into formal partnerships with local authorities. The World Bank has developed guidelines on how financial arrangements can support poor communities in a management role. The ILO has focused on how communities can organise and negotiate their role and how they can carry out the work as contractor and labourers. The International Training Centre of the ILO in Turin, in collaboration with the ILO's Employment and Investment Department, is negotiating a training course for national implementers of World Bank Community Driven Development Programmes. It is also intending to add sessions on labour organisation and management.

A further example of collaboration with the World Bank is the rehabilitation of social security schemes on the basis of recognized international labour standards through major technical cooperation projects in Western and Central Africa (Côte d'Ivoire, Cameroon, Gabon) and youth unemployment (preparatory phase of a socio-economic reinsertion project for the youth and vulnerable groups aiming at demobilizing and reinserting ex-combatants, including child soldiers, in the Democratic Republic of Congo).

\footnotetext{
${ }^{28}$ Referred to in the World Bank as Community Based Procurement.
} 
There are a number of organisations concerned with the issue of child labour. In order to maximise the efforts of these organisations, the World Bank, UNICEF and the ILO are collaborating on a project based at the Innocenti Research Centre called "Understanding Children's Work (UCW)". As part of a broader effort to develop long-term solutions to child labour, the programme aims to address the crucial need for more and better data. The project involves a mapping and analysis exercise in order to:

- promote transparency and share information;

- find synergies among the approaches used by the three agencies;

- minimizing duplication of efforts in future activities.

The ILO is a founding member of the "Committee on the Advancement and Promotion of Cooperatives" (COPAC, see www.copacgva.com), which brings together the ILO, the FAO, the UN-DESA, the International Cooperative Alliance and IFAP. The 63rd board meeting took place in 2003 in Stockholm to discuss, inter alia, the implementation of ILO Recommendation No. 193 on promoting cooperatives, adopted by the International Labour Conference in 2002. The ILO recently initiated the first conference of cooperative development partners, which attracted some 33 national and international cooperative development agencies, with the aim of discussing the role of cooperatives in poverty reduction. A strategy was developed which culminated in a meeting with the President of the World Bank in 2003. The World Bank has subcontracted the ILO on several occasions to provide technical expertise in the field of cooperative policy, legislation and human resources development (HRD). The most recent case is Turkey, where the ILO will implement the HRD component of a large cooperative restructuring project. The ILO has an agreement with the FAO stipulating that it is responsible, within the UN family, for cooperative development in general, while the FAO focuses on the promotion of producers' cooperatives in the agricultural sector. The ILO is closely collaborating with the International Fund for Agricultural Development (IFAD), and has just completed a joint project formulation mission to Guinea-Bissau. In February 2004, the ILO and the IAA concluded a partnership agreement.

In the field of local economic development (LED), the ILO is collaborating with UNOPS at the country level, mostly in countries that are recovering from a crisis situation. It has also agreed with FAO to organize joint LED formulation. Further, in the context of crisis management, collaboration with UNHCR has been intensified. A new ILO database on Poverty and LED was launched recently.

The ILO has a mandate to work on health-related issues as indicated explicitly in the Philadelphia Declaration, reflected through a large number of ILO Conventions on social security, and as reconfirmed by the 2001 International Labour Conference. However, the ILO does not aim to work on all health aspects. Only health issues closely related to the world of work have a place within its decent work mandate. Its action in this field is mainly focused on the demand side that is on the health needs of workers, employers and their families.

However, on the supply side, it is also concerned with the terms and conditions of health workers. The work that it does thus complements that of other UN agencies working in this sector, notably WHO, UNICEF and UNFPA (these agencies are more focused on the supply side). This complementarity of mandates has given rise to inter-agency agreements and various concrete collaborations, for example:

- ILO/Pan American Health Organization initiative on the extension of social protection in health in Latin America and the Caribbean;

- Coalition between ILO-STEP, UNFPA, UNICEF and WHO in the framework of a global programme on the improvement of access to quality health care for poor and excluded populations; 
- Joint ILO-STEP/WHO initiative on contracting between health care providers and health service users in Africa;

- ILO-STEP participation within the Commission on Macroeconomics and Health $(\mathrm{CMH})$ of the WHO, in collaboration with the World Bank, on community health care financing schemes;

- Partnership with WHO and the World Bank in a joint research project on community health care financing schemes.

Several ILO units are also involved in the ILO/Universitas programme. Jointly with UNDP and UNOPS, the ILO is directly in charge of initiatives aiming at identifying, promoting and transferring socio-economic innovations related to decent work.

The ILO and UN Habitat have had an inter-agency agreement since 1984 but direct project cooperation started in early 1990s with UN Habitat working with city and municipal authorities on environmental planning systems and ILO Employment-Intensive Investment Programme (EIIP) working with local communities on slum upgrading. The direct link between the two organizations aims at ensuring that city planning includes the poorest section of the cities and that employment and social inclusion become an integral part of the development strategies. The publication of "Cities at Work" (Boosting Employment through Small Enterprise Development (SEED) and EIIP) for the Istanbul +5 and the World Urban Forum (April 2002 in Nairobi) emphasized the need for local authorities to address urban poverty, the development of employment and the importance of local economic development strategies. The ILO has been requested to assist the local authorities and a joint ILO-UN Habitat sub-regional course for municipal authorities has been conducted in Bangkok, Dakar and Nairobi. There is also a joint ILO-UN Habitat publication on Shelter provision and employment generation.

The ILO has had long standing cooperation with the World Food Programme (WFP) on the Food for Work programme. This programme assists the absolute poor and food insecure households by providing food to people while they are improving their own assets. It supports the programmes by providing technical advice and training on labourbased infrastructure upgrading and supports the programme design and evaluation (EIIP, COOP). Its support aims at improving the quality of productive work and employment and the quality of the assets which are created under food for work programmes. A new guide, "Food as an incentive to support vulnerable households and communities in securing and improving their assets", has been produced jointly by the WFP and the ILO (EIIP). It has benefited from both ILO and WFP experiences in implementing communitybased Food for Work programmes. It highlights key features of well-designed Food for Work activities, and provides valuable guidance for planning and implementing them to benefit the poor and hungry people they intend to assist.

Continuous interaction is ongoing with international development partners both at the global and country level. 
"The ILO's means of action are knowledge, service and advocacy... We help formulate rules of the game and international standards. We offer technical cooperation for pilot projects and programmes. We leverage our modest resources."

Report of the Director-General, Working out of Poverty, ILC 2003

\section{PART 2: Specific poverty initiatives}

\section{Current regional challenges}

The ILO's Programme and Budget guidelines for 2004 and 2005 include poverty reduction as a shared objective for the ILO; noting that the Africa, the Americas, Arab States, and Asia and the Pacific Regions have identified poverty reduction as a key priority. Underlying problems encountered are different in different Regions and so adaptable ILO responses are called for.

\subsection{Africa}

The African continent is hardest hit by poverty. A study by the United Nations Conference on Trade and Development (UNCTAD) Economic Development in Africa, from adjustment to poverty reduction: what is new?, Geneva, 2002, estimates that the proportion of the population living on less that US $\$ 1$ a day in the least developed countries of Africa has increased continuously since 1965-1969, rising from an average of $55.8 \%$ to $64.9 \%$ in $1995-1999$. Africa faces many problems with poverty constituting a major threat to future growth, prosperity and security. Major pandemics such as HIV/AIDS and malaria have debilitated the workforce, left children as orphans and prevented economic investment.

Economic growth is still fragile in a large number of countries, and in the cases where there is modest growth this is not yet being translated into a reduction of poverty. The average annual growth rate in the African economy for 2000-03 is estimated at 3.5\%. This represents a marginally faster increase than the population growth rate. A doubled economic growth rate would be needed in order to achieve the MDG to halve poverty by 2015 .

The share of youth unemployment is very high, reaching almost $80 \%$ of the unemployed in some sub-Saharan countries. Over $50 \%$ of Africa's population is aged below 18 , challenging policy-makers to ensure that a conducive environment is created to match the growth in labour supply with an expansion in labour demand in the region. It is also clear that for most people in Africa labour is their only asset. However, low productivity (due to factors such as low levels of education and skills, as well as deplorable working conditions) leads to an inadequate income which is a major cause of poverty. Thus there is a striking need to improve productivity, particularly in the informal economy and the agricultural sector. This is coupled with the fact that over $70 \%$ of the labour force in many African countries is working in agriculture. At the same time rural-urban migration accounts for the main flow of labour in Africa, putting a high pressure on the urban labour markets. 
The poverty and employment pattern also shows a persistent gender unbalance as women and girls are disproportionately affected by poverty, often finding themselves trapped in the lowest paid, least skilled and most precarious occupations. In addition, the ILO estimates that in Sub-Saharan Africa 48 million children aged 5-14 were economically active in 2000, and 66.1 million aged 15-17. Many of these children often work under hazardous conditions and some in the worst forms of child labour. By continuing to work, children in the region put their education, health and development to adulthood, and even their lives at risk.

The problem of HIV/AIDS has reached alarming proportions. Africa is the continent that is most affected by this disease. People infected by HIV are often the victims of all kinds of discrimination, particularly in the workplace and/or in trying to access productive work and employment opportunities. The ILO through training and sensitisation campaigns is contributing to tackling the fight against HIV/AIDS infection, protection of vulnerable workers and elimination of HIV/AIDS-based discrimination at the workplace.

It is estimated that trade union density in Africa is lower than $25 \%$ on the average. A wide representational gap is evident in various sectors, including export processing zones and the informal economy where workers are either excluded or under-represented in tripartite dialogue. There is also a slow pace of reviewing labour laws and ratification and implementation of international labour standards. Many times these problems result from poor governance.

Working conditions, social protection and the health and safety situation of workers are precarious in most African countries, particularly in the rural and informal economies. The increasingly widespread use of new technologies, chemicals and pesticides, and the rising levels of pollution and environmental degradation are resulting in risks which are all the more serious because workers have inadequate information. The ILO estimates that in Sub-Saharan Africa $90 \%$ of workers lack adequate social protection. Everyday, many workers die as a consequence of work related accidents. The social protection gap is being aggravated by the onslaught of the HIV/AIDS epidemic.

The current situation, and recent developments in Africa point to a number of issues. First, it is clear that economic growth, while necessary, is not a sufficient condition for promoting increased productive employment and improved welfare. There is a need for pro-active policies for productive work and employment promotion. Second, it is important that the promotion of productive work and employment is accompanied by enhanced social protection. Third, it is clear that endemic processes of social and economic exclusion are at play which need to be countered by giving a "voice" to the poor, and allowing them to participate actively in policy making and initiatives for which they are ultimate beneficiaries. The promotion of good governance becomes the fourth cornerstone. $^{29}$

\footnotetext{
${ }^{29}$ To give proper attention and consideration to these issues and challenges, the African Union has convened an Extraordinary Summit of Heads of State and Government on Employment and Poverty Alleviation in Africa. Supported by the ILO, it is to take place in Burkina Faso in September 2004.
} 


\section{Box 8: ILO Tenth African Regional Meeting, December 2003}

The Director-General's report to the tenth African Regional Meeting of the International Labour Organization stipulates:

Key challenges for the continent's economic growth and the welfare of its people are how to raise agricultural productivity, and thus rural family incomes, while also shifting resources into higher value added industry and service sectors. This points to three strategic issues for promotion of decent work in Africa:

- Increasing the demand for labour and raising the productivity and incomes of people living and working in poverty;

- Integrating socially excluded communities into labour markets, establishing adequate protection mechanisms against income insecurity and other social risks and overcoming discrimination, particularly against women and girls;

- Improving the terms on which African countries trade with richer countries and obtain investment finance.

ILO: Decent work for Africa's development. Report of the Director-General, Tenth African Regional Meeting, Addis Ababa, December 2003.

\section{Americas - Latin America and the Caribbean}

On average, $40 \%$ of the households in Latin America and the Caribbean Region are considered poor. The new jobs that were created in the Region during the 1990s did not help make progress on the matter of equity, i.e. more equal distribution of income. Poor people have only had access to low quality work and employment and have benefited the least from growth. The continuing prevalence of adjustment in the majority of the countries impeded the capacity to create new jobs, which mainly affected the poor families. They are the ones who are the hardest hit by the instability and growing deterioration in the quality of employment. Further, women, youth and children have been identified as specifically vulnerable groups. Unemployment continues to significantly affect women. Most women find work in low-productivity, low earning activities. As a result women form the largest part of the poor. Almost all women of indigenous origin work in the informal economy. In 1998, 55\% of the unemployed in the region were aged 15-24 years. The fact that the majority come from poor families creates a vicious circle of poverty transferring from one generation to another. This is equally the effect of child labour. Available information shows that about $16 \%$ of the children aged 5-14 are economically active in the region.

The inter-linkages between youth unemployment and under-employment, and the informal economy and poverty are clear. The ILO, together with local partners, has produced a manual on Youth Employment for the Latin American Region. Work is underway to adapt these materials and to produce similar tools for the African and Asian Regions.

ILO activities in the region have addressed the problem of poverty and specifically vulnerable groups by interventions at different levels. For example in Chile, the ILO works with the public sector and policy makers to enhance awareness and capacity to address gender equality in public policies and programmes on employment generation and poverty reduction. 


\section{Box 9: Chile, strategic planning on gender equity and poverty}

Integration of a gender dimension is a critical element not only to promote gender equity in policies and programmes but also to increase their efficiency to combat poverty. It is important to recognise the greater role to be played by women in combating poverty in Chile, given the increasing number of households headed by women ( $27 \%$ of total households). Workshops were held at national and local levels, targeted to relevant policy makers, project and programme managers and administrators to enhance their technical knowledge and capacity so that gender issues are taken into consideration in the designing or implementation phase. Each workshop produced an Action Plan in accordance with the local context, which helped build a consensus among various actors to set a strategy and measures for this cause, as well as successfully induced greater commitment of decision-makers in some cases. Although direct impact of this activity in terms of poverty reduction itself is hard to measure, it is considered to have taken a significant step that would lead to improve employment-oriented poverty reduction policies and programmes in the long run.

Honduras, for example, suffers from recession and from devastating consequences of natural disasters. $70 \%$ of the population is affected by poverty, and the calamities hit the poorest population hardest. Poverty and extreme poverty are likely to be perpetuated as the lack of community organization and low educational attainment make it difficult to create work and income opportunities, thus maintaining low income levels. The ILO has provided technical assistance through a project addressing the lack of education, targeting poor farmers, including youth. The effectiveness of education systems to provide tools contributing to reducing poverty is essential.

\section{Box 10: Honduras, the National Centre for Continuing Education}

The project was devised to develop capacity for productive work by providing elements of instrumental and occupational education, which means equipping the target population with basic knowledge for the world of work in productive conditions, starting from reading and writing abilities. It also includes a background for the world of work with productive and entrepreneurial characteristics, such as creating associative enterprises. Specific concrete training methods are used where participants get hands-on problem solving. The National Centre for Education for Work (CENET) was created to harness the methodology and to expand and systematize it at the national level.

The ILO has provided technical assistance (1996 and 2001) for the institutional, financial and methodological strengthening of the Centre to make it an instrument for rural poverty reduction. The project has had a significant impact at the community and municipal levels, as well as at the institutional level with the implementation of a diploma programme in Education for Work. The main strength is the systematized methodology. The experience, the impact and the lessons learned have resulted in a valuable method of work used with the rural population in poor areas. In addition, these experiences can be extrapolated into marginal urban areas.

Breaking the poverty cycle by keeping children out of child labour and in schools has become a key initiative in Brazil. The ILO programme which integrates education and income generation for sustainability is further described in this document's part on Rights and Poverty.

\subsection{Arab States}

In some Arab states the economic stagnation and low employment-generating investment since the mid 1980s have caused increasing poverty. These have combined with ineffective national labour markets and the absence of social safety nets. Despite rising oil prices benefiting producer countries, per capita income has increased by only $1.3 \%$ on 
average. This has been insufficient to generate employment for a labour force set to grow at $3.1 \%$ per year during this decade. As a result the Region is experiencing explosive rates of youth unemployment (estimated at 30-40\%). These rates are even higher for young women. Existing education and training systems are insufficiently responsive to the changes in skills required for the labour market. Labour migration, especially for youth, to Arab oil-producing countries and the countries of the European Union is proving to be one of the ways young people are trying to escape poverty. However, migration often goes along with hardship. Usually, individuals and governments in countries of origin claim a share of the migrant's income, through remittances, in order to improve conditions at home. Immigrants seeking employment in the Arab Region have mostly come alone, without families. Migrants must face up to a complex system of discrimination in the countries where they seek employment. Most countries of the Region are known for not protecting migrant workers' rights. Mistreatment of women in domestic service in some host countries is common. Employment in the informal economy is generally rising. Social security systems are either totally absent or non-inclusive, in particular in the case of the self-employed, agricultural workers and workers in the informal economy. Finally, institutions and legal frameworks for social dialogue need to be reformed because freedom of association is not yet fully recognised in most countries. This is hampering the full participation of social partners. The ILO is increasingly promoting comprehensive responses to these challenges in the Arab Region.

\section{Box 11: Bahrain, an integrated decent work country programme}

In Bahrain, the Decent Work Agenda is closely linked to the country's democratization process and to labour market reforms that would facilitate the transition from an oil-based economy to a diversified one. The ILO Decent Work Pilot Programme supports the ongoing political and social reform in Bahrain by promoting extensive social dialogue and actions in four interrelated areas. The integrated programme includes (i) the consolidation of the right to freedom of association; (ii) a multi-component strategy on youth employability; (iii) generation of labour market data and statistics; (iv) and the design of a social protection strategy to support labour market reforms.

\subsection{Asia and the Pacific}

A quarter of this Region's 3.4 billion people live below the poverty line. The East and South-East Asian countries comprise a billion and a half people and have had high growth rates and incomes over the past two decades. However, in South Asia and the Pacific, as well as in some of the transition economies, lower growth and much lower incomes remain. Unemployment and underemployment levels for the poorer part of the Region are high. Its predominant informal economy is burgeoning, accompanied by livelihood insecurity, with women and children particularly vulnerable in all areas.

The Asian crisis followed by the global synchronised recession has exposed a new vulnerability of even the better off in this Region's population. The East and South-East Asian economies are vulnerable to global fluctuations. Long run trends of capital inflows, high growth, full employment, and poverty reduction, have been abruptly reversed. Weak governance and negligible social protection have exposed large portions of the population to loss of employment and incomes, re-introducing insecurity and poverty to people and communities that had apparently escaped from these some time back. This has led frequently to dramatic rises in poverty, for instance in Indonesia and Cambodia. 


\section{Box 12: Cambodia, vocational training and micro finance}

After more than 20 years of war and civil strife, in the early 1990s the per capita income in rural Cambodia was among the world's lowest. Banks were non-existent and few people had any savings. With support from the ILO and UNDP, the Association of Cambodian Local Economic Development Agencies (ACLEDA) emerged to fill this vacuum. In the first five years of operation, it expanded into 13 of Cambodia's 21 provinces, providing loans to more than 10,000 poor persons. In 1998, ACLEDA began the process to create a regulated financial institution, which would allow it to dramatically expand, offer savings accounts and wire transfers, while establishing formal financial infrastructure in rural Cambodia. A banking license was issued to ACLEDA Bank Limited in October 2000.

Along with better infrastructure, business skills and capital are necessary to sustain growth and alleviate poverty. The ILO helps to bring work to thousands of returnees from the border camps, internally displaced people and demobilized military personnel by organizing vocational training in several provinces. Courses vary from car repair to wood carving, hairdressing, bike-frame construction, plough making, radio and television repair, sewing and weaving, food processing, duck rearing, frog raising, fish farming, rattan furniture making, mat production and welding, as well as producing of leeks, mushrooms, onions and watermelons. In-service training is conducted in accounting, management, computers and language. By March 2002, ACLEDA Bank had 67 branch offices, 676 staff members and nearly 80,000 clients.

The ILO also provides technical assistance through vocational educational training to the Government of Cambodia. As a result the Government has followed the ILO's lifelong learning strategy and, with a belief that low-skilled people are vulnerable to under-employment, has set forth their policy which now ensures that vocational training corresponds to the labour market demands; consequently the Cambodian labour force now has access to better income generating opportunities.

The Region's 0.8 billion poor are most likely not covered by any form of social protection. In this Region poor people are particularly vulnerable to trafficking, bonded labour, child labour and HIV/AIDS.

\section{Box 13: Nepal, child labour and trafficking}

To date, more than 100 action programmes and mini-programmes have been implemented in Nepal in the areas of policy formulation, direct intervention with child workers, awareness raising, legislation and enforcement, etc. To date, nearly 12,000 working children, including child bonded labourers, have received educational support and their families been provided with alternative economic opportunities. Nepal was selected to be the first country in Asia to launch a Time-Bound Programme (TBP). Over the coming years, the TBP will target 75,000 children in bonded labour, child porters, child rag pickers, child domestic workers, children working in the carpet and mining sectors as well as those trafficked for sexual and labour exploitation.

Social dialogue has been used in many countries to help ease transition to a market economy (Mongolia). 


\section{Box 14: Mongolia, Social dialogue}

The 1991 Trade Union Rights Act recognized the independence of employers' and workers' organizations even before the new Constitution of 1992 enshrined political democracy and the transition to a market economy. A key consideration was the involvement of the social partners to ensure social stability and facilitate social adjustment to economic reforms which focused on economic stabilization and market liberalization. Since then, national tripartite machinery became the platform of choice from which to address practically every pressing economic problem with a social dimension: the Price Consensus Council (1992), the Wage Council (1992), the National Poverty Alleviation Council (1996), and numerous ad hoc Tripartite Consultative Meetings on employment policy, small enterprise development and vocational training. The principle of tripartite social dialogue has also been institutionally embedded in more specific areas such as social security (the National Tripartite Commission of Social Security (1994), occupational safety and health (National Tripartite Committee established in 1997), and other areas where employers and workers are key stakeholders.

To manage the impending admission or new entrance to the World Trade Organisation is of great importance to several countries, for example China and Vietnam. ILO technical assistance has been requested to analyse certain consequences of WTO membership, as well as to build capacity to manage the process of change. It is crucial not to leave parts of the population stranded on the banks of the mainstream economy.

\section{$5.5 \quad$ Europe}

A number of countries in the ILO's Europe Region, which includes some in Central Asia, are undergoing transition. The transition economies are re-structuring their large State Owned Enterprise (SOE) sectors. Under the earlier dispensation, social protection and welfare in these economies were largely delivered through SOEs. Therefore restructuring and retrenchment simultaneously de-links large parts of the labour force from social protection, throws them onto a new and alien labour market, which requires new skills, and then can only re-employ some part of those laid off. This restructuring threatens to add to urban poverty. Liberalisation of the large agricultural sectors exposes the high levels of underemployment there and threatens the livelihoods of a vast sea of surplus labour. Since the agricultural sector has much lower if not negligible social protection compared to the urban SOE sector, the threat of rural impoverishment is even greater. There is evidence of increases in child labour and trafficking of people. The ILO has a particular role to play in preventing poverty in these countries by providing support during this restructuring process.

Often women, especially older women and those from ethnic minority groups, have been hardest hit by the transition. To regenerate rural growth, entrepreneurship has become critical, however, in the past, the entrepreneurial culture and skills were lost. The ILO has assisted for example the Estonian government to address some of these problems. Alongside capacity building for local and national policy makers and planners in gender mainstreaming and entrepreneurship development, the activities to generate entrepreneurship development for women in two of the poorest counties generated widespread support. Dialogue has been established between women's organisations and the authorities, and training has been initiated in various entrepreneurial skills. The ILO's intervention has sparked some impressive changes in some women's lives. 


\section{Box 15: Estonia, one woman's story}

Koida is one of the many women from an ILO project in Estonia who has had a moving account of changes in her life. Here is her story:

"Before the project came to Valga county I felt very lonely and depressed. I did not have any confidence at all, I did not know even my neighbours and I did not have much money. I heard about the first meeting to bring together women of our community and I somehow gathered the courage to attend.

That first meeting was very difficult for me. I was so terrified. I had never spoken in public before in front of a whole group - even if it was just women from my community. When it came to my turn to introduce myself, I just wanted to run away and hide - I was so self-conscious and afraid. I don't even remember what I said - my heart was racing and my mind went blank. But that meeting was a turning point for me. I met so many women from my community, my neighbours - it was wonderful everyone had stories to tell and many of us were feeling the same sense of hopelessness and despair. These women are now my friends - we meet regularly and give each other support and strength. We have been on many of the training courses together so we share our ideas and give each other encouragement.

The project organized some training courses on starting a business. This helped me to come up with ideas to use to my creativity. I make soft toys - mostly witches out of scraps of material. As part of the project we took our crafts to the Christmas markets. In Russia my dolls were very popular and I sold all of them.

After I came back to Valga, the local newspaper was interested in my story and published pictures of me. Imagine me - in the local paper - having been so shy and lacking in confidence before! I would never have dreamed it was possible. One of the local textiles companies in Valga saw the article and offered to give me their scrap material. So now I can get my material for free.

I want to learn how to make dolls which will sell in other parts of Europe too. The project is going to bring in some international experts to help us with designs and styles that Western Europeans would like. I'm eager to participate in these courses.

I can't thank the ILO enough for helping me. I have gained so much - confidence, support, friends, creativity, crafts that I can sell. Before I couldn't even speak in public, now I attend all kinds of meetings and talk about my experiences - even at the meetings that we have with the local government authorities! I want to help other women in my community. If I can make these changes in my life - anyone can.”. Social Finance Programme. ILO, 2003. 
"Participation and inclusion are central to a new approach to poverty reduction.....Meeting the challenge of globalization requires strong local communities, strong local leadership and strong local solutions."

Report of the Director-General, Working out of Poverty, ILC 2003

\section{Supporting sustainable livelihoods}

The ILO believes that supporting and sustaining livelihoods is best achieved through productive work and employment creation. However, much of its work involves voice and empowerment through rights and participation. The approach it adopts can be seen to fit with the Sustainable Livelihoods (SL) approach jointly developed by a number of agencies at the beginning of the 1990s when traditional concepts of poverty, based on income and consumption, were not capturing all aspects of poverty or the perceptions of poor people themselves.

In particular, conventional approaches were not adequately capturing the reality of life for poor rural people or for those working in the informal economy. In response to this, the concept of SL was introduced, first by the Bruntland Commission on Environment and Development and then further in the UN Conference on Environment and Development in Rio in 1992. The SL approach goes beyond the traditional definitions and approaches to poverty reduction and offers a more coherent and integrated approach. It gives attention to factors and processes that constrain or enhance poor people's ability to make a living in an economically, ecologically and socially sustainable manner.

\section{Box 16: Sustainable Livelihoods, summarising the approach}

The SL approach puts people at the centre of development, starting with the analysis of people's livelihoods and how these are changing over time. The participation of local people is important as it is their livelihood goals and aspirations that matter. At the same time it is important to focus attention on the impact of policies and institutions on people's lives and their perception of poverty. The SL approach adopts a holistic and asset-based analysis, which builds on strengths and potential rather than weaknesses and gaps. It is a dynamic and responsive approach looking at trends, as livelihoods and influencing factors are constantly changing. The macro-micro links are established, analysing the influences of the macro environment on people's lives and making sure that policy and planning is informed by local insights and lessons. The approach involves analysis for environmental, economic, social and institutional sustainability. It provides the basis for an integrated approach within an organisation, as well as for multi-agency partnerships. The approach also has a strong rights dimension, as the realisation of basic rights is integral to achieving a sustainable livelihood. A further summary of the approach is provided in Annex 3. 
This approach has been inherent in much of the ILO's work because it has emphasised the importance of starting from the basic needs and assets of individuals and communities. These are then addressed through community management of labour-intensive infrastructure, cooperatives, support to the informal economy or provision of microfinance as a means of bringing people out of poverty. There are many ILO projects and programmes which provide support to livelihoods by helping to create productive work and employment, assisting in organising and empowering the poor, and working to ensure that the poor can access the rights necessary to sustain livelihoods (right to land, right to organise, etc.).

The ILO approach recognises that economic growth alone does not necessarily bring about decent work for all, and that the definition of poverty goes beyond income and consumption. Responding to the challenges of poverty and to the causes of poverty, the ILO undertakes activities at different levels to improve the assets and opportunities of the poor, as well as the service delivery to them. The work involves both the micro level with concrete action at the local level, and the macro level, by elaborating conducive policies to create an enabling environment for employment intensive growth leading to decent work and poverty reduction.

Poverty has declined during the 1990s in some countries such as Chile where the growthemployment-poverty linkage has been strong. In this instance poverty reduction was achieved through high rates of output growth accompanied by a steady reduction in unemployment and a similar rise in real wages. 


\section{Box 17: Research, linking employment policies and poverty}

Based on empirical evidence from Latin America, Asia and Africa, eight employment policy interventions were identified in an ILO Discussion paper on Employment Policies for Poverty Reduction, by A. R. Khan, 2001:

1. Rapid labour-absorbing growth to provide the poor with productive and remunerative employment. High growth rates need to be sparked by increase in domestic and foreign capital. Further, investment in socially productive activities needs to be ensured and institutions must be conducive to the pursuit of efficiency.

2. Conversion of the poor into productive entrepreneurs engaged in self-employment.

3. Increasing the productivity of poor workers both in wage employment and in selfemployment.

4. Improvement and adjustment in the skill composition of the poor members of the society.

5. Appropriate terms of exchange for the produce of the poor.

6. Orderly dismantling of the past systems of inefficient excess employment, especially in state-owned enterprises.

7. Specially designed employment opportunities for the labour-disadvantaged households.

8. Caution in the design of labour market interventions in protecting vulnerable workers by ensuring security of employment at living wage.

Two categories of policies are assumed to go alongside the above, to enable/support their implementation. First, subsidiary policies, such as providing efficient public services to the poor. Second, non-employment related interventions, such as direct income subsidies, cash or kind, which help vulnerable groups (can play a temporary role in times of chocks and transition).

\section{Ongoing research projects}

1. New research is underway in the ILO, involving 7 country studies. It will put more substantial evidence to the importance of employment as the key link between growth and poverty alleviation. The hypothesis to be examined is: A low average productivity of the work force can be due to the deficiency of capital relative to labour and the use of backward technology. When high rates of economic growth lead to sustained increase in productive capacity, employment opportunities with rising productivity are generated. This in turn allows for progressive absorption and integration of the unemployed and the underemployed into expanding economic activities with higher levels of productivity. In the process, the poor may be able to achieve higher productivity and increase their incomes in their existing occupations, or shift to new occupations involving higher level skills and/or better technology. It would enable workers to spend more on the education and skill formation of their children, raising the productive capacity of the future workforce, creating conditions for achieving higher levels of economic growth. The circle of economic growth leading to poverty reduction via growth of employment with rising productivity would be complete. Recovery and Reconstruction Department (EMP/RECON).

2. A further research initiative has also begun with the Policy Integration Department of the ILO. This is aimed at generating new knowledge on how globalisation is affecting the prospects for employment growth and poverty reduction in developing countries. This research is drawing from empirical evidence and is being done in two stages. The first stage is an analysis of major trends such as the relationship, and changes over time, between trade liberalisation and foreign direct investment on the one hand, and employment on the other. The second stage formulates proposals for reforms at both international and national levels to encourage a higher rate of decent job growth.

High rates of economic growth on a sustained basis are essential to reducing poverty, however, many developing countries have not been able to achieve this. Instead of sitting back and waiting for growth to come about, special measures and programmes directly targeted at the poor have been put in place. Direct interventions for poverty alleviation can be of two types: 
1. Programmes for employment and income generation through self-employment or wage-employment. The former targeting the poor assists them in undertaking income-generating activities by providing microfinance and sometimes skills training and marketing support. The latter is done by creating employment through labour-intensive methods, for example in infrastructure;

2. Measures to reduce vulnerability to risks and economic shocks, and to smooth consumption, such as access to savings, emergency loans and insurance, the provision of food subsidies, and education and health services.

As mentioned previously in this document, increasing the productivity of the working poor is the most effective way of raising the rate of economic growth in most developing countries. In order to achieve this it is necessary to provide poor households with access to resources like physical assets, appropriate financial services, public services, as well as opportunities to build their human capital. The ILO runs several programmes contributing to asset and capital building of the poor.

\subsection{Cooperative initiatives}

The ILO has for many years been involved in supporting the organisation of poor people to enhance their capital, land, finance, knowledge, and to make economies of scale possible. It has benefited rural populations and people living in peri-urban areas. Its programme on cooperatives has thus contributed to livelihood sustainability and helped prevent migration flows. Much attention has been given to the needs of women. Many people who have benefited from these programmes work in the informal economy. Due to their organisational structure and status, cooperatives can play a double role in both promoting enterprise development and enhancing association.

The ILO's long standing commitment to and experience in the promotion and development of cooperatives has led to accumulation of knowledge and recognition by the ILO tripartite constituents, who adopted a new ILO Recommendation (R No. 193) at the International Labour Conference in 2002. The recommendation notes that, "the term 'cooperatives' means an autonomous association of persons united voluntarily to meet their common economic, social and cultural needs and aspirations through a jointly owned and democratically controlled enterprise". Thus cooperatives serve to build social capital, to enhance dialogue and promote sustainable livelihoods in the context of internationally agreed rights frameworks. 


\section{Box 18: The Sahel, practical efforts to reduce poverty}

Since 1978 the ILO has been present in the Sahel region in Africa through African Cooperative Support to the World Food Programme (ACOPAM) projects. To date 85,000 men and women in rural areas have benefited from the projects. They are members of more than 2,000 grassroots organisations (cooperatives and other self-help organisations).

The main areas of activity are as follows:

- Self-managed cotton markets (decentralized collection in production zones): These markets today sell about $80 \%$ of the Sahelian cotton output.

- Village grain banks: More than 300 village grain banks have been set up in Senegal, Burkina Faso and Niger, benefiting more than 20,000 members. Trading between the different zones enables the farmers who produce a surplus to sell it, at non speculative prices, to farmers in zones that have experienced a poor harvest.

- Savings and credit schemes, involving 7,000 members of women's associations, have mobilized more than 400 million CFA francs over the years. These schemes have greatly contributed to an increase in economic activity and self-reliance in the communities concerned. Depending on the country, other support activities for women's organizations have also been carried out in cooperation with the relevant authorities.

- Village irrigation schemes: More than 3,000 hectares have been developed in Senegal, Mali and Mauritania benefiting more than 25,000 farmers. The farmers have been trained in how to improve rice growing techniques on the irrigation schemes. They have also been trained in how to manage their own individual plots, where more than 500,000 trees have been planted for crop protection and to provide additional income from the sale of wood.

- Natural resource management: Village management committees were set up to address the problem of land degradation especially in areas where people tend to settle, such as around dam reservoirs. The committees have learnt to master modern analytical and forecasting techniques and are now part of the regional consultation body that deals with land use management and development.

In addition, special attention has been paid to health issues. This has resulted in many grassroots organizations setting up mutual health insurance schemes that can cover anything from providing primary health care service to establishing and managing village pharmacies.

Regardless of which area of activity, the objective of an ACOPAM project is to enable producers to express and defend their interests. This is done by helping them adapt their organization to the changing needs and different experiences and know-how of the members at any given time. In practical terms, this approach requires that external experts and extension workers must act in partnership with the local people, as the local people are in charge and decide what is to be done. ILO Cooperatives Programme (COOP).

Drawing from its experience at the local level, the ILO is today actively involved at legislative and policy levels, feeding in the lessons learned to create a more favourable environment for cooperatives and associations, and helping to increase sustainability of efforts undertaken.

\subsection{Local and community-based development}

Also emanating from the work on cooperatives, the ILO is now active in promoting local economic and social development as a cornerstone for poverty reduction. It is a participatory development process that encourages partnerships between public, private and civil society stakeholders of a defined territory, the ultimate objective being the creation of decent jobs and stimulation of the economic and social activity in the region. Strong points of the approach are the organising of local people, giving them a voice in development debates at the local level. It empowers them to be influential also at national 
level, and ownership is built throughout which enhances sustainability. The latter is also increased by the use of local potential and competitive advantages in an integrated manner, also improving on impact. The local forum of stakeholders discusses the socioeconomic analysis made in the geographical area and adopts a common development strategy according to priority needs identified. The strategy brings together business development services, micro finance, infrastructure development, capacity building and training, as well as networking activities; getting away from fragmented approaches to technical operation, which often do not produce the desired results. The ILO has been executing a programme of this kind since 1997 in Comoros Islands, assisting a local support structure known as "AMIE" (see Box 19). In total 2,467 jobs have been created and 15 village groups have been assisted.

\section{Box 19: Grande Comoro, an entrepreneur's success story}

Saoudi Djambaé lives in the poor outskirts of Moroni on the island of Grande Comoro. For a long time he has worked as an itinerant carpenter and has had to struggle to cover the basic needs of his family. He was worried about the future of his nine children. They were in public school, which had difficulties in ensuring classes throughout the school year, but he could not afford to send them to a private school. Djambaé liked the idea of starting a business, as he was aware of the demand for bigger orders in furniture. Through his neighbour he heard about "AMIE", an organization that supports women and men to translate business ideas into feasible business plans. AMIE, set up with the assistance of the UNDP and ILO in 1997, prepared together with Djambaé the necessary documentation and informed him about the risks and opportunities of his undertaking. Through AMIE's intermediation Djambaé obtained credit of about 6'000 US\$ from the Comoros Development Bank. He invested the money in the construction of a modest workshop and purchased second hand equipment. AMIE put him in touch with other carpenters with whom he now jointly purchases wood for a reasonable price. Today, Djambaé employs five carpenters and three apprentices so that he can finish the orders in time. Four of his nine children can go to a private school now and he is confident that the younger ones will do so in the near future. ILO Cooperatives Programme (COOP).

The ILO is also promoting and using local development as a means to prevent and tackle poverty in China, where the ILO is carrying out five area-based studies. Liaoning Province is one of China's old industrial bases with a high concentration of State-owned enterprises that are being restructured. Local stakeholders have come to recognise the need to develop private enterprises and cooperatives. Guizhou province is a relatively economically disadvantaged area where there is little local community organisation and local communities have little awareness of their potential. Ningxia Province has a high concentration of ethnic minority groups and local communities are heavily dependent on small-scale agricultural activities and animal husbandry. With China's recent entrance into the World Trade Organisation, the country will not only be susceptible to the medium and long term benefits associated with entry but also to some of its short-term pitfalls and necessary sector/industry/locality adjustments. In this same context, the Chinese government has also recognised the increasing importance of micro, small and medium enterprise development, and cooperatives as a means for productive work and employment generation generally. Bringing together a wide range of public and private partners, including employers and workers, Local Development Agencies are well placed, not only to ensure that the jobs created as a result of their efforts improve the working and living conditions of the poor or unemployed, but also to promote a process of social dialogue. They therefore play a key role in promoting decent work at the local level which encompasses the promotion of fundamental principles and rights at work, job creation, the promotion of social protection and the promotion of social dialogue. 
Poverty and social exclusion is often a root cause of crisis. The ILO has found that bringing its values and principles to bear in crisis contexts is essential. It allows the tackling of immediate negative effects of the crisis and creates the conditions for a successful development process. The ILO Crisis Response and Reconstruction Programme draws upon and pools ILO experience around employment intensive works, skills training, employment promotion, social dialogue and reconciliation, the respect of fundamental rights, and social protection. Often work is undertaken within a framework of Local Economic Development. In Croatia, the ILO (since 1997) is associated with a programme providing support to returning and local populations. Four Local Economic Development Agencies have been set up throughout the country. Through these structures the ILO assists in providing technical and financial assistance to business starters, those already in business, as well as the public sector when it comes to economic development issues. Over 1500 people have benefited from credit and business facilities so far. Where societies and people have been pulled apart by conflict, the participation of local actors in economic decision-making processes has proved to be a powerful tool in stimulating new social and economic activities, and in reintegrating the most vulnerable members of society. Thus the involvement of stakeholders fosters social cohesion and decreases the risk for future conflict. Based on the experiences over the last years, an Operational Guide on Local Economic Development in Post-Crisis Situations, published in 2003, includes tools for implementing day-to-day activities at the grassroots level.

\section{Box 20: Croatia, credit for small entrepreneurs}

During the war Sanja Petrovic and her family lived in a refugee camp. In 1997, two years after the war came to an end, her parents returned to the Croatian village of Dragalic. They were among the first to settle in the completely destroyed village in Western Slovonia. Their daughter, however, decided to stay with her children in Yugoslavia as she was not able to make herself a living in the village. Only after her parents got a small loan through the UNDP/ILO Credit fund, for the purchase of 20 sheep and after they started to sell some meat and milk at the local market, Sanja tried her luck and applied for a UNDP/ILO credit to buy a sewing machine. Before the war she had worked as a seamstress in a textile company in the nearby city of Nova Gradiska. Making use of her previously acquired knowledge and skills, she started to make curtains and worked together with some relief agencies operating in the region. Sanja's venture in the meantime has grown and she recently got another loan approved through a new UNDP/ILO Guarantee Fund targeting Small and Medium Enterprises. She has diversified her product and expanded her market as she has started to produce clothes for a textile company in Zagreb. Currently Sanja employs three women.

What started as a small one-woman business has grown in a short time to a small promising business. She has received over the past two years technical support of the staff of the LEDA (Local Economic Development Agency) of Western Slavonia, not only in preparing her business idea, her formal loan application and her (legal) paperwork for the bank, but also with the search for new markets and recently by a 2-week Start Your Business (SYB) training course. Here she acquired useful basic entrepreneurial skills vital for the survival and growth of her business. The LEDA of Western Slavonia made an agreement with Sanjas' company to monitor the developments and to help her find new markets. Currently the LEDA has a core-group of more than 30 SME in the region which are monitored by them. (LED-CRISIS).

Even though people might be poor in monetary terms, they often have other assets that can be valued and built upon to earn a livelihood. Many indigenous people and certain rural communities have cultural, social and environmental assets that can be marketed. The ILO is concerned with excluded groups, and has for example developed programmes to help communities mainstream the use of their assets. 


\section{Box 21: Ecuador, strengthening ecological and cultural tourism}

It is only partly correct to describe the villagers of Upper Napo as poor. While they have been poor in monetary terms, their culture, community spirit and Amazonian environment are rich communal assets. Since the early 1990s, they have begun to realise the value of these assets to outsiders, notably the eco- and cultural tourists who travel to Ecuador to experience the indigenous way of life. In the past, tour operators have brought in tourists, but the villagers gained little (financially or otherwise) from the experience. To counter the process of being 'subjected' to tourism from outside, ten communities (with 2,700 inhabitants) have organised themselves into an eco-tourism network called RICANCIE. They jointly plan activities to provide the tourists with a varied and meaningful experience in the region.

What the communities cannot do by themselves is market their region to a potential clientele that lives far away in Europe and North America. To address this problem, RICANCIE has joined the national tourism association, Federación Plurinacional de Turismo Comunitario del Ecuador. The federation, in turn, is connected to a unique SEED-supported project which markets cultural tourism via the internet. The REDTURS web site not only offers foreigners information on ecotourism destinations (such as Upper Napo), but it also provides information and advice to other local communities on how they too can organise. SEED is working with tourism associations in Ecuador, Bolivia and Peru and with universities to spread best practises on eco-tourism for poor, indigenous communities. The program is being expanded to include the Central American region. Boosting Employment through Small Enterprise Development (SEED).

Poor people often work in substandard conditions, and don't earn enough to get out of poverty (these people are referred to as the working poor). ILO programmes have shown that by making simple improvements in working conditions, productivity and income can increase.

\section{Box 22: India, a practical example of promoting decent work}

In Moradabad, India, 25,000 small and household-based enterprises are engaged in the manufacture of brassware for export through large trading houses. The industry provides employment to some 200,000 people, but the quality of the jobs is generally dismal. Working hours are long, and employment is insecure. Workshops are dark and cramped, badly ventilated, with workers squatting for hours in smoke filled, often extremely hot spaces. This has a severe effect on the health and welfare of workers and their family members, most of who contribute to the production process. It also results in low levels of productivity and high levels of poverty. The marketability of the products is decreasing due to international buyers' concerns about poor working conditions and competition on price from producers elsewhere. This is further reducing the welfare of those working in the industry and diminishing their chances to break out of poverty.

In 2000 the ILO launched a project that aims to break this vicious cycle. It has raised awareness of the importance of improving business practices and the working environment among policy makers and all along the value chain, by involving manufacturer/exporters as well as small and household workshops. It has developed simple training materials and a methodology for training small and household workshops on business practices and working environment improvement, which are being used by local organisations. Enterprises have been encouraged to form self-help groups, and trade associations have been enabled to strengthen their competitiveness. These interventions have raised productivity, made work more decent at the workshop level, and strengthened trust and cooperation among the enterprises, including the exporter/manufacturers. Replication elsewhere in India is under consideration. Boosting Employment through Small Enterprise Development (SEED). 
The Employment Intensive Investment Programme (EIIP) started in the 1970s, and is one of the ILO's major long-term responses to the deteriorating employment situation in developing countries. Evaluations of the programme show several benefits. First, wages and incomes are distributed to a largely unskilled and poor workforce. Second, indirect employment generated has been estimated at 1.5 to 3 times. Third, wage distribution creates a multiplier effect of consumption, investment and savings, boosting the local economy. Fourth, the promotion of small-scale contractors helps expand the national construction industry with better back- and forward linkages. Finally, the EIIP has developed strategies to ensure that standards and conditions for workers are applied according to ILS, national legislation and ILO guidelines.

\section{Box 23: Cambodia, labour-based technology and infrastructure is expanding}

Since 1992, the ILO labour-based technology and rural infrastructure work projects have successfully promoted long-term sustainable employment in the country. Through the labourbased technology, available funds are kept inside the country whereas equipment-based technology sends off the profits to manufacturers and transporters outside the country. Moreover, concern for working conditions and compliance with international labour standards, which is part of the ILO decent work framework, is an essential component of the labour-based technology. Within eight years, the ILO infrastructure projects gave local workers over 3 million workday's directly paid employment and trained hundreds of managers, contractors and government official in business, accounting, language and computer skills in addition to labourbased construction and maintenance techniques. More than 540 kilometres of rural roads and 80 bridges, 439 culvert rows and 21 water gates were rehabilitated and maintained. Besides, the ILO labour-based infrastructure work and employment-generation project in the province of Siem Reap has successfully restored the World Heritage Site of Angkor where tourism holds special potential for poverty alleviation in the country. In addition the ILO infrastructure rural work have created secondary and tertiary roads which have served the poor and provided them with better access to basic social services and facilities, health care, education and skills, and domestic markets. Employment-Intensive Investment Branch (EMP/INVEST).

Since 1992, the ILO has been collaborating in Madagascar with the Ministries of Education and Health, and Planning and UNDP, UNICEF, WHO, EU/CARE and $\mathrm{UNCDF}$, to implement a large-scale rehabilitation programme in the aftermath of several destructive cyclones. The programme focused on rehabilitation of schools and health centres and on training and capacity building for the private construction sector. The ILO and the Ministry of Public Works are promoting small contractors and labour-based techniques in the road sector. A training institute has been set-up which is used by many major development agencies. The focus is on training small contractors in labour-based techniques and on labour policy and management issues. In 1995 alone, public investments carried out by labour-based methods created some 35,000 jobs $1 / 3$ of which were created directly through investments, and $2 / 3$ of which were created indirectly by the multiplier effect of spending wages locally. This is about 2.5 times more employment than would have been created had conventional equipment-intensive construction methods been used.

Using its long experience in labour intensive infrastructure programmes, foremost in rural but also urban areas, the ILO has developed a new programme tackling the problem of poverty in growing cities. By using the principles of public-private partnerships, local people can be contracted to perform community services. It is also a good example of two organisations (ILO and UN-HABITAT) pooling their knowledge, competences and resources. 


\section{Box 24: Better services and more jobs - Collaborating with UN-HABITAT}

Cities all over the developing world are experiencing growing poverty linked to unemployment, environmental degradation and the breakdown of urban services. Yet the economies of scale in cities offer great opportunities for improving service delivery for the poor and simultaneously creating employment to tackle poverty. Public-private partnerships offer great opportunities for both improved service delivery and employment creation, particularly through communitymanaged labour-based approaches and small enterprise involvement.

ILO has been working with UN-HABITAT over a many years to address urban poverty. Now, the two Agencies' respective accumulated expertise and networks are being put together in a series of (sub-) regional training workshops for local authorities, community organizations and representative organizations of urban communities and small entrepreneurs, and support agencies at city level.

The objective of the workshops is to strengthen participants' capabilities in planning and implementing city-wide employment initiatives that contribute directly to poverty reduction through the creation of sustainable jobs and improved services. Participants share practical ideas and tested tools to analyse urban employment problems, define possible solutions and propose targeted strategies. They learn about good practices in employment promotion and service delivery for poor people living in the cities. At the end of the workshops, frameworks for action are formulated for further discussion at local level. Employment-Intensive Investment Branch (EMP/INVEST).

As reflected in several examples, appropriate financial services play a key role in many ILO programmes. The importance of microfinance for poverty reduction has been widely recognised. The UN General Assembly has adopted two recent resolutions, "The Role of Micro-credit in the Eradication of Poverty" and "International Year of Micro-credit" (2005), on this topic. As illustrated by the Consultative Group to Assist the Poorest (CGAP; in which the ILO is participating), microfinance helps to achieve the MDGs and reduce poverty by building human, social and economic assets. ${ }^{30}$ Despite significant progress, a large majority of poor people still do not have access to sustainable or appropriate financial services.

The ILO's experience mirrors the lessons emerging from the development community. The Social Finance Programme, the ILO's focal point on microfinance, has shown that financial services have an important dual function: 1) to help the poor to improve and diversify incomes through micro-enterprises or other livelihood activities, while 2) reducing their vulnerability by helping them to manage risks and smooth consumption. Access to appropriate financial services is critical not just for the self-employed, but also for the working poor employed in both the formal and informal economies. For poor women, the ability to save, borrow and earn an income can empower them to confront systematic gender inequalities. For example, ILO has used microfinance as an important reconstruction tool following economic crisis and post-conflict situations as described in the boxes below.

\footnotetext{
${ }^{30}$ CGAP Donor Brief No. 9, December 2002.
} 


\section{Box 25: West Africa, mapping the microfinance landscape}

Following the banking crisis of the late 1980s and the liquidation of several development banks, the importance of more informal lending systems became apparent. Within the West African Monetary Union and through the Central Bank of West African States, the ILO is helping to map the financial landscape: With assistance from Norway, ILO has helped to set up a database on all micro finance systems currently operational. The objective is to improve access to financial services by the poor through promotion of mutual credit and savings systems. With assistance from the JFA programme, the approach will be expanded to the Southern African Development Committee (SADC) countries. Social Finance Programme (SFP).

\section{Box 26: Microfinance in conflict-affected communities}

UNHCR and the ILO are working together to bridge the gap between humanitarian assistance and development in conflict-affected communities. In the past, humanitarian and development organisations have operated in separate realms, often to the unintended detriment of the populations they are trying to serve. Since microfinance can be used to achieve an immediate and long-term impact, humanitarian agencies need to lay the appropriate foundation on which development agencies can then build. Towards that end, UNHCR and the ILO have developed a training manual to build the capacity of relief agencies, governments and civil society to employ sound microfinance practices during initial rebuilding efforts.

Upgrading knowledge and skills is an essential part of improving human capital and promoting employability. The ILO has developed Community-Based Training (CBT) for promoting employment and income-generation for the working poor.

\section{Box 27: Community-based Training}

The CBT provides necessary tools for development of capacities of the national and local employment and training organizations and initiates working arrangements between social partners and other support organizations. It also mobilizes support for the programmes among the population of the communities. The CBT advocates an area-target groups approach, combining direct and indirect measures, but with a strong emphasis on utilization of available local economic opportunities, needs and resources. ILO is playing a catalytic role in the introduction of the CBT approach through organisation of national and regional project formulation workshops. It provides also technical assistance to initiate and guide the process through technical cooperation projects, particularly in the initial stages when a CBT-based project is being piloted or field tested for a nation wide replication. CBT projects have been designed and implemented or are being implemented in 14 countries (Azerbaijan, Bangladesh, Belarus, China, Jamaica, Kenya, Nepal, Nigeria, Pakistan, Russian Federation, Sri Lanka, Tanzania, the Philippines, Uganda). Skills, Knowledge and Employability (IFP/SKILLS).

One of the most successful examples of CBT is in Fiji where the Integrated Human Resource Development Programme for Employment Promotion focuses on poverty reduction. This is designed as a pro-people programme. It represents a holistic approach to address unemployment issues through:

- creating an environment for investment (through policy interventions);

- creating decent productive work and employment (through direct interventions both in the formal and informal economies, rural and urban areas);

- making jobs sustainable (through skills development).

These interventions are mutually reinforced and coordinated by seven complementary sub-programmes: Policy and Coordination of Integrated Approach for Employment Promotion; Small and Micro Enterprise Development; Eco-Tourism Development; Cooperatives Development; Labour Administration and Productivity Improvement (with a 
strong component of developing a dynamic Labour Market Information System); HRD for Hotel and Tourism Development; and Advanced Vocational Training. The programme has created more than 3,000 jobs over two years of implementation despite political upheavals and regime change. Governments have continued their support by allocating approximately F\$1.4 (US\$0.7) million per year, in addition to UNDP funding. Further, based on the results and recommendations of a number of surveys, the Cabinet in Fiji adopted the "Sigatoka Declaration on Unemployment Free Zones". Policy frameworks have been developed in the following areas, with the intention to place "employment promotion at the centre of all economic and social policies" of Fiji:

- Small and Micro Enterprise Policy Framework

- Youth Employment Policy Framework

- Labour Market Information Policy Framework.

As part of the follow up to the National Conference on the informal economy in Mongolia, the ILO is working to help develop a plan for economic development and employment promotion in rural areas. This will be done in close concert with ongoing work on the UNDAF and the PRSP for Mongolia. The plan will draw on a number of ILO tools for addressing poverty reduction: the LED approach, Small Enterprise Development and Start and Improve Your Business (SIYB), Community-based training, cooperative development, employment-intensive investment, and social finance. Agriculture is a key source of production and employment in the country and particularly in the area of nomadic livestock it has been a mainstay of the economy during transition. Restructuring and privatisation of the Mongolian economy resulted in the collapse of livestock collectives and state farms. This left a vacuum in terms of support services, agricultural processing, information networks, transport infrastructure and marketing channels, private enterprises have been slow to move into processing and trade due to lack of working capital and investment capital. The cooperative system suffers from past associations with agricultural collectives and current lack of local capacity. The result has been low productivity and low income in rural areas.

\subsection{Vulnerable groups}

Certain specific groups are more inclined to fall into the poverty trap. Sustaining their livelihoods is of prior concern. One of these groups is people living with disabilities. For example, in Asia and the Pacific there are 370 million people with disabilities, of which 238 million are of working age. The unemployment rate for those with disabilities can be as high as $87 \%$. They are amongst the poorest of the poor and most reside in rural areas. They face barriers related to discrimination, access, stereotypes, fear, ignorance, policy etc. In tackling disability and work, the ILO is guided by key policy instruments. It is promoting the Vocational Rehabilitation and Employment (Disabled Persons) Convention 1983 (No. 159) and the ILO code of practice on managing disability in the workplace. It is promoting rights-based versus only welfare-based legislation and related policies. The ILO is encouraging rehabilitation measures in social security and workers' compensation legislation, as well as fostering inclusion of disability rights issues in collective bargaining, corporate social responsibility and hiring practices. The efforts undertaken by the ILO are contributing to the Biwako Millennium Framework, ${ }^{31}$ and the UN Convention on Disability.

\footnotetext{
${ }^{31}$ The Biwako Millenium Framework for Action Towards and Inclusive, Barrier-Free and Rightsbased Society for Persons with Disabilities in Asia and the Pacific. Resulting from an intergovernmental meeting (June 2003, Bangkok) to conclude and extend the Asia and Pacific decade of Disabled People through to 2012.
} 
Other vulnerable groups often found in poverty, such as, children, women, displaced people, different minorities, domestic workers, or sex workers, all merit a comprehensive approach to their problems. As a socially excluded group, the migrant population is vulnerable to labour exploitation and violations of their human and workers' rights. Bonded labourers are part of the most vulnerable and poorest persons. As described in the box below, a microfinance-led development strategy can help overcome deeply rooted social injustices such as bonded labour.

\section{Box 28: Microfinance-led strategies for preventing debt bondage}

Numerous South Asian workers are bonded to their employers, forced to work for substandard or no wages because their earnings are retained by the employer to repay an outstanding debt. The victims of bonded labour, mostly employed in the agricultural sector, tend to be the poorest and least educated segments of the population, from low castes and religious minorities.

To help the member States to abide by the Declaration on Fundamental Principles and Rights at Work, the ILO has introduced a proactive approach utilising technical cooperation projects to develop intervention models for preventing forced labour. Staring in June 2000, one such initiative began piloting microfinance-led schemes in Bangladesh, India, Nepal and Pakistan to reduce workers' vulnerability to debt bondage as described below:

\begin{tabular}{|l|l|}
\hline \multicolumn{1}{|c|}{ Vulnerability Factors } & \multicolumn{1}{c|}{ Project Response } \\
\hline $\begin{array}{l}\text { Low and irregular income based } \\
\text { mainly on casual wage labour or } \\
\text { sharecropping }\end{array}$ & $\begin{array}{l}\text { Loans for income generating activities; skill and } \\
\text { entrepreneurial training }\end{array}$ \\
\hline $\begin{array}{l}\text { Urgent, temporary, unforeseen } \\
\text { financial need (health, death, } \\
\text { natural disasters) }\end{array}$ & $\begin{array}{l}\text { Savings easily accessible, emergency loans; } \\
\text { preventive and curative health services as well as } \\
\text { referrals to the nearest health posts }\end{array}$ \\
\hline $\begin{array}{l}\text { Unsustainable expenses } \\
\text { alcohol, gambling, ceremonies, } \\
\text { dowry) }\end{array}$ & $\begin{array}{l}\text { Awareness raising within the groups on the } \\
\text { negative impact of overspending, and on the } \\
\text { direct benefit the employer gets out of this } \\
\text { practice }\end{array}$ \\
\hline $\begin{array}{l}\text { Financial market in the hands of } \\
\text { the employer }\end{array}$ & $\begin{array}{l}\text { The provision of alternative microfinance } \\
\text { services }\end{array}$ \\
\hline $\begin{array}{l}\text { Illiteracy renders the labourer } \\
\text { vulnerable to creditor's fraud } \\
\text { and limits livelihood options }\end{array}$ & $\begin{array}{l}\text { Adult literacy and numeracy classes, bridge } \\
\text { education for children to mainstream them in the } \\
\text { national curricula or to integrate them in a skill- } \\
\text { training programme. }\end{array}$ \\
\hline $\begin{array}{l}\text { In-kind benefits provided by the } \\
\text { employer increase } \\
\text { dependence of the labourer the }\end{array}$ & $\begin{array}{l}\text { Depending on the needs, provision of safe } \\
\text { drinking water, education, health services, and } \\
\text { (in the case of rehabilitation) land on a leasing } \\
\text { method or in connection with other programmes }\end{array}$ \\
\hline $\begin{array}{l}\text { Labourers are unaware of their } \\
\text { human and labour rights }\end{array}$ & $\begin{array}{l}\text { Awareness raising in the groups; introduce } \\
\text { collective bargaining concepts }\end{array}$ \\
\hline
\end{tabular}

In conclusion, much of the ILO's work focuses on participation and dialogue, organising poor people to gain voice, and exercise their rights which underpin empowerment. The ILO's programmes build upon assets and opportunities to create productive and sustainable livelihoods. 
"The ILO, like all actors in the development process, must learn what to do by listening, and learn from the experience of taking action. Identifying the key stages of life when people are vulnerable to falling into poverty is the starting point for understanding the dynamics of life and work of poor communities."

Director General, ILO Report of the Director-General, Working out of Poverty, ILC 2003

\section{Social exclusion and social protection}

There are many reasons for social exclusion. Some of these are not directly related to poverty. Many people are socially excluded because of ethnicity, disability, migrant or refugee status, drug addictions, or HIV/AIDS status, such that gaining access to even the most basic services, jobs and basic rights is a challenge. However, for many of these people social exclusion can lead to increased poverty. For the ILO social exclusion can be linked to exclusion from the labour market or from properly remunerated, productive work, to denial of rights at work and the right to organise. Therefore much of the ILO's work is concerned with preventing social exclusion.

\section{Box 29: Poverty and social exclusion, an overview}

Social exclusion can be regarded as a description of individual disadvantage. It is manifest in both the low levels of welfare (economic disadvantage) and in the inability to participate effectively in social life through work, access to rights, and legal claims. It can also be regarded as an attribute of societies, and is manifest in recurrent patterns of social relationships in which individual and groups are denied access to goods, services, activities and resources generally associated with citizenship. There are clear links between citizenship rights and livelihood, where the former determine an individual's rights and access (entitlements) to goods and services provided through the markets or the state. The relationship between concepts of poverty and social exclusion can be construed in many different ways. Social exclusion should not be seen as a replacement of the concept of poverty, but rather as a wide and multidimensional notion of poverty which considers material deprivation, employment situation and social relatedness (formal and informal) as major components of disadvantage. The social exclusion approach can go beyond entitlement failure by looking more deeply at processes behind entitlement failure. For example, labour, credit and insurance markets are fundamental for livelihood and security. In these markets, certain groups of people may be excluded because they are considered high credit or insurance risks, or because they belong to stigmatised social groups regarded by employers or creditors as less reliable, less trustworthy, or less productive. In all these markets, a person's rights (e.g. property) and social identity (characteristics such as their language, race, sex, kinship, education, occupation, religion and geographical origin) act as a basis for rationing and access. Gender, Poverty and Employment (GPE).

This section focuses on the provision of social protection as a means for preventing social exclusion. A longstanding method for providing social inclusion to poor people (a primary method for addressing poverty in northern countries) is to provide a system of social benefits and social security. 
From its inception, the ILO has been concerned with the social protection of workers and the unemployed and their families. The Declaration of Philadelphia set out its goal of the "extension of social security measures to provide a basic income to all in need of such protection and to comprehensive medical care". Further, international instruments adopted by the ILO and other UN bodies have established that every human being has the right to social security. However, the ILO's past work has tended to focus on formal systems for social protection in both countries of the North and South. In June 2001 the ILC agreed that the "highest priority should go to policies and initiatives to extend social security to those who have none". It is self-evident that an effective system of social protection will prevent workers from experiencing poverty when unemployed, will provide security for old age and will provide protection for sickness and ill health.

\subsection{People's security}

As noted in the 2001 ILC Report on social security, "not only is security very important for the well-being of workers, their families and the community, but if properly managed it also enhances productivity and supports economic development." 32

However, security can be defined in a much broader sense than simply the provision of social security systems. The ILO programme on Socio-Economic Security (SES) has provided new insights into people's sense of their own security. The project has developed a database both containing a comprehensive record of policy and institutional indicators, reflecting trends in seven dimensions of work-based security, and information on objective conditions of security confronting different groups of workers, the source of insecurity, and workers' perceptions of what constitutes security and social justice. For the latter, information is gathered through "People's security surveys", conducted on the assumption that workers themselves know what is best for them, and therefore their opinions and perceptions are important in the formulation of appropriate policies. Thus, as part of its work, SES has examined various cross-cultural and historical perspectives on work. Many of these perspectives have influenced the way work is recognised and rewarded in industrialised societies and in the context of globalisation where there are incentives for certain types of work and employment. The studies show that work is more than a means for obtaining an income - it is related to definition of self, to religious values and to ideas of dignity. It is clearly important to know more about poor people's perceptions of work as a means of ensuring that progress is made towards decent work for all. The data can also be used to identify trends and serve as early warning for upcoming crisis. Preventing crisis is preventing poverty.

${ }^{32}$ Social Security: Issues, Challenges and Prospects. ILC Report VI, $89^{\text {th }}$ Session. ILO, 2001. 


\section{Box 30: The Socio-Economic Security Programme}

The Socio-Economic Security Programme addresses the following key issues:

- What constitutes socio-economic insecurity?

- What are the sources of such insecurity?

- What economic, labour and social policies could improve socio-economic security while promoting sustainable economic dynamism?

- What forms of security are required to lay the foundations for "decent work", or occupational security?

The Programme blends primary research with action programmes to achieve its goal. Its strategy focuses on the following seven forms of security for decent work:

- Labour market security - Adequate employment and work opportunities, through high levels of employment ensured by macro-economic policy;

- Employment security - Protection against arbitrary dismissal, and employment stability compatible with economic dynamism;

- Work security (Occupational health and safety) - Protection against accidents and illness at work, through safety and health regulations, regulated limits on working time, unsociable hours, and a reduction in stress at work;

- Job security - A niche designated as an occupation or "career", the opportunity to develop a sense of occupation;

- Skill reproduction security - Widespread opportunities to gain and retain skills, through innovative means as well as apprenticeships and employment training;

- Income security - Provision of adequate incomes;

- Representation security - Protection of collective voice in the labour market, through independent trade unions and employer associations and other bodies able to represent the interests of workers and working communities. Socio-Economic Security (IFP/SES).

\section{Informal Economy}

As explored in Part I Section 2.4, the challenges of the informal economy cut across ILO concerns in the areas of rights, employment, social dialogue and social protection. In follow-up to the 2002 ILC conclusions on decent work and the informal economy, the ILO is experimenting with a shared project on this topic. Using a conceptual framework that stresses themes of governance, macro policies, representation and voice, productivity and marker enhancement, and addressing vulnerabilities, it builds on existing ILO work. Action in the area of social protection provides an illustration.

Workers in the informal economy, and others who are not covered by any form of social protection, face serious decent work deficits. The ILO has attempted to address this issue both conceptually and through action programmes such as Strategies and Tools against Social Exclusion and Poverty Programme (STEP). 


\section{Box 31: Mutual health organizations, the concept of social protection among informal workers}

Mutual health organizations are a possible answer to the need of social protection among informal workers. They are non-profit organisations of people, operating on the basis of solidarity between its members. On the basis of members' contributions and led by their own decisions, mutual health organizations organize provident, mutual aid and solidarity measures aimed at insuring against financial risks related to illness, absorbing the consequences and promoting health.

A recent ILO Guide entitled "Mutual health organizations and micro-entrepreneurs' associations" enables readers to appreciate the benefits and constraints involved in the creation of these organizations. It tries to combine the creation of new jobs and providing access to social protection within a single approach. Users of the Guide should be able to plan and organize for the technical support that can help them getting started to create mutual protection structures. Boosting Employment through Small Enterprise Development (SEED) and Strategies and Tools against Social Exclusion and Poverty (STEP).

Between 1996 and 1997 the ILO's Social Security Department undertook an action programme on the role of social security in the fight against poverty. Van Ginneken, ed.: (Social Security for the Excluded majority; Case Studies of Developing Countries, 1999). The first objective of the programme was to examine the reasons why statutory social security schemes did not reach larger proportions of the labour force. Secondly it aimed to establish a more informed basis for consideration, design and implementation of taxfinanced social assistance and self-financed social insurance schemes. In addition the action programme started to develop new technical cooperation activities, with the intention of strengthening the capacity of governments, social security agencies, social partners, NGOs and insurance companies, in their efforts to design and implement social security schemes for the informal economy. Various countries were selected as case studies (Benin, China, El Salvador, India and Tanzania).

\subsection{Gender aspects}

The ILC report on Social Security in 2001 also highlighted the fact that discrimination against women is produced by systems which fail to take into account (in effect penalise) women for their role as unpaid carers. The ILO's Gender, Poverty and Employment Manual provides advice on issues of gender and social protection. The ILO has paid particular attention to the issue of social protection for home-workers. In developing countries, home-workers (mainly women) are among the most vulnerable workers because their legal status is not clearly identifiable. 


\section{Box 32: Latin America, strengthening the voice of homeworkers}

Paula works but she doesn't go to work. From her home, she sews cosmetics bags. She doesn't know how many other women in her district, on the outskirts of Sao Paulo, are sewing the same bags, nor does she know what they are paid. Once a week a man comes to her with cloth and thread and instructions on what to make. He pays her for her previous week's production - but the pay is low. Paula is one of an estimated 2.7 million home-workers in Brazil who are connected to value chains with national producers and often with international buyers and foreign retailers. She is at the bottom end of the chain and has no rights and no social protection.

Over the past five years, SEED, in collaboration with the ILO's Bureau of Workers' Activities and the ILO Regional Office in Lima, have worked to build up the knowledge base on the contours of the phenomenon. The Home-workers in the Global Economy project, funded by the Danish government, organised a tri-partite research policy workshop in 1999 which called for better documentation and data. A subsequent workshop in Santiago in early 2001 brought together statisticians from a number of countries in the region to design a framework to include data on home-workers in national accounts. Country studies on homework and informal economy outsourcing in Mexico and Brazil were then commissioned. Those studies were used as background documents to a meeting of trade unionists in Sao Paulo in October 2001. Representatives from nine Latin American countries came together to develop innovative strategies to organise workers along the value chain, particularly home-workers. They acknowledged that unions have to change their ways to effectively represent and defend such workers. They developed approaches to expand the scope of union action beyond the industry and enterprise level, to build alliances with new actors, and to adapt their approaches to collective bargaining at the international level. Such changes in trade union attitudes should lead to greater representation and improvements in the decency of homework. Boosting Employment through Small Enterprise Development (SEED), Bureau for Workers' Activities (ACTRAV), Regional Office in Lima).

Work has been done on extending protection to home-workers in Thailand by developing participatory training programmes, mobilising NGO networks to reach home workplaces and training local trainers for sustained actions. Protection has also been extended to farmers in Vietnam and to hazardous child labour in Cambodia.

The ILO's work in Asia since 1986 provides rich experience and lessons as to how the objectives of employment promotion and social protection can be extended to homeworkers. The strategy consists of: organisation of workers to strengthen their bargaining power, creation of awareness of their rights among workers, and paralegal training and expansion of legal protection. Work has been carried out with Self-Employed Women's Association (SEWA) in India and the National network of Home-workers (PTAMABA) in the Philippines among others.

In developed countries social protection has been one of the main instruments for tackling or preventing poverty through benefit systems. However, for the majority of poor people in the world such protection is neither available nor affordable. This is partly because of past attitudes that social provision in developing countries would be provided by family and community members through extended social and family networks, which meant neglect of the development of structures within governments, and partly because of an ideological approach to economic growth and development which focused on modernisation and neglected the need for social provision. The model adopted by the IFIs was that of safety nets - so that social protection was treated as a residual welfare issue. For instance, definitions of social protection and the scope of policy interventions, which often require a multi-sector approach, remains a challenge in the context of PRSP work.

However, the financial crises of the late 1990s provoked the international community to examine the changing context for economic and social policy and the need for an institutional framework for managing risk and promoting opportunity. Debate is therefore 
current on the economic contribution of social protection as part of poverty strategies. There are, for example practical examples of social benefits which can provide support to whole communities - such as the old age pension provided to workers in South Africa. In communities distinguished by absent /migrant workers or ravaged by the effects of HIV/AIDS pensions have provided assets which can be drawn upon by an extended range of family members. In these cases social protection is providing a necessary support system that sustains livelihoods. Therefore, the question that has to be posed is not "Is social security affordable?" But rather, "Can we afford not to have social security - if poverty is to be reduced?".

\section{Box 33: A Zambian widow's story: life without social security}

Prudence K., a 45-year old widow with six children between the ages of four and fourteen, has lived in the Chilenje compound outside of Lusaka, Zambia for thirty-two years. Her husband, a low-level civil servant, died two years ago without life insurance or a pension.

She sells vegetables in the market and has been in business for ten years. Her monthly household expenditure is usually about US\$130, with over half being spent on food. Her business income fluctuates wildly, but she typically nets between US\$60 and $\$ 90$ per month. She makes up the difference between income and expenses by renting out rooms in her house, but she is extremely vulnerable to risks or economic shocks that might cause a spike in expenses, suppress income, or both.

When she does have a little bit of extra cash, she puts it in a jar under the floorboard in the bedroom. When asked whether this was a safe or productive means of saving, she replied: "Even if I wanted to earn some interest, where do I save? The conditions in the banks are bad. It costs me more to get to the bank than I would usually want to deposit. Then they would charge me fees every time I put money in or take it out."

With six children, education expenses are a crucial burden for Mrs. K. She participates in two chilimbas, or rotating savings group, because they provide discipline she needs to save her limited resources. The proceeds she gets from one chilimba she uses to pay for school fees, uniforms, books, etc.; she invests her takings from the other chilimba in her business.

In 1999, she was critically ill for long time and had to sell some of her clothes and maize to raise money for her medication. Later that year, thieves broke into the house and stole some valuable goods. According to her, it was a terrible experience. She had to cut way back on food expenditures and had to sell off almost the entire business capital to replace some essential items. Then she began the long struggle to re-capitalise her business; she received a real boost when she joined a solidarity group to borrow money from a local micro finance institution.

Another irregular yet difficult expense is the contribution she has to make for the funerals of close friends and relatives; to make her contributions, she relies heavily on the assistance of others, from friends, neighbours and the church. Mrs. K. testifies that things were better when her husband was alive. Social Finance Programme (SFP).

During the past decades, in the context of structural adjustment, emphasis was placed on "safety nets" for people in low income countries focusing on the need to protect those who might fall chronically or temporarily into unacceptable levels of poverty. A more enlightened approach to social protection recognises that in the absence of formal, collective arrangements to minimise risk, communities and individuals have to engage in informal risk management strategies which often impose high risks of their own. When crises do occur the poor are forced to take drastic action - reducing meals, taking children out of school, selling assets. Therefore, policies are needed which help poor people reduce exposure to risk, develop and maintain their human capital, to escape from exploitative social relations. Social security provision can therefore be linked closely with approaches for sustaining livelihoods. Much of the work that the ILO does in sustaining livelihoods can also be seen as a form of social protection providing support to those facing crises.

A distinction has to be made between social insurance where individuals buy protection, and social assistance that consists of non-contributory transfers. The latter affects the majority of poor people, although ILO has a number of projects that attempt to provide poor people with social insurance. 


\section{Box 34: West Africa, mutual health schemes are growing}

The poor populations, which are excluded from the social protection systems and the international community, have joined their forces to find solutions for the double challenge of improving health and ensuring sustainable health care financing in Africa. In that sense, STEP has, together with its partners, stimulated the creation of "the Concertation", among actors in the development of mutual health insurance schemes, whose headquarter is in Senegal. "The Concertation" is an innovative mechanism of local and international partnership. It enables the creation of synergies between African mutual health insurance schemes, the partners in development and the communities through concrete activities such as training, exchange workshops and thematic discussions. Since its creation, a lot of actors have shared their points of view, their knowledge and their experiences through a dozen of newsletters and the website of "the Concertation". Every month, new members join "the Concertation" which registered in 2002 around 500 members spread out over 11 French speaking African countries: Benin, Burkina Faso, Cameroon, Chad, Côte d'Ivoire, Guinea, Mali, Mauritania, Niger, Senegal and Togo. The last forum of "the Concertation", organised in September 2002, gathered 190 people out of 24 countries under the chairmanship of Senegal's Minister of Labour. Strategies and Tools against Social Exclusion and Poverty (STEP).

Social protection also falls within the framework of rights - particularly the right to livelihood security. This issue is usually accompanied by questions of affordability. In this respect the state's obligation in relation to social protection for its citizens does not mean that it has to achieve this solely or even primarily by providing social security transfers. Promoting an enabling environment in which people can use their own efforts to achieve security of livelihoods is equally critical.

However, the constraints to development of conventional social security systems in developing countries and the challenge of halving poverty by 2015 , call for new and innovative approaches. A pilot programme is currently promoting and testing a new global social solidarity fund, which is called the "Global Social Trust".

\section{Box 35: Global Social Trust Fund}

The idea of the programme is to address the challenge of alleviating poverty through an internationally financed social protection mechanism. The concept is to raise family income in the poorest countries through the provision of basic social security. By teaming up a developed country with a developing country, networks of individuals in the former would make regular, voluntary donations of a few dollars a month to create basic social protection systems in developing countries and support benefit payments until those systems become self supporting. Main benefits would go to basic income, education and health. The aim is to set up a concrete anti-poverty social protection benefit in the developing country. Social Security Financial, Actuarial and Statistical Services (SOC/FAS).

\subsection{The effects of the HIVIAIDS pandemic}

The HIV/AIDS epidemic is both a cause and consequence of poverty, and in many cases constitutes a violation of rights. HIV/AIDS is a cross-cutting issue in the ILO because it involves social protection policies, rights at the workplace and sustainable development. Poverty increases people's vulnerability to HIV and related diseases, and the disease itself is likely to drive people into poverty. It has posed new challenges related to social protection, rights and dialogue. 
The ILO global programme on HIV/AIDS and the World of Work was established in November 2000 following an ILC resolution. The objectives are to raise awareness of the economic and social impact of HIV/AIDS in the world of work, to help governments, employers and workers through TC projects, training and policy guidance on prevention, care and support, and to fight discrimination and stigma associated with HIV/AIDS. The programme uses the ILO code of practice which provides guidance on preventing HIV/AIDS and mitigating its impact in the world of work (both formal and informal).

\section{Box 36: HIVIAIDs strengthening informal workers' abilities to protect themselves}

- The ILO HIV/AIDS programme is particularly concerned with workers in the informal economy and training programmes include modules on workers and the informal economy.

- In Zambia, the National Union of Plantation and Agricultural Workers (NUPAW) has embarked upon an impact mitigation initiative for the agricultural workplace covering the entire country.

- In Dar es Salaam, the Federation of Informal Sector Associations is working with the ILO to see how a code of practice can be applied to workers in the informal economy.

- In India, with ILO support, employers' groups are working to urge larger companies to identify small enterprises with which they have production relations. The aim is to convince larger companies to extend their HIV/AIDS workplace information and educational programmes to also cover firms which supply their goods and services to them.

- $\quad$ ILO is working on a paper on PRSPs and HIV/AIDS.

While HIV/AIDS affects both rich and poor in the world of work, it has taken its biggest toll in the poorest countries, particularly in sub-Saharan Africa. Moreover, it is in the informal economy in those countries that the poorest people are most likely to be found. The informal economy is diverse and heterogeneous but there are a number of common features which make it vulnerable to HIV/AIDS. Informal economy workers are especially vulnerable to different types of external shocks, drought and famine, armed conflict, political and economic upheaval and severe illnesses such as HIV/AIDS. People working in the informal economy often suffer absence of a steady income, low educational levels, lack of social protection and limited access to health facilities. Further, there is likely to be a small labour force and a reliance on family members in informal economy enterprises. It is well known that the burden of care for sick family members is likely to fall on women who may themselves then lose business and trading opportunities. The prevalence of HIV/AIDS orphans has been linked with increases in child labour; especially leading to girl children taking up more domestic labour, care functions and even prostitution.

\section{Box 37: Zambia, sensitizing workers and employers}

Zambia is struggling to cope with a high incidence of people living with HIV/AIDS (PLWHA). Full care and support for these people, who represent $21 \%$ of the adult population, is just not possible in such a poor country. As result, many must remain economically active to generate an income. In 2000-01, SEED collaborated with the UN-AIDS agency to provide SIYB training to PLWHA in Lusaka. Following the training, a number of individual and group-based businesses were created. These included an urban transport business, which has generated a regular income for its owners. Revenues from such enterprises have allowed poor people to feed themselves and their families, and more importantly, to buy medicines and pay for health care. The Zambian initiative is part of a larger effort to mainstream HIV/AIDS into SIYB programming in Africa and other regions. Much of the work has involved sensitising employers to concerns of employees affected. In 1999, a training session was provided to master trainers from 14 poor countries in eastern and southern Africa (+ Mauritania) which provide the SIYB course. The prevalence of HIV/AIDS averages $25 \%$ in these countries. In mid-2002, a similar workshop on the Caribbean island of St. Lucia drew business trainers from five countries. UN-AIDS, which funded those two efforts, supported a similar workshop in Surinam in late 2002. Boosting Employment through Small Enterprise Development (SEED). 
To sum up, social protection is a fundamental requirement in all stages of life; birth, wellbeing of mother, childhood, adolescence, adulthood, old age and death. Social protection provides the means for preventing poverty from being transmitted from one generation to the next. The International Labour Organisation as an international organization has a key comparative advantage in developing strategies to prevent, address and overcome poverty because it is developing innovative approaches to social protection in the service of decent work. The work of the ILO seeks to break the intergenerational cycle of poverty by the following means. ${ }^{33}$ :

Child Workers. The role of social protection is to engage in active prevention through instruments such as labour inspections and to provide access to health care and ensure that parents work in conditions enabling their children to avoid exploitation in the work place.

Migrant Workers. Social protection promotes skills and potential by working towards better regulation of migrant labour flows and striving for training and respect for migrant workers. Migrant workers are confined to the most dangerous jobs. Their living conditions are poorest and often, especially if they are clandestine workers, they have the greatest difficulty gaining access to social security.

Disabled persons. Social protection provides active prevention in order to prevent disability; by ensuring access to essential goods and services when it is too late for prevention; and through the intermediary of social insurances and social security.

Informal Economy Workers. Most poor workers are employed in the informal economy. It is they who handle dangerous materials and work without protective equipment or using badly maintained, adjusted and controlled machinery or equipment, including in agriculture. Apart from carrying out active prevention, social protection ensures access to quality health care for all under the provisions of social security and its extension.

Workers with HIV/AIDS. All three functions of social protection must be mobilized: active prevention to educate, support and protect; access to essential goods and services to enable the sick person to receive medical attention, including state-of-the-art health care; the promotion of individuals' potential by engaging in dispassionate and constructive social dialogue in the work place.

Elderly or disabled persons no longer able to work for a living. Access to essential goods and services can be guaranteed by broad social protection schemes.

The ILO makes important links between poverty and social protection. Social protection can:

- Mitigate the impact of "shocks" caused by risks such as illness, loss of breadwinners job, accidents leading to disability. Poor people are most affected by risks and yet the least protected against those risks. These shocks push people into poverty.

- $\quad$ Contribute to economic growth by encouraging investment, in particular for small business entrepreneurs in terms of productivity. Social protection can provide better health status for workers, sustainability of economic activities and wage security. It can also contribute towards human and social capital growth in general, through the promotion of social cohesion. Social protection could, and should, be a condition for the implementation of structural reforms aiming at economic growth and development.

33 This work involves several ILO units, in particular from the Social Protection Sector (Safe Work, CONDI/T, SOC/POL, SOC/FAS, STEP, MIGRANT, ILO/AIDS). 
- $\quad$ Reduce inequality. Social protection mechanisms can be powerful instruments for redistribution of wealth between different population categories.

- $\quad$ Provide access for the poor to social services (health care services, education, etc.)

ILO/STEP, for example, supports the development of social protection schemes for the poor, based on a combination of public provision and civil society efforts. It is working on risk prevention and the coverage of its consequences (insurance) as well as access to social services. It focuses on health - a priority for poor people. It places great emphasis on the participation of the poor and strengthening their organisation. It works particularly on community-based micro-insurance schemes. 
"The ILO is committed to helping people work out of poverty. We know this challenge will take new thinking, ideas and approaches and-above all-action. First and foremost it means removing the barriers of discrimination and accumulated deprivation that trap people in low productivity and low paid jobs".

Report of the Director-General, Working out of Poverty, ILC 2003

\section{Rights and poverty}

Human Rights themselves underpin poverty eradication. The Human Development Report 2000 notes that civil, political, economic, social and cultural rights are causally linked and can be mutually reinforcing. They can create synergies that contribute to poor people securing their rights, enhancing their human capabilities and escaping poverty. Further, a decent standard of living, adequate nutrition, health care and other social and economic achievements are not just development goals but human rights inherent in freedom and dignity. These rights, however, do not necessarily mean entitlements but are rather claims to a set of arrangements - norms, institutions, laws and an enabling economic environment that can best progressively secure enjoyment of these rights.

There has been an increased interest in recent years in what are called "rights-based approaches" to development. Such an approach essentially places a new emphasis on the individual actor as a bearer of rights rather than just as a factor of production and shifts the discourse of development from welfarism to empowerment and participation. It shifts the dialogue away from one in which it is taken for granted that there may inevitably be "losers" in development towards one in which the state has a role to play in creating an enabling environment to ensure that "trampolines" not just safety nest are provided. This is an approach which has been taken by UNICEF in placing child rights at the centre of their work. Similarly, a paper produced by the United Kingdom Department for International Development (DfID) set out three cross-cutting principles for integrating a rights-based perspective into development.

- Participation: enabling people to realise their rights to participate in, and access information relating to, the decision-making processes that affect their lives;

- Inclusion: building socially inclusive societies, based on the values of equality and non-discrimination, through development, which promotes all human rights for people;

- Fulfilling obligations: strengthening institutions and policies, which ensure that obligations to protect and promote the realisation of all human rights are fulfilled by states and other duty bearers. ${ }^{34}$

By this definition, the ILO is both a rights-based organisation by virtue of its Constitution and the practices and emphases of many of its programmes (the sustainable livelihoods approach as discussed in Chapter 3 is in effect a rights-based approach), and an organisation that promotes particular rights (i.e. employment, labour, child rights, rights of associations, etc).

The ILO's contribution to the achievement of the latter is its longstanding work on developing international labour standards and ensuring their application (work for which the ILO was originally created). This has not been explicitly linked to poverty reduction. But it is clear that many ILO Conventions and Recommendations underpin the conditions necessary for either preventing people from falling into poverty or for enabling them to

${ }^{34}$ DfID, Realising Human Rights for Poor People, October 2000. 
escape from poverty. The ILO has adopted some 184 Conventions and 194 Recommendations covering a broad range of subjects: abolition of forced labour, freedom of association and collective bargaining, equality of opportunity and treatment, employment promotion and vocational training, social security, conditions of work, prevention of work-related accidents, maternity protection, protection of migrants and other categories of workers such as seafarers, nursing personnel or plantation workers. It is only natural that some of the Conventions and Recommendations adopted since 1919 are outdated. The Office and the Governing Body have reviewed the ILS and come up with a list of around 70 "up to date" Conventions and Recommendations on which to focus promotional efforts. Further, a normative "integrated approach" has been adopted to harmonise ILS around certain themes, as for example, maritime work or occupational safety and health.

Many ILS are relevant to poverty reduction. Among these are eight core ILO Conventions (Nos. 29, 87, 98, 100, 105, 111, 138, 182), the principles of which are reflected in the ILO Declaration on Fundamental Principles and Rights at Work (the Declaration). The latter marked a turning point in international commitment to certain core principles. In 1998 the ILC adopted the ILO Declaration, reaffirming the ILO's member States commitment to "respect, and realize in good faith, the principles concerning the rights to freedom of association and the effective recognition of the right to collective bargaining, the elimination of all forms of forced or compulsory labour, the effective abolition of child labour and the elimination of discrimination in respect of employment and occupation". The Declaration underscores the obligation of all ILO members to respect the principles regardless of whether they have ratified the relevant ILO Conventions.

The Declaration principles have strong links with poverty reduction. Poverty is not only about income, or employment. It is also about rights and capabilities. The social foundation is critical for the poor. The right to freedom from child labour, for instance, is the basis for all members of society to have the chance to fully develop their capabilities. Freedom from discrimination is essential if all are to have the same opportunities. The right to organize is vital if the poor are to claim their rights, to improve their capacity to earn a living and to secure a fair share in economic benefits. Similarly, more women are entering paid work, but more jobs have often not meant better jobs; gender inequalities in the labour market continue to persist and poverty is increasingly becoming feminised. Poverty thus encompasses a lack of rights, a lack of income and a lack of decent work. This includes the denial of freedom of association and the incidence of forced labour, child labour and discrimination.

\subsection{Human rights and the PRSP}

The Office of the High Commissioner for Human Rights (OHCHR), together with other UN organisations, international development agencies and governments, has produced Guidelines on a Human Rights Approach to Poverty Reduction Strategies (2002).

The introduction to the guidelines points out that "the essential idea underlying the adoption of a human rights approach to poverty reduction is that policies and institutions for poverty reduction should be based explicitly on the norms and values set out in the international law of human rights". These norms and values have the potential to empower the poor. Without this, poverty reduction cannot be achieved. The poor not only have needs, they have entitlements. Rights and obligations also require accountability by all duty holders, including States and Inter-governmental organisations. The Guidelines continue: 
"The twin principles of equality and non-discrimination are among the most fundamental elements of international human rights law. Thus the international human rights framework has a particular preoccupation with individuals and groups who are vulnerable, marginal, disadvantaged and socially excluded."

A human rights approach to poverty reduction requires active and informed participation by the poor in the formulation, implementation and monitoring of poverty reduction strategies. The international human rights framework recognises the interdependence of rights - - economic, social, cultural, civil and political. The ILO has made a key contribution to the development of these guidelines by providing a Section on "The right to decent work" (See Annex 4).

\subsection{Equality at work}

The Declaration Global Report, Time for Equality at Work, provides a comprehensive analysis of the issues. It was discussed at the International Labour Conference in 2003. In summary, millions of people in the world are denied jobs, confined to certain occupations or offered lower pay simply because of their sex, their religion or the colour of the skin, irrespective of their capabilities or the requirements of the job. Discrimination that certain groups such as women, ethnic or racial minorities, migrants, and persons with a disability face in the labour force can even involve forced and compulsory labour. In addition, barriers to decent jobs often compel parents belonging to an ethnic minority or a denigrated caste to resort to the labour of their children to make ends meet. Discrimination at work deprives people of their voice at work and full participation, thus undermining democracy and justice in the workplace.

Time for Equality at Work argues that the benefits of eliminating discrimination in the workplace transcend the individual and extend to the economy and to society. Workers who enjoy equal treatment and equal opportunities improve the efficient use of human resources and diverse talents. This improves workplace morale and motivation, leading to better labour relations with positive implications for overall productivity. A more equal distribution of job opportunities, productive resources and assets, including education, between men and women of different races, religious or ethnic origins, contributes to higher growth and political stability. The elimination of discrimination at work is an indispensable component of any strategy for poverty reduction and sustainable development.

Discrimination excludes people from work. Equality at work enables people to break out of the cycle of poverty by developing their productive capabilities and competencies. Equality at work increases people's dignity, well-being and sense of self worth, thus helping them overcome the sense of powerlessness and lack of self-esteem associated with income distribution. It lies at the heart of the ILO's mandate and the notion of decent work.

Discrimination creates a vicious cycle of poverty. If people are excluded from access to the education, skills and voice necessary to provide productive work they are more likely to fall into poverty. Discrimination issues often create the foundation for social unrest or armed conflicts, which has many times been the case in Africa and Latin America. Discrimination between different groups of people or classes of population hampers social peace. For example, a more even income distribution would favour social peace and peace in general.

Discrimination based on ethnic origin, sex, creed or social group can lead to, and also make it more difficult to escape from, poverty. However, discrimination may occur 
outside the context of poverty. The UN Human Rights Committee defines discrimination as any distinction, exclusion, restriction or preference which is based on any social group such as sex, race, colour, language, religion, political or other opinion, national or social origin, property birth or other status, and which has the purpose of nullifying or impairing the recognition, enjoyment or exercise by all persons, on an equal footing of all rights and freedoms. ILO Convention No. 111 defines discrimination as "Many forms of discrimination continue to be practised worldwide: in all regions of the world, people are denied rights to franchise, political participation and the exercise of citizenship because of some real or perceived distinction. They may be denied equal rights to food, shelter, work, health care, education or credit".

The ILO has helped to advocate gender and race mainstreaming into national policies and programmes developed by ILO constituents. For example in Brazil, the ILO is implementing the Gender, Poverty and Employment (GPE) programme which includes a new module on race, in order to contribute to the integration of gender and race dimensions into public policies on poverty reduction and fight against social exclusion. The ILO and the Ministry of Labour and Employment have jointly produced a Portuguese version, adapted to the Brazilian reality, of the kit on GPE. This has raised interest among governmental and non-governmental organizations to use it as an instrument for developing employment policies and mainstreaming gender and race.

\section{Box 38: Brazil, action to reduce gender and race discrimination}

Since 2000, ILO has been providing technical and financial support for the implementation of the Project "Gestão local, empregabilidade e equidade de gênero e raça: uma experiência de politica pública na região do ABC paulista", implemented by the Municipality of Santo André, Brazil with technical support of the Centro de Estudos sobre Relações do Trabalho. The main objective of the Project is to enhance employment opportunities for women and blacks in the region by integrating gender and race dimensions into the indicators and in the agenda of the Regional Development Agency.

Under this Project, the ILO supported:

- $\quad$ production of a conceptual paper entitled "O quesito cor em instituições públicas $e$ privadas" to build the capacity of managers to address and mainstream race and gender issues in public and private institutions;

- production of guidelines, "Informação é a melhor arma contra o racismo $e$ a discriminação", to train researchers on how to incorporate the race component into public policies and programmes;

- design of campaign and production of material (folders, booklets, posters) to raise awareness on the issue;

- development of a methodology to organize workshops on the issue;

- monitor the implementation of the Project;

- $\quad$ assessment on the application of the designed practical tools was elaborated.

In July 2002, the Project was awarded with the International Dubai Prize on Best Practices on the Improvement of Living Conditions. The international and national recognition of the results of the project is stimulating the development of new projects and initiatives. The outputs of the Project were presented at the World Social Forum, in January 2003 and in a national workshop at the end of 2003 .

\subsection{Labour standards}

The economic case for labour standards as a means of reducing poverty overlaps with the social case. Social and political stability, to which labour standards can contribute, increases private investments, including foreign investment. Freedom of association can help markets to function effectively by increasing freedom of choice, equality of bargaining power and availability of information. Freedom from discrimination reduces 
the risks of skills and capabilities being wasted. Elimination of exploitative child labour improves economic prospects by getting more children educated. These elements do certainly contribute to prevention of both civil and social conflicts.

There is also an economic case which goes beyond core labour standards to support more specific interventions, such as minimum wages and obligations to provide decent working conditions. Such specific labour standards can raise productivity, by boosting labour motivation and effort, by improving workers' health, and by inducing employers to adopt new business strategies. Good wages and working conditions can reduce wasteful labour turnover, while the empowerment and security of workers can facilitate creativity and cooperation in the workplace. Thus the link between rights, development and poverty reduction lies at the heart of the ILO's comparative advantage in tackling poverty reduction. To a large extent this is a governance issue - concerning the importance of an enabling environment for democracy and poverty reduction, which also involves social dialogue in its broadest form. There is an opportunity here to further explore the role of the ILO's supervisory bodies to effectively promote compliance with the ILS at the country level.

\section{Box 39: Asia and the Pacific, improving labour standards}

In 2000, the Asian Development Bank (ADB) and the ILO (Executing Agency of the Regional Technical Assistance programme) joined forces to improve labour standards as a means of promoting development and reducing poverty in the Asia-Pacific region. Since then, joint research has been undertaken, associating both labour and financial ministries. Social partners and civil society. Joint workshops were also undertaken to test research conclusions in a couple of countries. The work was brought together and discussed in a Regional Technical Workshop on Labour Standards, in Manila in September 2002. At this occasion, the ADB Director General of the Regional and Sustainable Development Department stated the following:

"there is overwhelming evidence that promoting decent working conditions reduces poverty, raises living standards, and enhances the quality of growth by increasing productivity. For these reasons, many countries and development agencies are supporting improved labour standards. ADB has taken this very important challenge. Since the approval of ADB's Social Protection Strategy in September 2001, labour standards are an integral part of ADB's development mission. (...) Improving the conditions of labour is essential for economic and social progress in the Asia Pacific region. Most of the poor in the region, among whom a significant proportion consist of women, are the working poor. Labour-related concerns are significant to the ADB's overarching goal of poverty reduction, and its strategic development objectives of economic growth, improving status of women, human development, as well as protection of the environment. Improved understanding and application of labour standards is important for reducing poverty..."

A Memorandum of Understanding between the two agencies, signed in February 2002, is laying the ground for continued collaboration on this important issue.

\subsection{Freedom of association}

A robust system of labour institutions, rights and standards contribute to broader processes of social and political development. Freedom of association is a fundamental political right, and labour organisations can play a key role in the development of responsive and democratic policies. The struggle to achieve workers' rights may involve some conflict in the short run, but core labour standards promote social justice and hence social and political stability, in the longer run. 
"Freedom of expression and of association are essential to sustained progress" (ILO Constitution). The ILO believes that organising and collective action is a strategic means for the empowerment of the poor so that they can improve their living and working conditions. Two examples from the ILO's Bureau for Workers' Activities (ACTRAV) of reaching out to poorer workers can be cited here. One project gives assistance to rural workers' organisations in Latin America, where some remarkable progress was made in 2000 .

\section{Box 40: Costa Rica, the challenges of the Banana Traders' Union}

An agreement signed between the banana workers' trade union SITRAP and various employers in the banana sector is one very significant impact of the ILO project. SITRAP requested assistance regarding an idea on ethical trading. The background was that the banana sector has experienced very difficult times during the last two years. In order to make an effort to avoid unemployment SITRAP wished to explore the possibilities to open alternative markets. It was decided to invite the employers to sign an agreement on ethical trading which would serve as a door opener for ethically produced bananas in Europe. Upon request from both the Employers and SITRAP, the project provided technical assistance during the negotiations as well as in the efforts to find markets. In addition to the efforts made in Costa Rica, trade unions in various countries in Europe assisted in creating awareness about ethical trading in their respective countries. As a result an agreement was signed between SITRAP and the Employers, and a Norwegian fruit importer, COOP, agreed to sign a three years contract to buy 6000 boxes (72 tons) per week from these independent producers.

The agreement includes: full respect of the freedom of association and recognition of the trade union's right to collective bargaining; compliance with national labour laws and international labour standards; all the workers will be covered by the social security system; no to child labour; equality between men and women regarding salaries and rights in general; establishment of a social fund (US\$ 0,40 from each box sold). This agreement can serve as an example on how social dialog can be practiced in a way that all parties involved are beneficiaries. Therefore, this experience is not applicable only in the banana sector, but could be applied for any sector and in any country. Bureau for Workers' Activities (ACTRAV).

The second initiative seeks to organise the unorganised poor in the informal economy. The project began in June 1998 in Mali, Niger, Burkina Faso and Senegal, and lasted till August 2001. In each of these countries, activities were developed for the working poor in the informal economy through the respective national trade unions' coordinating structures.

What was done in these countries? Informal economy workers, who were mostly women, were helped by the trade unions to identify their needs, define their priorities and develop their strategies. This was done through training activities, the setting up of local structures composed of trade unionists and informal economy workers to oversee activities, the organisation of informal economy workers around different trades, and the development of various socio-economic activities in line with the identified needs of the poor workers.

What were the results of the project? In Burkina Faso, 43 professional structures of informal economy associations were created with an autonomous national coordinating structure working in close collaboration with the unions. Furthermore, a mutual help society was set up to cater for the socio-economic needs of informal economy workers. In Mali, 12 trade unions and 2 associations of informal economy workers were set up. These organisations created a micro finance scheme for themselves and won some degree of recognition from the authorities. In Niger, 25 informal economy unions were created throughout the country and were structured into a National Confederation. Furthermore, a Mutual Health Organisation was created as well as a foundation to oversee the continuity of the project after it ended. In Senegal, 4 cooperatives of second-hand dealers were created as well as 4 mutual health organisations of informal economy workers. 
At least two lessons can be learnt from this project. First, that organising and collective action is a strategic means for the empowerment of the poor so that they can develop their own strategies to improve their living and working conditions. Second, when organising is accompanied with well-targeted project support, the poor develop programmes that reinforce their social protection, increase their incomes and strengthen their voice.

\subsection{Child labour}

As part of the follow-up to the Declaration, a Global Report, A Future without Child Labour, was produced for the International Labour Conference in $2002^{35}$. This provides a comprehensive review of child labour issues. It points out that the links between poverty and child labour are by no means as straightforward as might be expected. Not all extremely poor families resort to child labour and in some relatively well off households child labour is encountered - for example where a shortage of family labour is an issue. In addition there is evidence of gender, caste and ethnic disparities. Girls may be denied education because of preference for boys to have education and amongst certain ethnic and indigenous groups, education may be denied because of language and other cultural differences.

In many poor families, child labour occurs as a contribution to family income. But even where a family can afford to send a child to school, poor facilities and learning environment can dissuade families from spending money on education. Depriving a child of education and health (children in hazardous work are likely to suffer ill-health) in turn weakens the skills base and productivity of a country. The cycle of deprivation continues into future generations.

It is clear that a comprehensive multi-sectoral approach is required to tackle the problem of child labour. This is why ILO's InFocus Programme on Child Labour (IPEC) involves all four objectives of ILO's work, rights, employment, social protection and social dialogue.

${ }^{35}$ ILO: A future without Child Labour. Global Report under the Follow-up to the ILO Declaration on Fundamental Principles and Rights at Work. 2002 


\section{Box 41: Brazil, a response to child labour in sisal production}

One of the most important compensatory programmes to alleviate poverty has been implemented in Brazil in the past years. Based on local initiatives developed by Municipal and the Federal District Governments, the Federal Government is implementing the so-called "Bolsa-escola" programme, which provides to each family a grant to complement their income. To receive the benefit families are obliged to enrol their children in school (compulsory education). A similar programme specifically designed to combat child labour is also in implementation in the country. ILO has been providing institutional support for the implementation of those projects. Direct action programmes have been able to complement national efforts by integrating education and income generation programmes in some regions in order to ensure the sustainability of the programmes in the long-run.

Children working with sisal are considered to be in one of the worst forms of child labour in Brazil. Living conditions in the Sisal Region are part of the worst in the country. Besides harsh natural conditions, many children were wasting their lives in sisal production. They had no school, appropriate food, free time to play, and, above all, they were literally losing their hands to the domestic machines that were used to process the sisal fibre. IPEC supported the following activities:

- National Confederation of Workers in Agriculture raised awareness and promoted the "Goat-to-school project"

- At the local level awareness raising and mobilisation of local partners was ensured by a rural trade union, Sindicato dos Trabalhadores Rurais de Retirolandia, and an NGO, Movimento de Organização Comunitária

- Selected families received one male goat and three female goats, in exchange of enrolling and maintaining their children in schools on a full time basis

- Once the reproduction of the herd became sustainable, the initial share of goats was returned to a revolving fund, and then reallocated to new families

- The NGO assisted families to introduce more productive land management technologies. Planned initiatives were presented to financial institutions for alternative credit loans.

Apart from keeping children in school, the project has also improved nutrition and created future opportunities for the families. The goal is to contribute to the sustainable development of the Sisal Region, taking into account the human, social and economic aspects of that community. An empowerment process has taken place as all changes were implemented with the participation of the population. The project is today self-sustainable and benefits over 250 families.

IPEC was launched as a technical cooperation programme on child labour in 1992. Since then it has become the ILO's biggest operational programme with activities in over 70 countries. The aim is to progressively eliminate child labour while giving priority to the urgent elimination of its worst forms by strengthening national capacities and providing alternatives for children and families. The programme focuses on:

- Vulnerable groups (children in prostitution and pornography, trafficked children, child domestic workers, children trapped in slavery and forced labour, children in the drug trade and other illegal commerce, and children in armed conflict);

- Education and social partner consultations;

- Hazardous child labour, which includes work such as mining, deep sea fishing, fireworks and match production, work with acids and other dangerous chemicals, scavenging and informal economy work.

In addition to advocacy, institutional development and policy development, IPEC provides direct action to vulnerable children and their families by providing basic services, counselling, stipends and facilitating the withdrawal of children from damaging working conditions and reintegration into mainstream society. 
The essentially experimental approaches tried and tested by IPEC throughout the 1990s are increasingly being brought to scale through larger integrated programmes. Such projects have multiple components, including child labour surveys and awareness raising alongside the three central pillars of the IPEC approach - prevention of child labour, the withdrawal of children from child labour, and their rehabilitation. The latest step in this evolution is the time-bound programme (TBP), which assists member States in putting into practice the provisions of the Worst Forms of Child Labour Convention (No. 182).

\section{Box 42: Turkey, reducing poverty to reduce child labour}

In very poor areas of Turkey, some parents send their children out to work. While this provides short-term relief in securing the family's necessities, it negatively affects the child's development and future income-earning capacity. Efforts to eliminate child labour in Turkey need to address the income needs of the family. In response, SEED and IPEC have jointly implemented a two-year pilot project. It provided Start Your Business training to the parents of child workers. A total of 15 training courses, in the city of Mersin and in the rural areas of Sinop and Diyarbakir, were attended by 228 men and women. Rural participants also received loans and vocational training in animal husbandry, bee-keeping and greenhouse operations by the Development Foundation of Turkey. The combined program resulted in 95 businesses being developed, contributing to increases in family income. Along with other efforts to reduce child labour, 285 children were wholly or partially withdrawn from work in the project areas and there has been a significant rise in school attendance. SEED is currently working on a guide on small enterprise development to be used in IPEC's programs worldwide. Boosting Employment though Small Enterprise Development (SEED).

Linked to child labour is the growing problem of child and youth (mostly women) trafficking. Just as with child labour, preventing trafficking and the rehabilitation of victims requires a comprehensive approach, bringing many ILO competences together. The ILO Mekong sub-regional project to combat trafficking in children and women addresses the issue through productive work and employment creation, education and skills training in "out-migration" or "source" areas of trafficking. The project also explores legal labour migration alternatives to trafficking in collaboration with workers and employers organisations. The project is operative in Cambodia, Lao PDR, Vietnam, Thailand and China's Yunnan province. Its interventions include capacity building to create an enabling environment, advocacy for policy change, and awareness raising to change attitudes and behaviour. The project operates where trafficking is a problem, in areas carefully selected through a participatory process engaging government authorities and other stakeholders at various levels. It offers a comprehensive set of focused direct assistance interventions in these areas, partly through ILO funds, and partly through collaboration with other agencies. These interventions encourage documentation of practices and lessons learnt for replication in other areas, and for purposes of mainstreaming into national government policy. The project focuses strongly on a participatory approach at the community level, which enable people to analyse the situation that has lead to trafficking - and helps them to take control and ownership of the issue. The approach involves participatory monitoring, by poor people themselves. 


\section{Box 43: China's rural-based training}

In Yunnan province, China, the provision of rural-based skills training (combined with microfinance support) has had positive results beyond increasing the disposable income of target families. Some of these have a direct bearing on the prevention of trafficking including:

- Increased school attendance of children whose families could not afford to send them to school previously.

- Er Du, a 17 year old girl, planned to follow other villagers and leave home for a job after graduating from middle school. The ILO TICW project was then being implemented in her village. Based on her increased awareness about the dangers of trafficking she dropped the idea of leaving. Instead her family sent her to participate in agricultural training. She learned how to reform low-yielding tea gardens and how to plant new tea. Since she has mastered how to pick, process and appraise tea, her family has established a small processing workshop and she is happy to be able to work within the village.

O Xiao Luo, a villager was trafficked to Shangdong province in 2000. She returned with the assistance of the County, Township and Village Working Committees and attended agricultural training. She now tends 6 pigs and 10 chickens and plants coffee.

\subsection{Forced and bonded labour}

Forced and bonded labour is both a denial of basic dignity and rights and a means for trapping people in cycles of poverty. The ILO Declaration Global Report, Stopping Forced Labour (2001) sets out the issues comprehensively. Whilst definitions of forced labour evolve over time, it is clear that many forms of forced labour still exist and are growing. The ILO report covers the various forms of forced labour - which are linked to consequences and causes of poverty. Slavery and abduction, compulsory participation in public works projects, forced labour in agriculture and remote rural areas (coercive recruitment practices); domestic workers in forced labour situations; bonded labour; forced labour imposed by the military; forced labour in the trafficking of persons; and prison labour under certain circumstances illustrate types of forced labour.

Forced labour is a truly global problem, with very few states fully exempt. Some of the structural aspects of forced labour can be linked to poverty, or to a weak State presence and infrastructure in developing countries. Following the Global Report, a Special Action Programme on Forced Labour (SAP-FL) started with awareness raising, research and technical assistance. In Nepal, a project undertaken together with IPEC seeks the rehabilitation and reintegration of "Kamaiya", bonded labourers in western districts. In India, a project is undertaken together with the ILO's Social Finance Programme (see 7.3). For Latin America, the main emphasis to date has been on Brazil. An ILO project seeks to strengthen and coordinate actions of the Executive Group for the Abolition of Forced Labour (GERTRAF) and other key partners to combat forced labour, to rehabilitate victims and prevent them from falling back into forced labour situations. The project has played a significant role in mobilizing federal action by federal prosecutors, police and judiciary. A major meeting on combating "Slave Labour" was held at the Supreme Court of Justice in Brasilia (attended by over 250 persons including several Cabinet ministers, over 40 federal judges, police, prosecutors and key NGOs). In a special session, its findings were presented by the State Secretary for Human Rights and SAP-FL to the President of the Republic, who expressed support for new federal laws and constitutional amendments against forced labour. Federal action has intensified since that time, with the first prosecutions. There has been intensive media debate about the true extent of forced labour in Brazil, and whether or not it is increasing. SAP-FL has responded by supporting field studies in different regions, in collaboration with the Presidential Adviser on Forced Labour, academics, worker organizations and NGOs. 
Incidence measurement should help to establishing possible correlation between forced and bonded labour systems and its links to incidence of poverty and extreme poverty. A strategic medium term objective is to encourage international development partners, including multilateral development banks, to address forced and bonded labour concerns in the context of PRSP.

\section{Recommendations and next steps}

The considerations put forward in this section are based on the findings presented in Parts 1 and 2.

The ILO has made a major contribution to conceptual work on poverty reduction during its history. This has focused particularly on the importance of employment and creation of jobs and in the recognition of the necessity of supporting the productive capacity of the working poor. With the emergence of the Decent Work Agenda there is recognition that the creation of jobs is not sufficient in itself to address the fundamental issues underlying poverty. A new approach is called for which builds on the work of the past but also provides a coherent framework integrating employment, rights, social protection and social dialogue.

Although the ILO has provided a strong conceptual approach to the importance of employment policies, it is by no means clear that these policies have been accepted in the context of the work of major development players such as the Bretton Woods Institutions. It is particularly important in the light of the MDGs that such policies should be promoted as integral to poverty reduction strategies. This is one of the major challenges for the PRSP work - alongside that of making the case for the links between decent work and poverty reduction. Many of the projects/programmes described in this paper show that links are already being made operationally. One recommendation could be to challenge those involved in operational activities to build in monitoring mechanisms that provide for the collection of data and evidence to show that decent work is contributing to poverty reduction.

Some of the "products" developed as operational tools in the fight against poverty (labour intensive infrastructure programmes, small scale enterprise development, social finance, skills development, and health insurance, for example) have been developed in order to operationalise ILO's approach to employment, work and poverty reduction. There is a need to show more clearly how other products in the four ILO Sectors ${ }^{36}$ link to an overarching framework for poverty reduction and decent work. It might be logical to suggest that more emphasis could be given to the development of those ILO products which are clearly focusing on poverty reduction and to provide some incentives to further refine those "products".

The ILO is a relatively small player in the poverty reduction scene. Its field staff is small in numbers and historically its role has been that of providing technical assistance in ILO's traditional areas of competence. With the changing international agenda (which calls for the achievement of the MDGs, better coordination of the UN system within an overall development framework, and a greater focus in countries on poverty reducing strategies), ILO has to be able to respond by showing how its services/products can be adapted in order to contribute to this agenda. Hence, ILO technical staff needs to develop competencies in a broad range of development related skills - including those of project planning, monitoring and evaluation, as well as knowledge of national level strategic planning processes. Methods need to be developed for providing flexibility in

\footnotetext{
${ }^{36}$ Rights, Employment, Social Protection and Social Dialogue
} 
the type of services offered by the ILO - especially where these may be outside traditional areas of competency.

The main clients for ILO's services are its traditional constituents (Ministries of Labour, trade unions and employers' organizations). These are important allies in the fight against poverty - but in some cases these partners do not always view the role of the ILO as being primarily concerned with poverty reduction. Continued advocacy and training is needed with the constituents in considering the issues involved in poverty reduction.

\section{ILO works at a number of levels:}

1. The ILO can exert considerable influence on global policies through reports, conferences, workshops and seminars. However, it needs to remain fully engaged with the work of the rest of the UN system and to see itself as an integral part of that system. (In this respect the cross UN work on youth employment led by the ILO may be a useful model to consider). The ILO needs to make clear to the outside world where decent work adds value as an integrated concept to poverty reduction. It has a particular role in the context of global social policy to work towards a system which develops global social principles to cover the following:

- A common understanding of the "social floor" of rights at work as a means of both economic growth and social justice (both pre-requisites for poverty reduction).

- A much greater commitment internationally to developing systems of social protection which address the needs of those in developing countries and those who are outside the formal economy. This has to be set firmly in the context of internationally agreed rights.

- A stronger internationally agreed understanding of the notion that a large majority of poor people work. Some of this work is paid and recognised but much of it is in the unpaid care economy, in which women predominate.

- Greater commitment to supporting policies which focus on putting people at the centre of development, such as the sustainable livelihoods approach, and to work with others in developing related methods (for example, social impact assessments of policies).

- Commitment to the role of social partners and civil society more generally in advocating for the above, as well as enhancing social dialogue to improve workers' rights, collective bargaining and negotiated policy making.

2. The ILO exerts influence on the enabling environment within a country by:

- Monitoring the implementation of ILO Conventions and Recommendations. This is an important element of governance - without respect for these rights democracy is undermined. However, support to this kind of work (a substantial part of the work of the ILO) is not generally made in the form of an explicit link between governance and poverty reduction. It is therefore important to examine how the ILS supervisory bodies' work can be more widely used and made relevant. Other parts of the ILO's work are also concerned with governance issues, for instance, social security accounting and auditing systems, labour administration, and the management of labour markets. 
- Helping to develop legislative/enabling frameworks. Examples of this are work in support of labour law, active labour market policies, policy frameworks for small-scale enterprise development and for cooperatives, and assistance with the development of local development frameworks.

- Advocacy around key issues. Examples of this are advocacy for the abolition of child labour and forced labour, advocacy for prevention of HIV/AIDS in the workplace, advocacy for employment policies within the context of overall economic and social planning in a country (including during times of crisis and (post-) conflict), as well as advocacy around gender and work.

\section{The ILO carries out grass roots activities}

Over the years the ILO has also been involved in activities that directly benefit people through small-scale projects. The argument for doing this has often been linked to donor funding, because a particular donor (or UNDP) has seen the ILO as a suitable partner to implement this work, or to the fact that the ILO needs to have a visible presence through some tangible activities on the ground.

In the current international environment, many people now question the value, impact and sustainability of small-scale initiatives/projects especially where they are not linked to country priorities or to other wider frameworks. Therefore, given ILO's human and financial resources, it may be more effective to develop an organizational strategy focused on poverty which concentrates efforts on:

- exerting influence on global policies (see point 1 above), and

- influencing the enabling environment within countries (see point 2 above).

Within these clearly delineated priority areas, any grass roots activities should be shown to be linked to them. This implies focussing the activities and drawing lessons to allow for up-scaling and influencing of policies at the higher level, as well as making ILO work relevant to major actors. 
Next steps

- The ILO needs to continue the discussion on decent work and poverty reduction (including MDGs and PRSPs) to further clarify and refine the links and issues involved. This can be done through research work as well as cross-office (including field) consultative groups. The Director-General Report Working out of poverty to the ILC 2003 provides guidance in this regard and follow-up work is being pursued.

- Capacity building both for ILO staff and ILO constituents and partners on decent work and poverty reduction is still requested and required. This both involves substance and process issues. To respond effectively to field needs, practical tools, instruments and guidelines (especially for monitoring and evaluation) need to be adapted and developed. Many ILO activities in the field focus on training and workshops. Therefore the ILO has a niche in capacity building for poverty reduction. Much of its work in effect focuses on empowering constituents (for example, to be involved in PRSPs). There is a need to bring together the work that the ILO does on capacity building for poverty reduction into a more consistent and coherent framework. A joint effort has started to develop these capacities, however mainstreaming and sustainability remain a major challenge.

- The ILO needs to deliver on the Programme and Budget 2004-2005, which identifies Poverty Reduction and Social Inclusion as a priority in several Regions and initiates it as a Shared Policy Objective on poverty reduction and social inclusion for the Office as a whole. How to monitor progress towards this objective and report on it remains to be developed. 


\section{References}

Anker, R., et. al. 2002. Measuring decent work with statistical indicators. Working Paper No. 2, Policy Integration Department, Statistical Development and Analysis Group. ILO, Geneva.

Birchall, J. 2003. Rediscovering the cooperative advantage - Poverty reduction through selfhelp, ILO, Geneva.

Buckley, G. J. (ed.) 2003. Social Dialogue and the Poverty Reduction Strategy Paper (PRSP) Process in Cambodia: an Assessment. ILO InFocus Programme on Social Dialogue, Labour Law and Labour Administration, Paper No 1, ILO, Geneva.

Casale, G.; Pursey, S. (ed.) 2002. Towards a Decent Work Strategy for Poverty Reduction in Tanzania. ILO InFocus Programme on Strengthening Social Dialogue Working Paper No.8.

Chambers. R. 1997. Whose Reality Counts: Putting the first last.

Chambers. R.; Conway G. R. 1992. Sustainable Rural Livelihoods: Practical Concepts for the $21^{\text {st }}$ Century. Institute of Development Studies. Discussion Paper 296.

Conway, T.; Norton, A. (ed.) 2002. "Poverty, Risk and Rights: New Directions in Social Protection", Development Policy Review 20 (5).

DfID. 2003. Working Paper on Labour Standards and Poverty Reduction. DfID, London.

Edgren, G. 2001. Employment Policy for Poverty Reduction - More and Better Jobs. Sida, Stockholm.

Fawzi El-Solh, C. 2003. Gender, poverty and employment in the Arab Region. ILO Policy Integration Department, National Policy Group Discussion Paper, ILO, Geneva.

Ginneken van, W. (ed.). 1999. Social security for the excluded majority: case-studies of developing countries. ILO, Geneva.

IILS. 1995. New approaches to poverty analysis and policy - I-III. ILO, Geneva.

IILS. 1995. Evolution de l'approche de la pauvreté par l'OIT (web).

ILO. 2003. A review of the ILO Decent Work Pilot Programme. Governing Body, Committee on Employment and Social Policy, Geneva, Nov. 2003. GB.288/ESP/5.

ILO. 2003. Decent work for Africa's development. Report of the Director-General. Tenth African Regional Meeting, Addis Ababa, Dec. 2003.

ILO. 2003. General report. Seventeenth International Conference of Labour Statistics, Geneva, 24 Nov.-3 Dec. 2003.

ILO. 2003. Programme and Budget Proposals for 2004-2005.

ILO. 2003. Poverty Reduction in Pakistan - the Strategic Impact of Macro and Employment Policies. Regional Office for Asia and the Pacific, ILO, Bangkok

ILO. 2003. Reply by the Director-General to the discussion of his Report. International Labour Conference. Provisional Record No. 25. $91^{\text {st }}$ Session, Geneva, 2003. 
ILO. 2003. Review of the core elements of the Global Employment Agenda. Governing Body, Committee on Employment and Social Policy, Geneva, March 2003. GB.286/ESP/1.

ILO. 2003. Time for Equality at Work. Global Report under the ILO Declaration on Fundamental Principles and Rights at Work. ILO, Geneva.

ILO. 2003. Working out of poverty. Report of the Director-General. International Labour Conference, $91^{\text {st }}$ Session 2003. ILO, Geneva.

ILO. 2002. Decent Work for Poverty Reduction: An ILO contribution to the PRSP in Nepal. EMP/STRAT. ILO, Geneva.

ILO. 2002. Disability and Poverty Reduction Strategies. IFP/SKILLS Discussion Paper. ILO, Geneva.

ILO. 2002. Poverty Reduction Strategy Papers (PRSPS): An assessment of the ILO's experience. Governing Body, Committee on Employment and Social Policy, Geneva, March 2002. GB.285/ESP/2.

ILO. 2002. Poverty Reduction Strategy Papers (PRSPS) - An assessment of the ILO's experience. Governing Body, Committee on Employment and Social Policy, Geneva, Nov. 2002. GB.283/ESP/3.

ILO. 2002. Decent work and the informal economy. International Labour Conference $90^{\text {th }}$ Session. ILO, Geneva.

ILO. 2002. Report of the Committee on the Informal Economy. International Labour Conference, Provisional Record No. 25. ILO, Geneva.

ILO. 2002. Decent Work and Poverty Reduction in Africa - ILO's Contribution to the NEPAD Agenda. ILO, Geneva.

ILO. 2002. A Future without child labour. Global Report under the ILO Declaration on Fundamental Principles and Rights at Work.

ILO. 2001. Decent Work for Poverty Reduction: An Agenda for Development in the Least Developed Countries. ILO, Geneva.

ILO. 2001. Global Employment Agenda. ILO, Geneva.

ILO. 2001. Promotion of cooperatives, International Labour Conference, $89^{\text {th }}$ Session. ILO, Geneva.

ILO. 2001. Reducing the Decent Work Deficit - a global challenge. International Labour Conference, $89^{\text {th }}$ Session. ILO, Geneva.

ILO. 2001. Social Security: Issues, Challenges and Prospects. International Labour Conference, $89^{\text {th }}$ Session. ILO, Geneva.

ILO. 2001. Stopping Forced Labour. Global Report under the ILO Declaration on Fundamental Principles and Rights at Work. ILO, Geneva.

ILO. 2000. Your Voice at Work. Global Report under the ILO Declaration on Fundamental Principles and Rights at Work. ILO, Geneva.

ILO. 2000. Perspectives on Decent Work. ILO, Geneva. 
ILO. 2000. Gender Poverty and Employment - A reader's kit. ILO, Geneva.

ILO. 1999. Decent Work. Report of the Director-General. International Labour Conference, $87^{\text {th }}$ Session. ILO, Geneva.

ILO. 1999. Decent Work and Protection for All - Priorities of the Americas. Report of the Director-General. $14^{\text {th }}$ Regional meeting of the ILO American Member States. Lima, Peru, Aug. 1999.

Kaijage, F.; Tibaijuka, A. 1996. Poverty and Social Exclusion in Tanzania. Research Series No. 109. IILS. ILO, Geneva.

Khan, A. R. 2001. Employment Policies for Poverty Reduction. ILO, Geneva.

Krantz, L. 2001. The sustainable Livelihood Approach to Poverty Reduction. Sida, Stockholm.

Lund, F. and Srinivas, S. 2000. Learning from experience: A gender approach to social protection for workers in the informal economy. ILO Geneva.

Majid, N. "The working poor in developing countries", --. in: International labour Review. Geneva: International Labour Office. Vol. 140, No. 3 (2001). pp. 271-291.

Office of the High Commissioner for Human Rights. 2002. Draft Guidelines: A Human Rights Approach to Poverty Reduction Strategies. UN, Geneva.

Peck, L. and Widmark, C. 2000. Sida Documents in a Poverty Perspective. Sida, Stockholm.

Phongpaichit, P. 1996. Challenging social exclusion: Rights and livelihood in Thailand. Research Series No. 107. IILS. ILO, Geneva.

Rodgers, G. "Decent work as a development objective", in: The Indian Journal of Labour Economics, Vol. 44, No. 1, 2001.

Rodriguez-Pose, A. 2001. The role of the ILO in implementing Local Economic Development strategies in a globalised world. ILO, Geneva.

Sen, A.K. 1999. Development as Freedom. Anchor Books, New York.

Tchernina, N. 1996. Economic transition and social exclusion in Russia. Research Series 108. IILS. ILO, Geneva.

Torres, R. 2001. Towards a socially sustainable world economy - An analysis of the social pillars of globalization. ILO, Geneva.

UNDP. Human Development Report. 2000. UNDP, New York.

Valenzuela, M. E., 2003. The incorporation of gender in employment and anti-poverty policies: challenges for the future. ILO Policy Integration Department, National Policy Group Discussion Paper. ILO, Geneva.

World Bank. 2002. Empowerment and Poverty Reduction - A Sourcebook. World Bank, Washington, DC.

World Bank. World Development Report 2000/2001: Attacking Poverty. World Bank, Washington, DC. 
Annexes

Annex 1

\section{Millennium Development Goals}

Goals and targets

Indicators

\section{Goal 1. Eradicate extreme poverty and hunger}

Target 1. Halve, between 1990 and 2015, the proportion of people whose income is less than one dollar a day

Target 2. Halve, between 1990 and 2015, the proportion of people who suffer from hunger
1. Proportion of population below $\$ 1$ per day

2. Poverty gap ratio (incidence $x$ depth of poverty)

3. Share of poorest quintile in national consumption

4. Prevalence of underweight children (under five years of age)

5. Proportion of population below minimum level of dietary energy consumption

\section{Goal 2. Achieve universal primary education}

Target 3. Ensure that, by 2015, children everywhere, boys and girls alike, will be able to complete a full course of primary schooling
6. Net enrolment ratio in primary education

7. Proportion of pupils starting grade 1 who reach grade 5

8. Literacy rate of 15-24-year olds

\section{Goal 3. Promote gender equality and empower women}

Target 4. Eliminate gender disparity in primary and secondary education, preferably by 2005, and to all levels of education no later than 2015
9. Ratio of girls to boys in primary, secondary and tertiary education

10. Ratio of literate females to males of 15-to-24year-olds

11. Share of women in wage employment in the non-agricultural sector

12. Proportion of seats held by women in national parliament 


\section{Goal 4. Reduce child mortality}

Target 5. Reduce by two thirds, between 1990 and 2015, the under-five mortality rate

13. Under-five mortality rate

14. Infant mortality rate

15. Proportion of 1-year-old children immunized against measles

\section{Goal 5. Improve maternal health}

Target $6 . \quad$ Reduce by three quarters, between 1990 and 2015, the maternal mortality ratio

16. Maternal mortality ratio

17. Proportion of births attended by skilled health personnel

\section{Goal 6. Combat HIVIAIDS, malaria and other diseases}

Target 7. Have halted by 2015 and begun to reverse the spread of HIV/AIDS

Target 8 . Have halted by 2015 and begun to reverse the incidence of malaria and other major diseases
18. HIV prevalence among 15-to-24-year-old pregnant women

19. Contraceptive prevalence rate

20. Number of children orphaned by HIV/AIDS

21. Prevalence and death rates associated with malaria

22. Proportion of population in malaria risk areas using effective malaria prevention and treatment measures

23. Prevalence and death rates associated with tuberculosis

24. Proportion of tuberculosis cases detected and cured under directly observed treatment short course 


\section{Goal 7. Ensure environmental sustainability ${ }^{a}$}

Target 9. Integrate the principles of sustainable development into country policies and programmes and reverse the loss of environmental resources

Target 10. Halve by 2015 the proportion of people without sustainable access to safe drinking water

Target 11 . By 2020 to have achieved a significant improvement in the lives of at least 100 million slum dwellers
25. Proportion of land area covered by forest

26. Land area protected to maintain biological diversity

27. GDP per unit of energy use (as proxy for energy efficiency)

28. Carbon dioxide emissions (per capita) (Plus two figures of global atmospheric pollution: ozone depletion and the accumulation of global warming gases)

29. Proportion of population with sustainable access to an improved water source

30. Proportion of people with access to improved sanitation

31. Proportion of people with access to secure tenure

(Urban/rural disaggregation of several of the above indicators may be relevant for monitoring improvement in the lives of slum dwellers) 


\section{Goal 8. Develop a Global Partnership for Development ${ }^{a}$}

Target 12. Develop further an open, rule-based, predictable, non-discriminatory trading and financial system

(Includes a commitment to good governance, development, and poverty reduction - both nationally and internationally)

Target 13. Address the Special Needs of the Least Developed Countries

(Includes: tariff and quota free access for least developed countries' exports; enhanced programme of debt relief for HIPCs and cancellation of official bilateral debt; and more generous ODA for countries committed to poverty reduction)

Target 14. Address the special needs of landlocked countries and small island developing States (through the Programme of Action for the Sustainable Development of Small Island Developing States and the outcome of the twenty-second special session of the General Assembly)

Target 15 . Deal comprehensively with the debt problems of developing countries through national and international measures in order to make debt sustainable in the long term
[Some of the indicators listed below will be monitored separately for the least developed countries (LDCs), Africa, landlocked countries and small island developing States]

Official development assistance

32. Net ODA as percentage of OECD/DAC donors' gross national income (targets of 0.7 per cent $\%$ in total and 0.15 per cent for LDCs)

33. Proportion of ODA to basic social services (basic education, primary health care, nutrition, safe water and sanitation)

34. Proportion of ODA that is untied

35. Proportion of ODA for environment in small island developing States

36. Proportion of ODA for transport sector in landlocked countries

\section{Market access}

37. Proportion of exports (by value and excluding arms) admitted free of duties and quotas

38. Average tariffs and quotas on agricultural products and textiles and clothing

39. Domestic and export agricultural subsidies in OECD countries

40. Proportion of ODA provided to help build trade capacity

Debt sustainability

41. Proportion of official bilateral HIPC debt cancelled

42. Debt service as a percentage of exports of goods and services

43. Proportion of ODA provided as debt relief

44. Number of countries reaching HIPC decision and completion points 


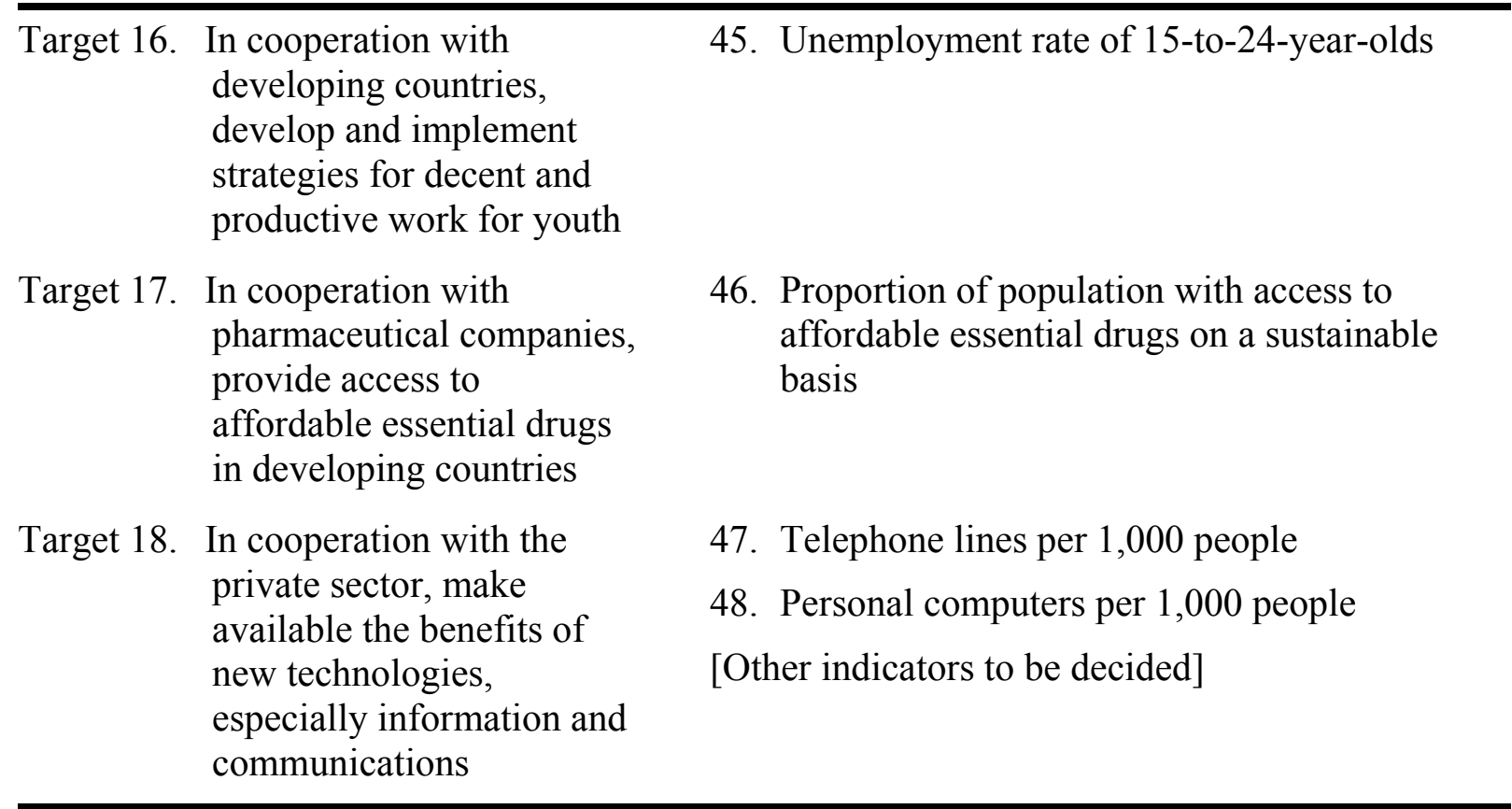

a The selection of indicators for goals 7 and 8 is subject to further refinement. 


\section{Annex 2}

\section{ILO Turin Workshop on Decent Work \& Poverty Reduction, July 2002}

\section{Conclusions on the way forward}

Among the participants a strong consensus emerged on the following issues:

a) A need for an exercise which made clear the links between the Decent Work Agenda and the Poverty Reduction Agenda to guide future work in the ILO.

b) This was essential so that ILO could be more focused and effective in contributing to the PRSP and in developing a strategy for achieving the MDGS in partnership with other key UN organisations.

c) Tackling poverty reduction effectively posed challenges to ILO as it required an integrated approach. This would need continual rethinking of ILO's ways of doing things, in particular ways in which ILO HQ and field relationships could be structured and strengthened to meet the needs of constituents, country priorities and poor people themselves.

d) It was strongly felt that ILO's work should begin with country priorities, with constituents as key actors.

e) All ILO sectors/field offices should have an equal stake in poverty reduction policies. Different approaches as represented by different sectors had equal value as entry points in contributing to poverty reduction in the framework of the decent work approach. Each sector should ensure that this approach is appropriately flanked by the aspects of decent work covered primarily by other sectors.

f) Social partners had to be key partners in taking this agenda forward; opportunities presented themselves for helping them strengthen their capacity as well as for strengthening ILO's capacity for understanding and working with social partners.

g) Monitoring and evaluation needed strengthening with the development of a more consistent and coherent approach across ILO.

h) Program and budget processes should provide more specific guidance on how poverty reduction should be addressed in the design of proposals.

The consensus around these issues was captured in the format of a logical framework that sets out the goal, purpose and outputs for the ILO to make a contribution to poverty reduction on the basis of the Decent Work Agenda.

\section{There is need for action in the following areas:}

1. Providing a conceptual framework as the basis for the articulation between decent work and poverty reduction

2. Implementing operational programmes in field and headquarters that contribute to poverty reduction

3. Supporting and involving the constituents in the poverty debate at country, regional and global level

4. Providing resources, developing skills and enabling structures that promote ILO's contribution to poverty reduction

5. Providing tools, guidelines, research to support the overall process 


\section{Summary note on the sustainable livelihoods approach}

The concept of Sustainable Livelihoods (SL) was first introduced by the Bruntland Commission on Environment and Development and further expanded in the UN Conference on Environment and Development in Rio1992.

It was felt that traditional concepts of poverty, based on income and consumption, and where conventional analysis would focus on measurability, were not capturing all aspects of poverty and the perceptions of the poor people themselves. They would not give the full answers and were in particular not adapted to the realities or life for poor rural people and many parts of the informal economy.

Therefore the idea of SL is to go beyond these definitions and approaches to poverty reduction and to offer a more coherent and integrated approach, which pays more attention to factors and processes which constrain or enhance poor people's ability to make a living in an economically, ecologically and socially sustainable manner.

SL also focuses on examining the root causes of poverty and tackling them, rather than treating symptoms of poverty. Different institutions and organisations, for example the Institute for Development Studies, DFID, UNDP, Oxfam and CARE, have since taken up the SL approach. They have put it into operation and applied it, each time adapted to their specific needs, using it for analytical, assessment or programming purposes, or even as a programme in itself. The DFID adapted definition of SL reads as follows:

A livelihood comprises the capabilities, assets (including both material and social resources), and activities required for a means of living. A livelihood is sustainable when it can cope with and recover from stresses and shocks and maintain or enhance its capabilities and assets both now and in the future, while not undermining the natural resource base.

Today, the SL approach comprises a number of components which are directly or indirectly related to each other, building an analytical model.

\section{Livelihood}

A livelihood comprises the capabilities, assets (material and social) and activities required for a means of living. The livelihood assets include different capitals such as: human (skills, knowledge, information, health, etc.), financial (credit, savings, pensions, etc.), social (networks, associations, trust, etc.), physical (housing, transport, energy, etc.), natural (land, water, environment, etc.). The objective is to find out how to best expand, maintain, reinforce or compensate capital levels through interventions at different levels.

\section{Sustainable livelihood}

A livelihood is sustainable when it can cope with and recover from stresses and shocks, maintain or enhance its capabilities and assets, both now and in the future, while not undermining the natural resource base. It is important to take into account the vulnerability context, external factors over which people have little control. Poor people's livelihoods are especially vulnerable to shocks linked to illness, natural disaster, economic shocks, seasonality, governance and conflict. 


\section{PIPS}

People's livelihoods are constantly influenced by and operating in a larger context of policies, institutions, processes and systems/structures, present at all levels. They very much determine the transaction costs (time, hassle, difficulty, financial cost, opportunity, risk, etc.) in deriving a sustainable livelihood. They also influence access to the different sources of capital, as well as livelihood strategies and decision-making bodies. Getting the "PIPS" right means creating an enabling environment, pro-poor and supportive. Any reforms would be informed by experiences and needs at the lower level.

\section{Livelihood outcomes}

With their assets and strategies, people are trying to achieve livelihood outcomes, which can be classified in categories such as: more income, increased well being, reduced vulnerability, improved foods-security, and more sustainable use of the natural resource base.

\section{Principles of SL}

The departure point for the SL approach is to put people in the centre, starting with the analysis of people's livelihoods and how these are changing over time. The participation of local people is important as their livelihood goals and aspirations that matter. At the same time it is important to focus attention on the impact of policies and institutions on people's lives and their perception of poverty. The SL approach adopts a holistic and asset-based analysis which builds on strengths and potential rather than weaknesses and gaps. It is a dynamic and responsive approach looking at trends, as livelihoods and influencing factors are constantly changing. The macro-micro links are established, analysing the influences of the macro environment on people's lives and making sure that policy and planning is informed by local insights and lessons. The approach analysis environmental, economic, social and institutional sustainability. The approach lends itself for "joined-up" work, integration within an organisation, as well as for multi-agency partnerships.

\section{The Sustainable Livelihoods Framework}

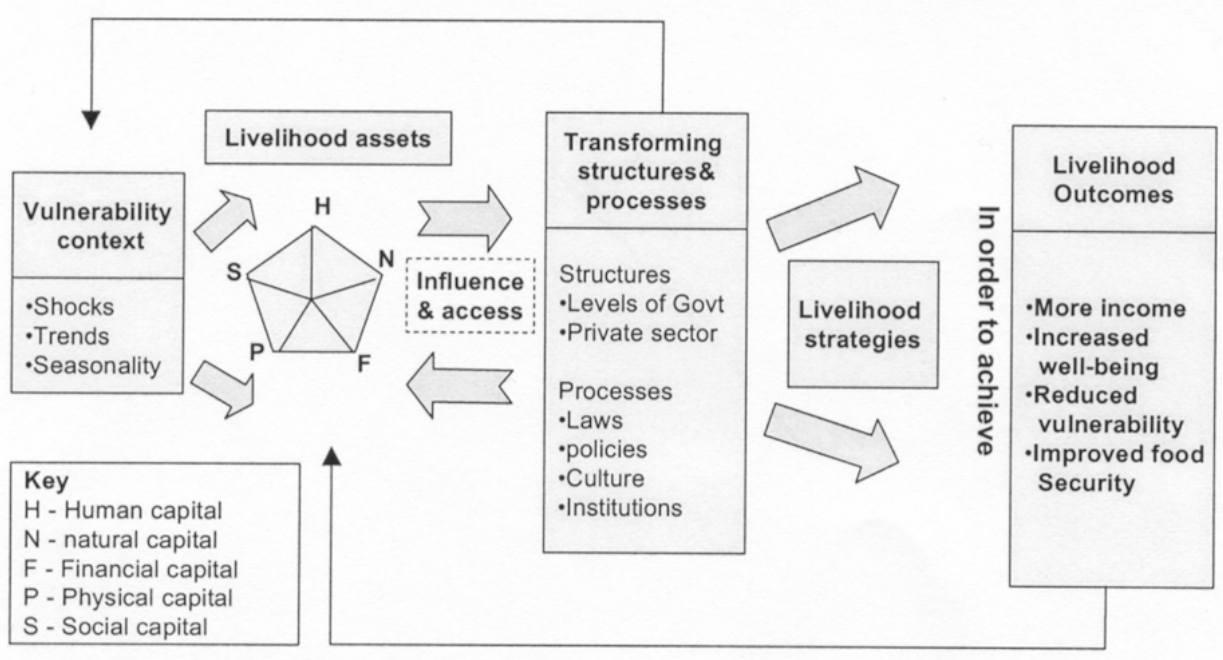


What we really want to change are institutions - the rules of the game. For this people need "voice" and "choice", rights and entitlements, and there needs to be a focus on inclusion and multi-level consistency.

\section{Strengths and weaknesses}

Among the strengths count the recognition of the multiple assets and the combination of resources that is important for (poor) people to construct livelihoods. It includes not only physical and natural capital but equally social and human capital. This leads to a positive startoff point where the focus is on people's assets and how they can be improved rather than on the absence of income and goods. The approach offers a more realistic framework (compared to one-dimensional criteria) allowing for the identification of underlying causes of poverty, factors at different levels that directly or indirectly hamper poor people's access to assets and thus a livelihood.

There are some points one should keep in mind when considering or using the SL approach. It is important to think of what method to use to identify and target the poor, as this is not directly discussed in the SL approach. Power relations and gender aspects are reflected in market inequalities and social domination. To give adequate consideration and time to gender aspects of poverty this must be made a conscious choice of the user.

For the ILO and other organisations, it might be difficult to fully respect the idea of the SL approach to start with a broad and open-ended analysis, as this requires a highly flexible planning situation which rarely exists. However, it can be used to make already identified and/or decided, as well as new development initiatives, better fit with and improve on people's livelihood strategies. Finally, the SL approach is fairly complex and counterparts in developing countries, e.g. local development administrations, might experience difficulties in applying the approach.

SL provides a holistic view and approach for analysis. It creates a meaningful picture to which not necessarily holistic intervention can be related and put into context. 


\section{Annex 4}

\section{Guideline 9: $\quad$ RIGHT TO DECENT WORK}

Source: Office of the High Commissioner for Human Rights. Draft Guidelines: A Human Rights Approach to Poverty Reduction Strategies. (UN, 2002).

\section{A. Importance of the right to decent work}

120. Poor people invariably lack adequate and secure livelihoods. In the countryside and cities, they experience unemployment, underemployment, unreliable casual labour, poverty wages and unsafe working conditions. In the countryside, their livelihoods are made precarious by multiple factors such as: inadequate access to land and irrigation, lack of seeds and fertilisers, deficiencies of transport, and the overexploitation of common resources such as pastureland, forests and fish.

121. Confronted with this daily vulnerability, poor people often struggle to diversify their sources of income and food. They work on the land, in quarries and mines, take temporary and part-time jobs, sell goods in the streets, and do piecework in factories and at home. They suffer harassment and corruption from officials, as well as mistreatment from employers, with no form of redress. With their opportunities so limited, many poor people are drawn into work that is anti-social, dangerous and illegal, such as sex work, child labour, bonded labour and other slavery-like practices. They may become trapped by those trading in women and children.

122. Inadequate and insecure livelihoods are constitutive of poverty. Thus, the right to decent and productive work has a direct role to play in relation to PRS. Further, the enjoyment of this right is instrumental in securing other rights such as food, health and housing, which are also relevant to poverty reduction.

123. The Millennium Declaration highlights the importance of decent and productive work. Moreover, one Millennium Development Goal is to halve, by the year 2015, the proportion of people living on less that one dollar a day. Both provisions underline the importance of the right to decent and productive work in relation to poverty reduction.

\section{B. Scope of the right to decent work}

124. The right to decent work encompasses productive and sufficient work of acceptable quality in which rights are protected and which generates an adequate income with adequate social protection. Sufficient work means that all have full access to income-generating opportunities. Thus, the right to decent work has three rights dimensions: the right to work, rights in work and the right to adequate social protection.

125. The right to decent work is not confined to wage employment, but extends to self-employment, home working and other income-generating activities. It demands the creation of a social, economic and physical environment in which all people have fair and equal opportunities to prosper by virtue of their own endeavour and in a manner consistent with their dignity. Thus, the right to decent work carries with it the responsibility to promote the personal capabilities and expand the opportunities for people to find productive work and to earn a decent livelihood.

126. Accordingly, the right to decent work implies the availability of both employment opportunities and the preconditions for income generation such as the availability of assets, credit and a favourable regulatory environment.

127. Rights in work include the right of everyone to the enjoyment of just and favourable conditions of work, including fair wages, equal remuneration for work of equal value, equal opportunities, safe and healthy conditions of work, and reasonable hours of work and rest, as well as the rights to organize and bargain collectively. Various forms of work, such as bonded labour and other forms of slavery-like practices, are prohibited. All employment opportunities and income- 
generating activities must be of acceptable quality i.e. culturally appropriate and consistent with the dignity of the individual.

128. The right to decent work also requires that well-designed and adequate social safety mechanisms are put in place for those occasions, such as economic and political crises, when regular employment becomes unavailable to some individuals.

\section{Box 4: The right to decent work}

\section{- International Covenant on Economic, Social and Cultural Rights (ICESCR), Art. 6:}

"1. The States Parties to the present Covenant recognize the right to work, which includes the right of everyone to the opportunity to gain his living by work which he freely chooses or accepts, and will take appropriate steps to safeguard this right.

2. The steps to be taken by a State Party to the present Covenant to achieve the full realization of this right shall include technical and vocational guidance and training programmes, policies and techniques to achieve steady economic, social and cultural development and full and productive employment under conditions safeguarding fundamental political and economic freedoms to the individual."

\section{- ICESCR, Art. 7:}

"The States Parties to the present Covenant recognize the right of everyone to the enjoyment of just and favourable conditions of work which ensure, in particular:

(a) Remuneration which provides all workers, as a minimum, with: (i) Fair wages and equal remuneration for work of equal value without distinction of any kind, in particular women being guaranteed conditions of work not inferior to those enjoyed by men, with equal pay for equal work; (ii) A decent living for themselves and their families in accordance with the provisions of the present Covenant;

(b) Safe and healthy working conditions;

(c) Equal opportunity for everyone to be promoted in his employment to an appropriate higher level, subject to no considerations other than those of seniority and competence;

(d) Rest, leisure and reasonable limitation of working hours and periodic holidays with pay, as well as remuneration for public holidays"

\section{- ICESCR, Art. 8:}

"1. The States Parties to the present Covenant undertake to ensure:

(a) The right of everyone to form trade unions and join the trade union of his choice, subject only to the rules of the organization concerned, for the promotion and protection of his economic and social interests. No restrictions may be placed on the exercise of this right other than those prescribed by law and which are necessary in a democratic society in the interests of national security or public order or for the protection of the rights and freedoms of others;

(b) The right of trade unions to establish national federations or confederations and the right of the latter to form or join international trade-union organizations; (...)

(d) The right to strike, provided that it is exercised in conformity with the laws of the particular country.

2. This article shall not prevent the imposition of lawful restrictions on the exercise of these rights by members of the armed forces or of the police or of the administration of the State."

\section{ICESCR, Art. 9:}

"The States Parties to the present Covenant recognize the right of everyone to social security, including social insurance."

\section{See also ICCPR, Art. 22 (see box 9)}

\section{- International Covenant on Civil and Political Rights (ICCPR), Art. 8:}

"1. No one shall be held in slavery; slavery and the slave-trade in all their forms shall be prohibited. 2. No one shall be held in servitude.

3. (a) No one shall be required to perform forced or compulsory labour; 
- See also Convention on the Elimination of Discrimination Against Women (CEDAW) (Arts. 6 and 11), Convention on the Rights of the Child (CRC) (Arts. 32, 34, 35 and 36), Committee on the Elimination of Racial Discrimination (CERD) (Art. 5 (e) (i)), ILO Conventions on Child Labour (Conventions $\mathbf{N}^{\circ} 138$ and 182), ILO Conventions on Forced Labour (Conventions $N^{\circ} 29$ and 105), ILO Conventions $N^{\circ} 87$ on Freedom of Association and $\mathrm{N}^{\circ} 98$ on the Right to Organize and Collective Bargaining and ILO Conventions No. 100 on Equal Remuneration and No. 111 on Discrimination on Employment and Occupation.

- World Conference: World Summit for Social Development (1995).

\section{Key targets and indicators}

\section{Target 1: Full employment}

Indicators:

- Rate of unemployment

- Rate of underemployment

Target 2: All workers to be able to earn a minimum necessary income

Indicators:

- Proportion of working poor (working but earning less than poverty-line income) in the labour force

- Proportion of labour force covered by minimum wage legislation

\section{Target 3: All workers to receive reasonable financial support during spells of} unemployment.

Indicator:

- $\quad$ Proportion of labour force covered by adequate social security provisions

\section{Target 4: To eliminate gender inequality in access to work}

Indicator:

- Female and male labour force participation rates 
Target 5: To eliminate gender inequality in remuneration for work

Indicators:

- Average wages of males and females in different economic sectors

- Proportion of working poor in labour force disaggregated by gender

\section{Target 6: To eliminate child labour}

Indicators:

- Labour force participation rate of children under the age of 15

- Prevalence of the worst forms of child labour (in the sense of ILO Convention No.182)

Target 7: To eliminate bonded labour

Indicator:

- Proportion of bonded labourers in the workforce

\section{Target 8: All workers should be able to work in safe and healthy working conditions}

Indicator:

- Proportion of the workforce working in hazardous conditions

\section{Target 9: No worker should be subject to unfair dismissal}

Indicator:

- $\quad$ Proportion of the workforce covered by labour laws giving protection against unfair dismissal 


\section{Key features of a strategy for realizing the right to decent work}

Source: Office of the High Commissioner for Human Rights. Draft Guidelines: A Human Rights Approach to Poverty Reduction Strategies. (UN, 2002).

129. A strategy to realize the right to work in the context of poverty reduction must aim at improving the quantity and quality of work for poor people. This entails reducing unemployment/underemployment of the poor, on the one hand, and raising the return to their labour, on the other. For this to be possible on a wide and sustainable basis, action should be guided by three principles.

130. First, measures should be taken to improve the production potential of the economy on a sustained basis because without growth in economic activity an adequate quantity and quality of work cannot be provided for any substantial number of people in a sustainable manner.

131. Second, policies should ensure that growth in production takes place in such a way as to maximize the demand for labour, because it is only through greater demand for labour that unemployment and underemployment can be reduced and returns to labour increased. Policies that provide artificial incentives for the use of capital at the expense of labour - at the level of the aggregate economy - ought to be avoided, although in specific sectors greater capital intensity may sometimes be warranted on productivity grounds.

132. Third, conditions should be created to enable poor people, especially the poorest among them, to integrate into economic processes so that they can take advantage of labour-demanding growth.

133. While all three principles are important, the rights-based approach demands that special attention be given to the third principle since the factors preventing poor people from integrating into economic processes are often related to various kinds of violations of human rights. For example, social discrimination may prevent some of the poor from gaining access to certain types of jobs. Similarly, if people in certain groups are discriminated against in the provision of education and health care - for example, on the grounds of their ethnicity, religion or gender they may not be able to acquire enough human capital to take advantage of expanding employment opportunities.

134. The precise nature of the impediments facing the poor in their efforts to integrate into economic processes varies from one case to another. An essential component of poverty reduction strategies consists in identifying and taking measures to eliminate them as expeditiously as possible. In particular, explicit acts of discrimination that prevent some individuals and groups from gaining access to an adequate quantity and quality of work must be ended immediately.

135. Even when explicit acts of discrimination are not involved, the poor may still face impediments because of the disadvantages that ensue from the state of poverty itself. Thus, poverty may prevent them from gaining adequate access to education, health care, credit, infrastructure, etc. Without such access, they will not have the assets - human, financial or physical - that are necessary for realizing the right to work. The human rights principle of equality and nondiscrimination requires that priority be accorded to eliminating these impediments faced by the poor.

136. If some economic sectors are dominated by a few large employers, the State should take steps to encourage greater competition among producers, or else try to regulate the labour market so that employers cannot use their superior power to depress the wage level.

137. Laws should be passed, and accessible and effective procedures adopted, to ensure that workers enjoy just and favourable conditions of work, including fair wages, equal pay for work of equal value, safe and healthy working conditions, and reasonable hours of work and rest. 
138. Workers must be given the legal power to organize and bargain collectively with employers so that the latter cannot use their superior bargaining strength to offer unfavourable terms of employment. However, care should be taken to ensure that labour market policies do not create a "protected" and non-poor labour aristocracy in the formal sector who can shut out competition from poor labourers working in the informal sector.

139. States must prohibit and eliminate bonded labour, forced prostitution, oppressive forms of child labour and other forms of employment strategies that the poor are often compelled to adopt as a means of coping with their poverty but which violate their human rights. These prohibitions must be combined with employment-creating policies so that the poor can earn their livelihood in a manner consistent with dignity and human rights.

140. An adequate system of social security must be put in place to protect the unemployed. This system should include standard unemployment insurance schemes, wherever applicable, as well as other safety-net mechanisms such as creation of short-term work for the poor unemployed and direct social transfers. 


\section{List of Policy Integration Department working papers}

No. 1 ILO activities on the social dimension of globalization: Synthesis report

No. 2 Measuring decent work with statistical indicators, Richard Anker, Igor Chernyshev, Philippe Egger, Farhad Mehran and Joseph Ritter

No. 3 Globalization and decent work: Options for Panama, Philippe Egger

No. 4 Globalización y trabajo decente: Opciones para Panamá, Philippe Egger

No. 5 Indicators of social dialogue: Concepts and measurements, Lane Kenworthy and Bernhard Kittel

No. 6 Assessing the impact of the attacks of 11 September 2001 on women's employment in the United States,

Gertrude Schaffner Goldberg and Helen Lachs Ginsburg

No. 7 Decent work and the informal economy in Central America, Juan Diego Trejos Solórzano and Miguel Del Cid

No. 8 Poverty initiatives in the ILO: A review of past and present approaches, Pat Holden and Dagmar Walter

No. 9 Whither the International Standard Classification of Occupations (ISCO-88)?, Debbie Budlender

No. 10 Improving occupational classifications as tools for describing labour markets: A summary of recent national experiences, Debbie Budlender

No. 11 Recent developments in China's labour economy, Thomas G. Rawski

No. 12 The Impact of economic liberalization on employment and wages in India, Sonia Bhalotra

No. 13 The impact of trade liberalization upon inequality in developing countries, Donald J. Robbins

No. 14 The impact of liberalization and globalization on income inequality in developing and transitional economies, Giovanni Andrea Cornia

No. 15 The impact of technology transfer on employment and income distribution in developing countries: A survey of theoretical models and empirical studies, Mariacristina Piva 


\section{Policy Integration Department Working Papers prepared for the World Commission on the Social Dimension of Globalization}

No. 16 International finance: Meeting the needs of people in developing countries, José Guilherme Almeida dos Reis

No. 17 The gender dimensions of globalisation of production, Stephanie Barrientos, Naila Kabeer and Naomi Hossain

No. 18 Social exclusion in the context of globalization, Jan Breman

No. 19 Gender and globalization: A macroeconomic perspective, Çağatay Nilüfer and Ertük Korkurt

No. 20 Globalization, social exclusion, and work: With special reference to informal employment and gender, Marilyn Carr and Martha Chen

No. 21 Resources for social development, Antony Clunies Ross

No. 22 Does the new international trade regime leave room for industrialization policies in the middle-income countries?, Alisa DiCaprio and Alice Amsden

No. 23 Social dimension of globalisation in Latin America: Lessons from Bolivia and Chile,Alvaro García Hurtado

No. 24 Globalization: Social impact and policy actions: A partly annotated bibliography, Bernhard Gunter and Rolph van der Hoeven

No. 25 The social dimension of global production systems, Susan Hayter

No. 26 Reforming global economic and social governance: a critical review of recent programmatic thinking, Jeremy Heimans

No. 27 Corporate social responsibility: An issues paper, Michael Hopkins

No. 28 Upgrading in global value chains, John Humphrey

No. 29 Implications of globalization and economic restructuring for skills development in Sub-Sahara Africa, Richard K. Johanson

No. 30 The outcome and impact of the main international commissions on development issues, Frédéric Lapeyre

No. 31 Globalization and structural adjustment as a development tool, Frédéric Lapeyre

No. 32 Globalization and perceptions of social inequality, Malte Luebker

No. 33 The changing structure of trade linked to global production systems: what are the policy implications?, William Milberg

No. 34 Corporate social responsibility: An overview of principles and practice, Jill Murray

No. 35 Inclusive development strategy in an era of globalization, Ignacy Sachs

No. 36 Social consequences of the globalization of the media and communications sector: Some strategic considerations, Seán Ó. Siochrú

No. 37 Globalization, history and international migration - A view from Latin America, Andrés Solimano

No. 38 Towards a different kind of globalization, or how the anti-globalizers view the world, Gijsbert van Liemt 


\section{List of Policy Integration Department working papers}

No. 39 How do trade union rights affect trade competitiveness?

David Kucera and Ritash Sarna

No. 40 Statistics on the employment situation of people with disabilities: A compendium of national methodologies, (in collaboration with the In Focus Programme on Skills, Knowledge and Employability)

No. 41 Employment in the informal economy in the Republic of Moldova, (in collaboration with the Department for Statistics and Sociology of the Republic of Moldova)

No. 42 Decent work in a least developed country: A critical assessment of the Ethiopia PRSP, Graeme J. Buckley 